University of Redlands

\title{
Modeling the Impact of Terrain on Wind Speed and Dry Particle Deposition Using WindNinja and ArcGIS Spatial Analyst
}

\footnotetext{
A Major Individual Project submitted in partial satisfaction of the requirements for the degree of Master of Science in Geographic Information Systems

By

Amber Nicole Brooks

Douglas Flewelling, Ph.D., Committee Chair

Rebecca A. Lyons, Ph.D.
}

December 2012 
Modeling the Impact of Terrain on Wind Speed and Dry Particle Deposition Using WindNinja and ArcGIS Spatial Analyst

Copyright (C) 2012 By Amber Nicole Brooks 
The report of Amber Nicole Brooks is approved.
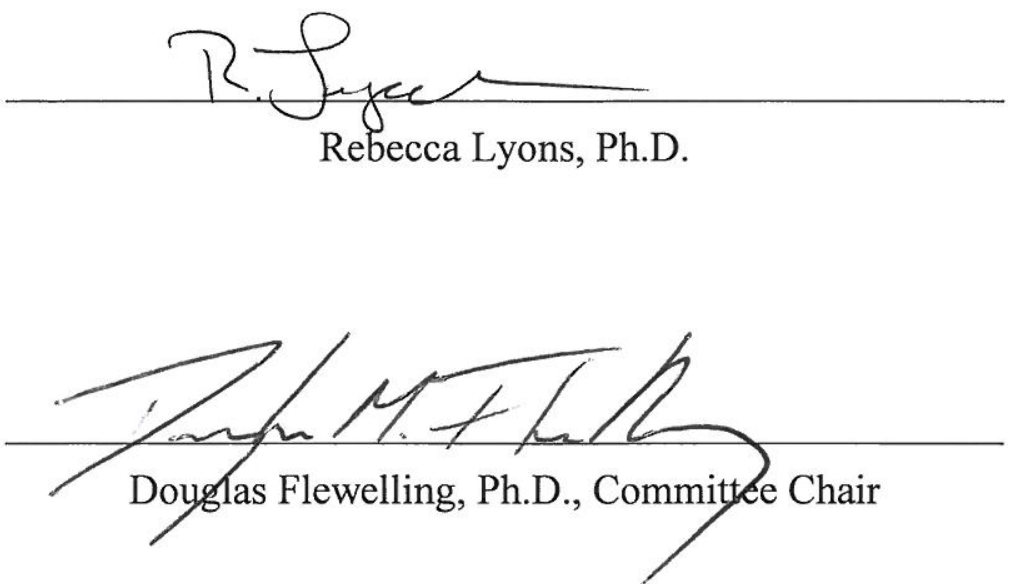

December 2012 



\title{
Acknowledgements
}

\begin{abstract}
Dr. Douglas Flewelling
Advisor and committee chair, thank you for recognizing my nature to complicate things and for your time ironing out the hefty details of this project.
\end{abstract}

\section{Dr. Rebecca Lyons}

Client and $2^{\text {nd }}$ Reader, thank you for meeting with me, at times on a moment's notice and for pitching such an awesome MIP topic.

\section{Eric Wittner}

Esri's analysis pro, thank you for teaching me core concepts of spatial analysis, how to use certain tools in special situations and which tools to avoid...you saved me time and kept me sane through the MIP process!

\section{Debbie Riley}

Den Mother. It's simple. Without you, this program wouldn't have been the same for me. You're the glue that kept us all together. Thank you.

\section{Cohort 21}

I will never forget every cohort experience. Each taught me something new, but most of all I learned, while working alone one can get done faster, working together as a group we went further. \#DataIsKing 



\begin{abstract}
Modeling the Impact of Terrain on Wind Speed and Dry Particle Deposition Using WindNinja and ArcGIS Spatial Analyst
\end{abstract}

By

\author{
Amber Nicole Brooks
}

While developed countries have been able to implement engineering techniques and sanitation technologies to keep water resources clean from runoff and ground contamination, air pollution and its contribution of harmful contaminants to our water resources has yet to be fully understood and prevented.

Due to the large spatial and temporal extent and subsequent computational intensity required to understand atmospheric deposition as a pollutant source, a geographic information system (GIS) was utilized. Specifically, the flux of particulate matter at the air - water interface of a lake surface was quantified by season for the year of 2009 for Lake Perris in Southern California.

This project developed a multi-step workflow utilizing a variety of technologies including command line processing, Microsoft Excel, WindNinja, ArcGIS 10.1, 3D and Spatial Analyst extensions, and mathematical formulae provided by the client to process the source information, simulate the behavior of wind, and calculate the spatial distribution of contaminant deposition, as flux, across a selected water body. The deliverables included: a data retrieval processing workflow, datasets used for simulation and analysis, five ModelBuilder models, and maps of analytical results to aid in future lake surface sampling techniques. 



\section{Table of Contents}

Chapter 1 - Introduction ................................................................................................ 1

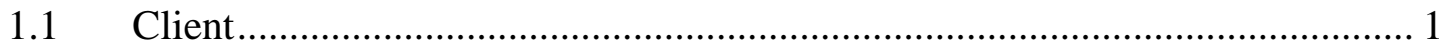

$1.2 \quad$ Problem Statement ........................................................................... 2

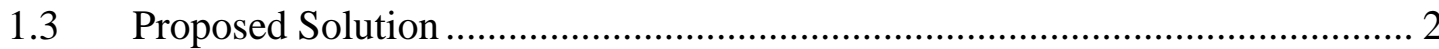

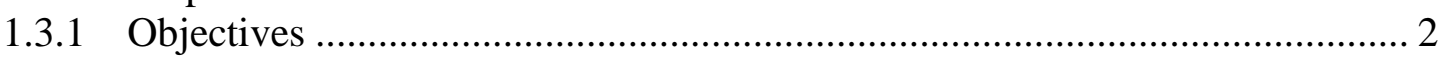

1.3.2 Scope

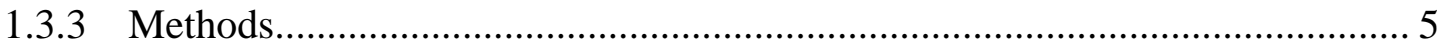

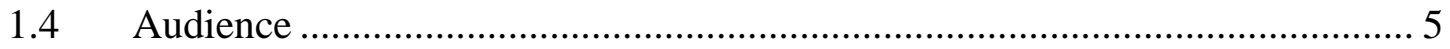

1.5 Overview of the Rest of this Report ............................................................ 5

Chapter 2 - Background and Literature Review ............................................................... 7

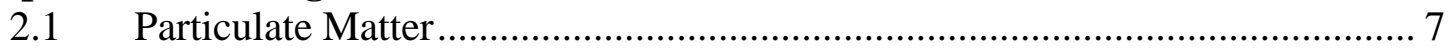

2.2 Dry Deposition Calculation Methodologies ................................................ 8

2.3 Interpolation Methods .............................................................................. 10

Chapter 3 - Systems Analysis and Design........................................................................... 12

$3.1 \quad$ Problem Statement ............................................................................. 12

3.2 Requirements Analysis ……………………….................................... 12

3.3 System Design ................................................................................... 13

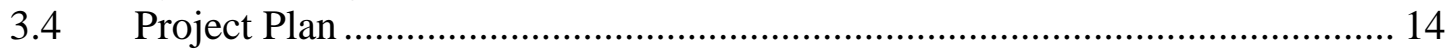

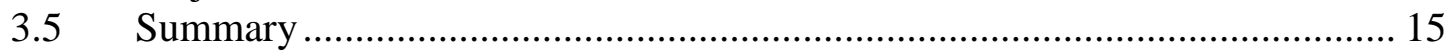

Chapter 4 - Database Design.............................................................................................. 17

4.1 Conceptual Data Model .................................................................... 17

4.2 Logical Data Model .......................................................................... 17

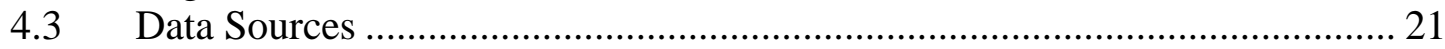

4.4 Data Collection Methods ........................................................................... 22

4.4.1 Elevation Dataset ............................................................................... 23

4.4.2 Water Body and Drainage Basins ............................................................. 24

4.4.3 Air Quality Data........................................................................... 24

4.4.4 Wind Speed and Direction Data ………………….................................... 24

4.5 Data Synthesis.................................................................................. 25

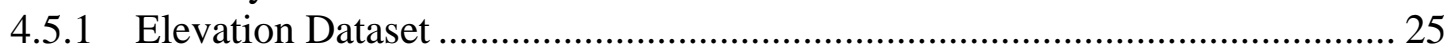

4.5.2 Water Body and Drainage Basins ............................................................... 27

4.5.3 Air Quality Data................................................................................. 27

Chapter 5 - Implementation.................................................................................................. 30

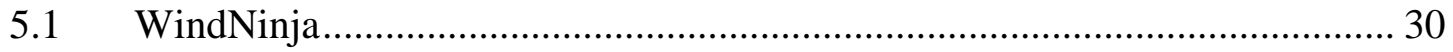

5.1.1 Application of WindNinja.......................................................................... 30

5.1.2 Spatial Simulation of WindNinja Outputs ................................................... 31

5.2 Physical Model Formulae for Flux ……………….................................... 32

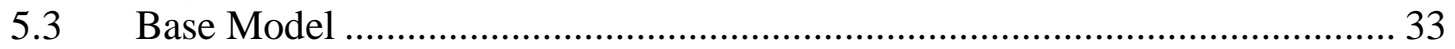

5.4 Comparison Model................................................................................... 34

5.5 Zonal Standard Deviation and Mean Model.................................................. 35

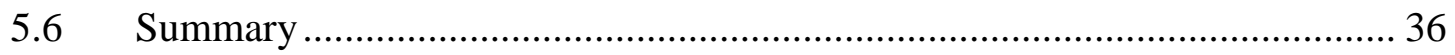


Chapter 6 - Results and Analysis............................................................................................. 37

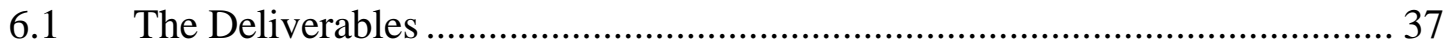

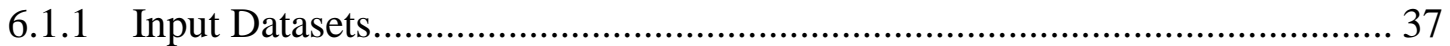

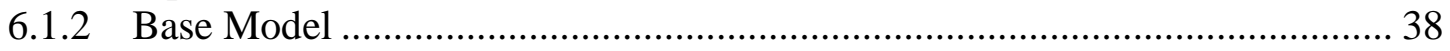

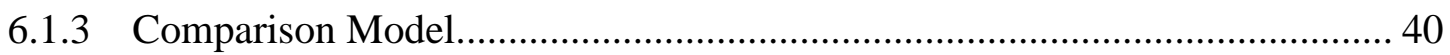

6.1.4 Zonal Standard Deviation and Mean Model ............................................ 41

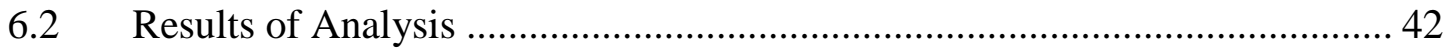

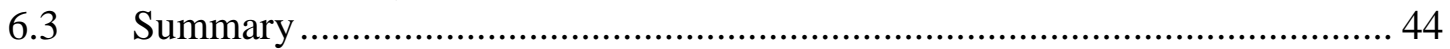

Chapter 7 - Conclusions and Future Work .......................................................... 45

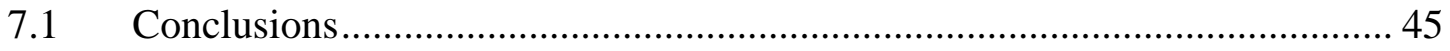

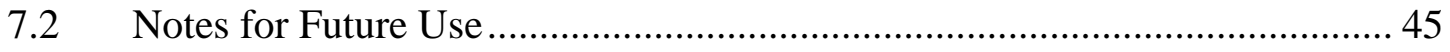

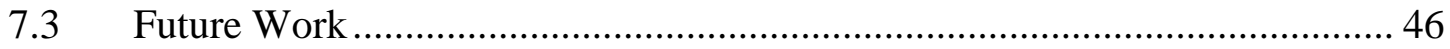

7.3.1 Atmospheric Physics and its effects on the deposition of contaminants. ....... 46

7.3.2 Chemical Engineering and the air/water interface impact on contaminant

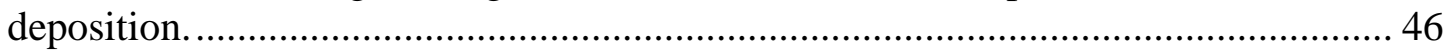

7.3.3 Fluid Dynamics, subsurface mixing of deposited contaminants and their

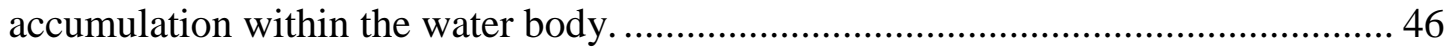

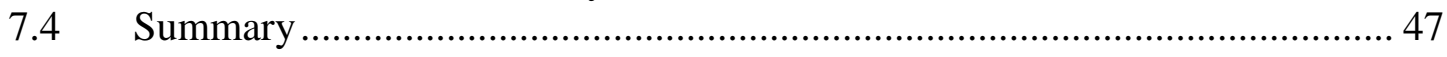

\section{Bibliography 49}

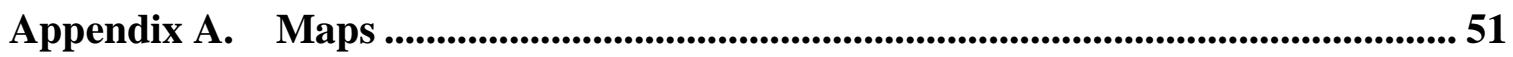

Appendix B. Model Builder Models.......................................................................68

Appendix C. Computer Requirements ...................................................................... 71

Appendix D. Master Data List ......................................................................... 72 


\section{Table of Figures}

Figure 1-1: Wind Stations, left in blue. Air Quality Stations, right in red................... 3

Figure 1-2: Lake Perris at lower left, Lake Crowley at upper right........................... 4

Figure 2-1: A depiction of the relative sizes of PM2.5 and PM10. (EPA, 2012) ....... 7

Figure 2-2: Sources and Receptors of wet and dry deposition. (EPA, 2012) .............. 8

Figure 2-3: Comparison of considered interpolation methods. .............................. 11

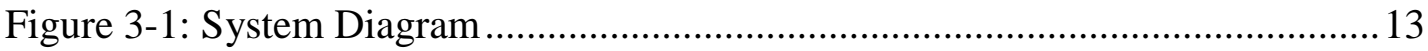

Figure 3-2: Project System Workflow ...................................................................... 14

Figure 3-3: Initial and revised tasks as a percentage of time............................... 15

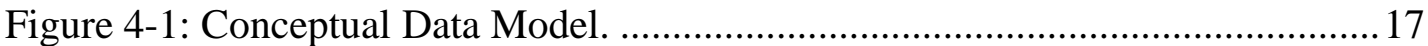

Figure 4-2: Data Synthesis decision workflow..................................................... 18

Figure 4-3: Windows File Folder and Data Synthesis geodatabase contents........... 19

Figure 4-4: Data path structure, interaction and storage workflow. ........................20

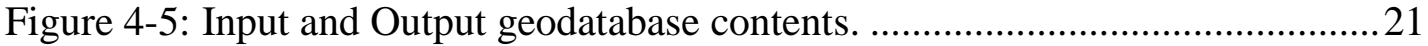

Figure 4-6: Conceptual diagram of wind station selection. ................................... 22

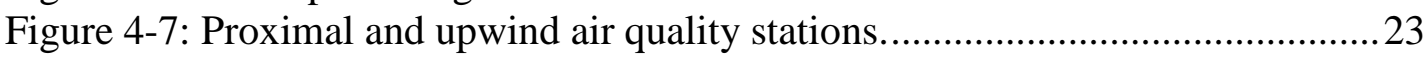

Figure 4-8: Mosaic of six DEMs over study area extent. .......................................24

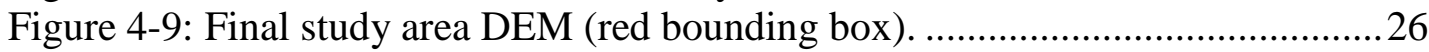

Figure 4-10: Final DEM extent used for wind simulation within WindNinja...........27

Figure 4-11: ArcMap table of contaminant samples summarized by season. ...........28

Figure 4-12: ArcMap table of seasonal wind speed and direction.............................28

Figure 4-13: Summarized wind speed and direction values.................................29

Figure 5-1: WindNinja interface for user inputs and parameter selection..................30

Figure 5-2: Sample of the WindNinja point attributes for the fall of 2009. .............. 31

Figure 5-3: Digital Elevation Model of the Lake Perris State Recreation Area........32

Figure 5-4: WindNinja 3D visualization check, for winter 2009. .......................... 32

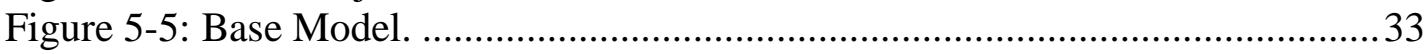

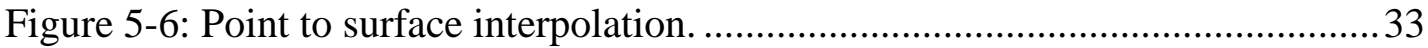

Figure 5-7: Bilinear interpolation of flux using buffered \& non-buffered points...... 34

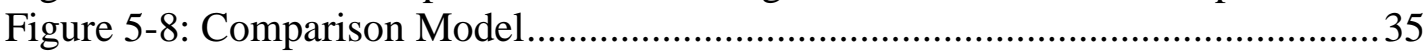

Figure 5-9: Comparative Lake Zone Statistics Model ........................................... 36

Figure 6-1: Seasonal wind directions and selected stations of interest......................38

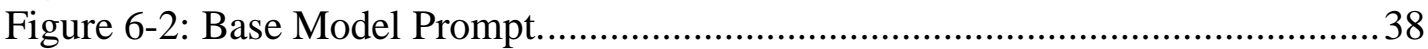

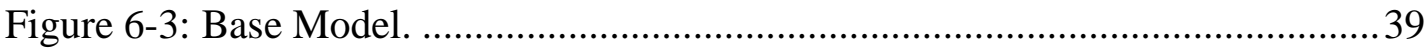

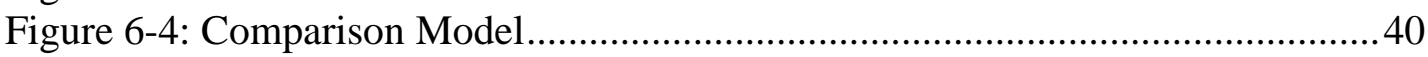

Figure 6-5: Comparison Model Prompt.................................................................. 41

Figure 6-6: Spatial distribution of seasonal fluxes from seasonal mean. ..................42

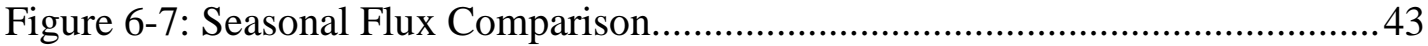




\section{List of Tables}

Table 1. Project Functional and Non-Functional Requirements ............................... 13

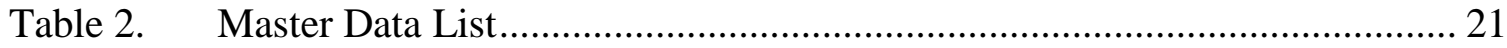

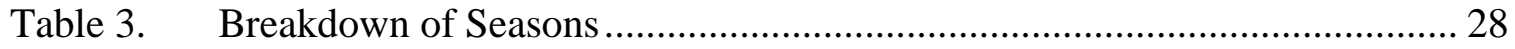

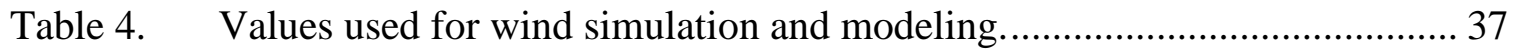





\section{List of Acronyms and Definitions}

$\begin{array}{ll}\text {.DDF } & \text { Data Directive File } \\ \text {.TIF } & \text { Tagged Image File } \\ \text {.txt } & \text { text file } \\ \text { ASCII } & \text { American Standard Code for Information Interchange } \\ \text { CARB } & \text { California Air Resources Board } \\ \text { CFD } & \text { Computational Fluid Dynamics } \\ \text { CSV } & \text { Comma Separated Values } \\ \text { DEM } & \text { Digital Elevation Model } \\ \text { Emi Sig } & \text { Emergency Management Issues Special Interest Group } \\ \text { EPA } & \text { Environmental Protection Agency } \\ \text { FTP } & \text { File Transfer Protocol } \\ \text { GIS } & \text { Geographic Information System } \\ \text { IDW } & \text { Inverse Distance Weighting } \\ \text { ishJava } & \text { integrated surface hourly, NOAA wind data format using Java } \\ \text { LOI } & \text { Lake of Interest } \\ \text { NAD27 } & \text { North American Datum of 1927 } \\ \text { NCDC } & \text { National Climactic Data Center } \\ \text { NHD } & \text { National Hydrography Dataset } \\ \text { NOAA } & \text { National Oceanic and Atmospheric Administration } \\ \text { NVIDIA } & \text { graphics card brand } \\ \text { OpenGL } & \text { API for rendering 2D/ 3D computer graphics } \\ \text { PAH } & \text { Polycyclic Aromatic Hydrocarbon } \\ \text { PM } & \text { Particulate Matter } \\ \text { PMmass } & \text { Particulate Matter mass file } \\ \text { RAM } & \text { Random Access Memory } \\ \text { SDTS } & \text { Spatial Data Transfer Protocol } \\ \text { U* } & \text { U star, variable of Friction Velocity } \\ \text { UNEP } & \text { United Nations Environment Programme } \\ \text { USDA } & \text { United States Department of Agriculture } \\ \text { USGS } & \text { United States Geological Survey } \\ \text { UTM } & \text { Universal Transverse Mercator } \\ & \end{array}$





\section{Chapter 1 - Introduction}

While developed countries have been able to implement engineering techniques and sanitation technologies to keep water resources clean from runoff and ground contamination, air pollution and its contribution of harmful contaminants to our water resources has yet to be fully understood and prevented.

Polycyclic aromatic hydrocarbons (PAH), one such contaminant, are organic compounds released during combustion processes, such as industrial and automobile pollution.

PAHs present a significant health risk to both terrestrial and aquatic organisms because they are semi-volatile, known to bioaccumulate, and are known carcinogens, causing cancer and developmental delays. PAHs stick to particulate matter, are carried by the wind, and then deposited onto the surfaces of water bodies. Southern California is particularly at risk for higher than average atmospheric deposition of these compounds due to a combination of dense population and unique wind and weather patterns (Lyons, 2012).

This project has created a multi-step work flow to process wind speed and direction and air contaminant sample data, simulate the behavior of wind, and calculate the spatial distribution of the flux (mass per unit area per unit of time) of particulate matter size PM10, known to transport contaminants such as PAH, at the air - water interface of a water body. Lake Perris, an artificial lake completed in 1973, was used as the case study for this project.

Lake Perris, with 10 miles of accessible shoreline, an island and an average water temperature of 70 degrees, is one of Southern California's most popular outdoor recreation areas with an average of 1.1 million visitors a year (Rocky Mountain Recreation, 2013). It is located approximately 65 miles south of Los Angeles; 11 miles south of Riverside off the I-215 within the hilly landscape of the Lake Perris State Recreation Area.

This chapter serves as an introduction of the project for the reader. Section 1.1 introduces the client. The problem addressed is discussed in section 1.2. Section 1.3 describes the proposed solution including project objectives, scope and methods. The intended audience is described in section 1.4 and section 1.5 provides a layout for the rest of the document.

\subsection{Client}

The client and point of contact for this project was Dr. Rebecca Lyons, Assistant Professor within the Department of Chemistry at the University of Redlands. Dr. Lyons conducted a study to determine which suspected source of PAH compounds is the greatest contributor to water resources. Her suspected sources were defined as tributaries, motorized vehicle traffic, ground water run-off, and atmospheric deposition. Dr. Lyons needed a GIS to explore atmospheric deposition as a contaminant source. 


\subsection{Problem Statement}

A method was needed to calculate the rate at which contaminants precipitate from air, as they pass over open water. Specifically, the flux of particulate matter at the air - water interface of a lake surface needed to be quantified. Due to the large spatial and temporal extent and subsequent computational intensity required to understand atmospheric deposition as a pollutant source to a water body, a geographic information system (GIS) was needed.

\subsection{Proposed Solution}

The proposed solution was a multi-step workflow that utilized a variety of technologies to process the source information, simulate the behavior of wind, and then calculate the spatial distribution of flux of contaminants across a selected water body. Within ArcGIS 10.1 Desktop, the solution utilized tools from the Data Management and Spatial Analyst Geoprocessing toolsets and was automated utilizing ModelBuilder. WindNinja, a computer program that simulates wind over terrain, was used to derive wind speed and direction over the specific area of interest, given a DEM and wind station observation. The output of WindNinja was used as one of the required inputs to the solution. Wind speed and direction points (generated by WindNinja), a water body polygon and contaminant value were input into a ModelBuilder model that applied mathematical equations to each wind point, utilizing the wind speed value, to calculate the friction velocity ( $\mathrm{U}^{*}$ ) and flux of particulate matter at each individual wind point. The flux point values were then interpolated into a continuous surface and were classified to illustrate the spatial distribution of particulate matter across Lake Perris.

\subsubsection{Objectives}

The objective of this project was to use free government data in conjunction with the mathematical formulae provided by the client to create a tool to spatially represent local deposition for selected PAHs. The tool enabled Dr. Lyons and interns to conduct analyses of surface concentrations on other lakes of interest in a spatial context. However, data for selected PAH compounds were not consistently recorded by all California Air Quality stations. Sample values for particulate matter were used in place of PAH sample values and further details about their correlation are available in Section 2. The overall objective of this project was to create a methodology to quantify the flux of particulate matter at the air-water interface of a lake such that the workflow be repeatable with minimal complexity for the user. The datasets developed and used for this case study served as a sample dataset.

\subsubsection{Scope}

The scope of this project was to create a tool to spatially quantify the flux of contaminant deposition across one lake. Data for the project, while available at no monetary cost, had vast temporal and spatial ranges. NOAA wind speed and direction samples were available from 556 California stations with hourly observations available from 1902 to 
2009, and California Air Quality average daily samples were available from 902 stations from 1980 to 2009 (Figure 1-1).
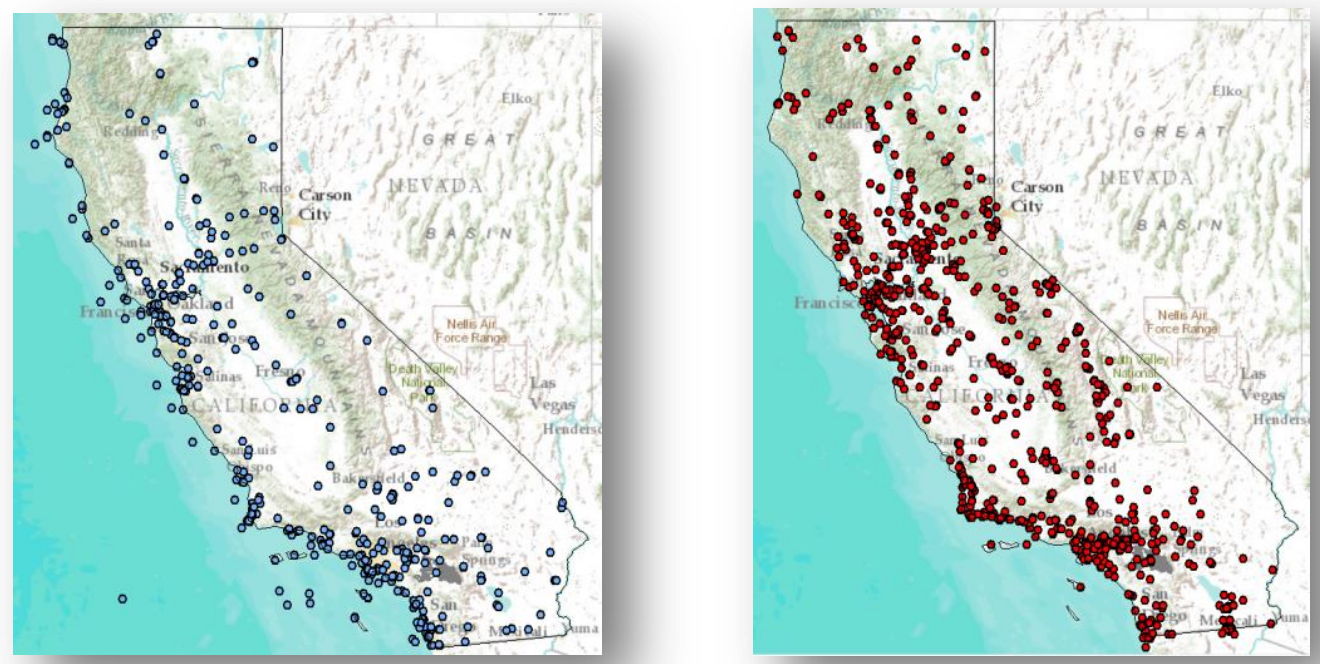

Figure 1-1: Wind Stations, left in blue. Air Quality Stations, right in red.

In order for the project to be completed according to plan, the data had to be constrained geographically and temporally. Given consistent overlap between the two datasets, data for initial exploration were limited to the years 2007, 2008, and 2009 and summarized by season. To avoid project expansion, selected California lake(s) of interest (LOI) were limited to fit the following criterion:

- Must have a wind station with recorded observation values of wind speed and direction within the watershed of the LOI

- Must have an air quality station with recorded observation values of particulate matter within the watershed of the LOI

- Must have corresponding time frames for both station datasets of the LOI

Given the above criteria, the client chose Lake Perris in Riverside County (Southern California) and Lake Crowley in Mono County (Northern California) in hopes of providing LOIs contrasted with clean and unclean air. Figure 1-2 shows the geographic location of Lake Perris and Lake Crowley. 


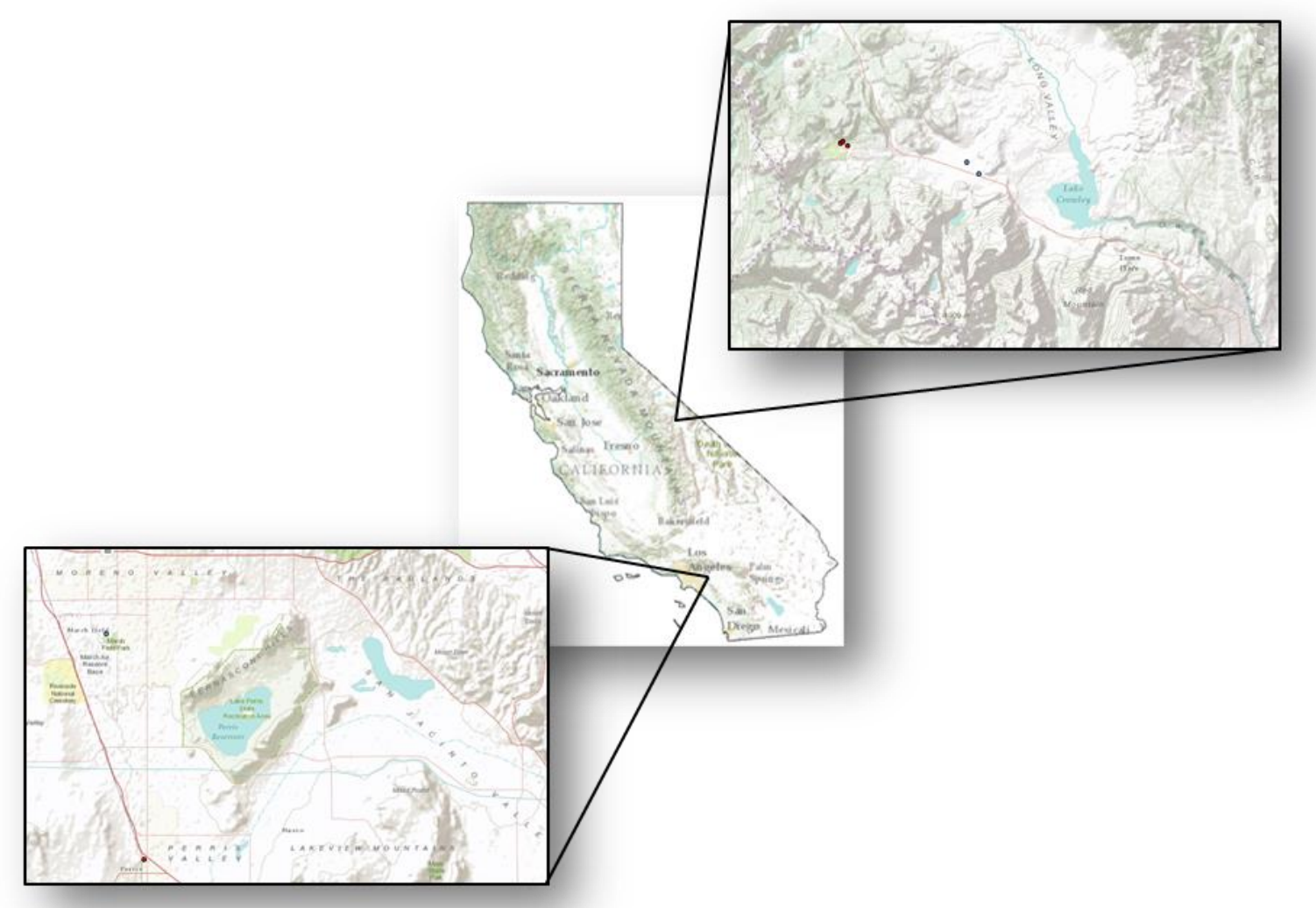

Figure 1-2: Lake Perris at lower left, Lake Crowley at upper right.

However, due to inconsistent station sampling and possible station sensor errors in both data domains of wind and air quality, Lake Crowley in Mono County was discarded. Furthermore due to the mass of available data, additional measures were taken to further narrow the scope for the analysis of Lake Perris:

- Use of the calculated maximum wind speed per season

- Use of the calculated mean wind direction per season

- Use of the calculated mean value of sampled contaminant per season

The above measures were chosen based on the criteria described in Section 4 under wind and air quality data. The temporal breakdown allowed for ease of implementation of WindNinja and user input of the calculated concentration amount, reducing the required time to create inputs for the model. The scope of this project was impacted largely, both geographically and temporally, due to the large effort required for data processing. The final spatial extent for this project was limited to Lake Perris with a temporal scope of one year, 2009, summarized by season that included air quality and wind speed and direction data for analysis. 


\subsubsection{Methods}

This project had a two stage methodology: the first data acquisition and conditioning and the second, analysis. This two stage approach allowed for re-iteration of data scrubbing and analysis testing to ensure the project had a firm scientific approach.

Wind speed and direction and air quality samples were acquired from government entities at no cost. The datasets were then processed into an ArcGIS friendly format using Microsoft Excel and ishJava, spatial and temporal overlaps of both datasets identified and applicable samples summarized using the Data Management and Spatial Analysis toolsets (Section 4). Additional datasets acquired included six 10 meter DEM quadrangles incorporating the surrounding study area of Lake Perris that required conversion and processing prior to use in the solution. Refer to section 4

Stage two of the project focused on analysis. While less exhaustive than the first, this stage consisted of running WindNinja on summarized wind data and the conditioned DEM of the study area to produce a wind speed and direction shapefile of points, in a grid pattern 100 meters apart, for each season in 2009. Then within ArcScene the wind points were visualized in 3D atop the DEM to visually check for evidence of terrain influence on wind speed. With the 3D validity check complete, the points were utilized within ModelBuilder. Math was applied to each individual wind speed point, using map algebra tools within ModelBuilder, calculating the friction velocity ( $\mathrm{U}^{*}$ ) and flux of contaminants given a contaminant concentration value. Once each point had its respective friction velocity $\left(\mathrm{U}^{*}\right)$ and flux value, bilinear interpolation was used to create a continuous surface. Several models were created and refined in the analysis stage and further explained in Chapter 5.

\subsection{Audience}

The intended audience for this project was Dr. Lyons and Dr. Lyons' GIS interns. Other potential audience members may include environmental scientists, government agencies, and perhaps policy makers who seek to regulate maximum contaminate levels in surface water, and drinking water in particular. Knowing the relative contribution that atmospheric deposition contributes as one of the four suspected sources of toxic compounds may assist in making regulatory decisions.

\subsection{Overview of the Rest of this Report}

Section 2 of this report discusses background information on the relation of PAH compounds, and particulate matter, and other important information relative to this project. Section 3 describes the project plan, changes that occurred during the course of the project, the system and requirements analysis, and the system design. Section 4 presents the methods taken for data acquisition and conditioning, database design, and the logical and conceptual data models developed for this project. Section 5 covers the steps taken to implement the solution. Section 6 reports the results and analysis. Section 7 provides project conclusions and insights for future work. 



\section{Chapter 2 - Background and Literature Review}

In order to grasp the concept and simulate the process of atmospheric deposition within a geographic information system, research was conducted on the pollutant type of interest, the transport methods of the chosen pollutant and the types of analysis considered for mapping the results. The following sections describe the nature and transport methods of particulate matter, the inferential method taken to calculate dry deposition, and the mathematical process chosen for estimating a continuous surface based on a known set of point values.

\subsection{Particulate Matter}

Particulate matter (PM) is a type of air borne pollution comprised of extremely small solid particles and liquid droplets and can originate from natural processes, such as forest fires and wind erosion, and from anthropogenic sources, like agricultural practices, smokestacks, car emissions, and construction (Environmental Protection Agency, 2012). Smoke, dust, soot and soil particles are all examples of PM. Particle pollution is comprised of acids (such as nitrates and sulfates), organic chemicals, metals, and soil or dust particles and is subdivided into two categories: fine particles and coarse particles. Fine particles, PM2.5, have diameters that are 2.5 microns and smaller. Coarse particles, PM10, have diameters larger than 2.5 microns, but smaller than 10 microns. Figure 2-1 illustrates that the average human hair has a diameter of 50 to 70 microns and is approximately 30 times larger than a large fine particle (Environmental Protection Agency, 2012).

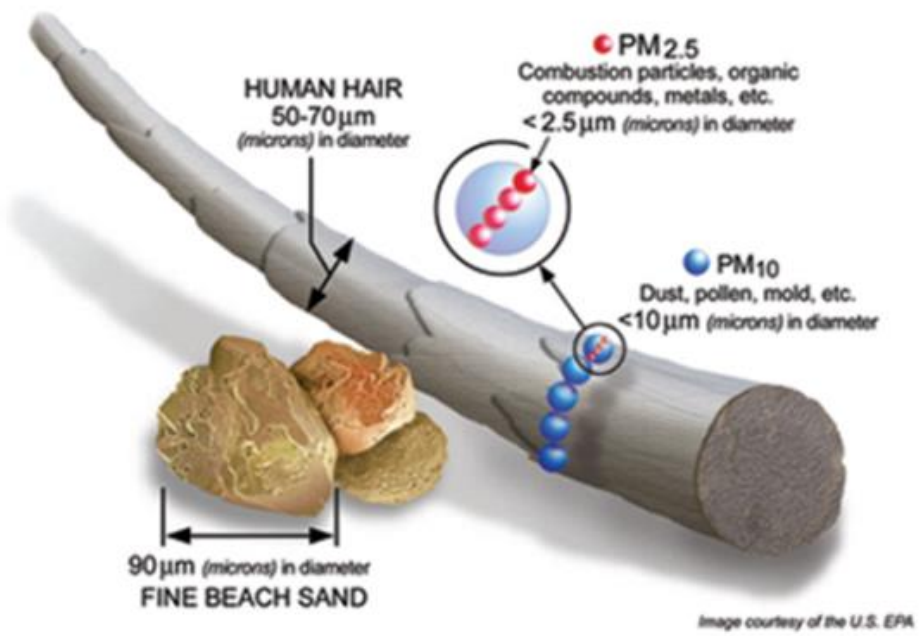

Figure 2-1: A depiction of the relative sizes of PM2.5 and PM10. (EPA, 2012)

The United States Environmental Protection Agency (EPA) is concerned about particles of PM10 and smaller because they affect the heart and lungs, causing serious health effects such as lung disease, emphysema and lung cancer (Environmental Protection Agency, 2012). The further particles travel into the human respiratory system the worse 
the adverse health effect. Factors that affect how deep into the lungs particles reach include: nose or mouth breathing, exercise, age, lung disease, weather (temperature) and the presence of other pollutants in the air (Pima County Department of Environmental Quality, 2012). In all, exposure to PM increases the use of medications and causes more emergency room visits (Pima County Department of Environmental Quality, 2012).

Particulate matter is deposited onto the Earth through the processes of wet and dry deposition. The EPA defines wet deposition as a process that occurs when gaseous pollutants in the atmosphere, at times combined with particulate pollutants, are blown into areas of wet weather, then fall to the ground in the form of rain, snow, fog, or mist (Environmental Protection Agency, 2012). Dry deposition occurs in areas of dry weather where gaseous pollutants combine with dust or smoke (particulates) through molecular bonding, and fall to the ground. In comparison, dry deposition as defined by the Emergency Management Issues Special Interest Group (Emi Sig) as "the process of transferring gaseous and particulate components to the environment (ground, trees, buildings, water etc.) in the absence of precipitation". Wet and dry deposition sources and receptors are both man-made and of the natural environment (Figure 2-2).

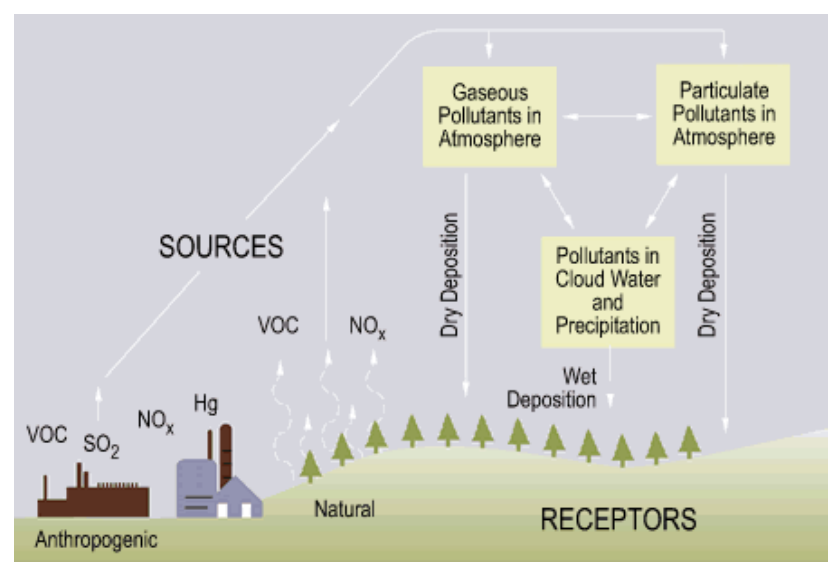

Figure 2-2: Sources and Receptors of wet and dry deposition. (EPA, 2012)

\subsection{Dry Deposition Calculation Methodologies}

The United Nations Environment Programme (UNEP), Regional Resource Centre for Asia and the Pacific state: "dry deposition may be calculated by direct measurement or by computing it through inferential methods from the measurement of concentrations of air pollutants". Calculating dry deposition through field data collection is considered to be a "direct method" (Asian Institute of Technology, 2012). The Regional Resource Centre for Asia and the Pacific also state that: "while the sensors, protocols and study areas exist for implementing a direct method, it can be very complex, so much that the routine use of a direct method in a monitoring network is not practical" (Asian Institute of Technology, 2012). Additionally, use of direct methods does not seem likely in the future due to: the chemical sensors required not being suitable for unattended use, the high cost of equipment and facilities, the requirement of skilled field equipment operators being unavoidable, and the lack of applicability to non-homogeneous sites (Asian Institute of Technology, 2012). Hence the use of standard air quality stations for collection of 
pollution concentrations is the only readily available option. Thus, the use of either the concentration monitoring approach or the inferential approach as subdivisions of the indirect method are best in most cases because " (they) are based on the equation $\mathrm{F}=\mathrm{Vd}$ $\mathrm{x} \mathrm{C}$, where flux $\mathrm{F}$ is derived from dry deposition velocity $\mathrm{Vd}$ and the concentration of the airborne species C" (Asian Institute of Technology, 2012). And because air concentration measurements can be automated in a routine fashion, and techniques of sampling can be defined for site-specific characteristics, the inferential approach is now the most popular method in some regions... and... the best most cost effective method for modeling dry deposition (Asian Institute of Technology, 2012). The inferential method for data acquisition was used for this project.

Dr. Lyons provided two equations for primary use in the calculation of flux. The first equation, for calculating the friction velocity $\left(\mathrm{U}^{*}\right)$ at an air-water interface, equation 2.1, was created and parameterized by S.A. Hsu (2007).

$$
U^{*}=\frac{0.4\left(U_{10}\right)}{14.7-2 \ln \left(U_{10}\right)}
$$

Equation 2-1

Hsu reviewed wind stress, atmospheric stability, wave height and peak wavelength for deep water waves and arrived at a roughness factor that was incorporated into the final parameterized equation for overwater friction velocity. Where $U_{10}$ is the wind speed at a height of 10 meters above the surface (obtained from generated wind points), the value 14.7 represents the wave form value and can be recalculated depending on the wave surface type. The value 0.4 known as the von Karman constant is a dimensionless constant describing the logarithmic velocity profile of turbulent fluid flow near a boundary with little to no-slip condition. It should be noted Hsu parameterized overwater friction velocity for hurricanes and that while this project used the default values of the parameterized equation; they have been set as user input parameters within the models and can easily be changed once re-calculated using a smaller wave height, wave period between waves, air and water temperatures, and shallower depth profile typical of a lake environment.

The second equation, equation 2-2, calculated the flux of contaminants by multiplying the air contaminant concentration $\left(\mu \mathrm{g} / \mathrm{m}^{3}\right)$, cell size $\left(\mathrm{m}^{2}\right)$, and friction velocity $\mathrm{U}^{*}(\mu \mathrm{g} / \mathrm{s})$ together.

$$
\text { Flux }=(\text { Concentration })(\text { Area })\left(U^{*}\right)
$$

\section{Equation 2-2}

This flux calculation was completed for each individual wind point, using each wind point's individual wind speed generated using WindNinja. The distance between the each of the generated points was 100 meters, the finest mesh created by WindNinja. The resolution of the DEM used for wind simulation was 10 meters, thus each point represents the center of a 100 square meter $(10 \times 10 \mathrm{~m})$ cell, the representative area for the flux calculation. 


\subsection{Interpolation Methods}

Interpolation is a mathematical process of estimating surface values based on a known set of surrounding points and can be used to estimate ocean temperature, elevation, chemical dispersion and other spatially based phenomena (Esri Press, 2006). A continuous surface of estimated flux values was needed in order to aid in understanding the spatial distribution of flux across a lake surface. The three types of interpolation considered for this project were inverse distance weighted (IDW), spline, and bilinear.

Inverse distance weighted (IDW) interpolation estimates a surface from a set of sample points that have been weighted according to their distance from the cell being evaluated (Esri Press, 2006). The further the point value from the cell being calculated, the less weight or influence it has on the calculated cell value. Given the square, equidistant gridded nature of the calculated points, IDW was not an optimal interpolation method for this project. Each point was exactly 100 meters from its immediate neighbor.

Spline interpolation estimates cell values using a piecewise polynomial function that minimizes overall surface curvature, resulting in a surface that only passes through the original input points (Esri Press, 2006). Given the range of values in the original point dataset, spline created too smooth a surface resulting in less differentiation across areas of the lake when compared to the bilinear interpolation method. Estimation of cell values was needed based on a nearest neighbor approach.

Bilinear interpolation is a resampling method that uses the weighted average of the four nearest cells to calculate a new cell value.

In mathematics, bilinear interpolation is an extension of linear interpolation for interpolating functions of two variables (e.g., $x$ and $y$ ) on a regular $2 \mathrm{D}$ grid. The interpolated function should not use the term of $x^{2}$ or $y^{2}$, but $x y$. The key idea is to perform linear interpolation first in one direction, and then again in the other direction. Although each step is linear in the sampled values and in the position, the interpolation as a whole is not linear but rather quadratic in the sample location (Wikipedia, 2013).

Because bilinear interpolation looks at the four nearest neighboring points and the points in the project dataset were 100 meters apart, wind points just outside the lake boundary had to be included in order to obtain a smooth approximate surface with no missing cell values. IDW, Spline and bilinear were each tested and their outputs studied. 

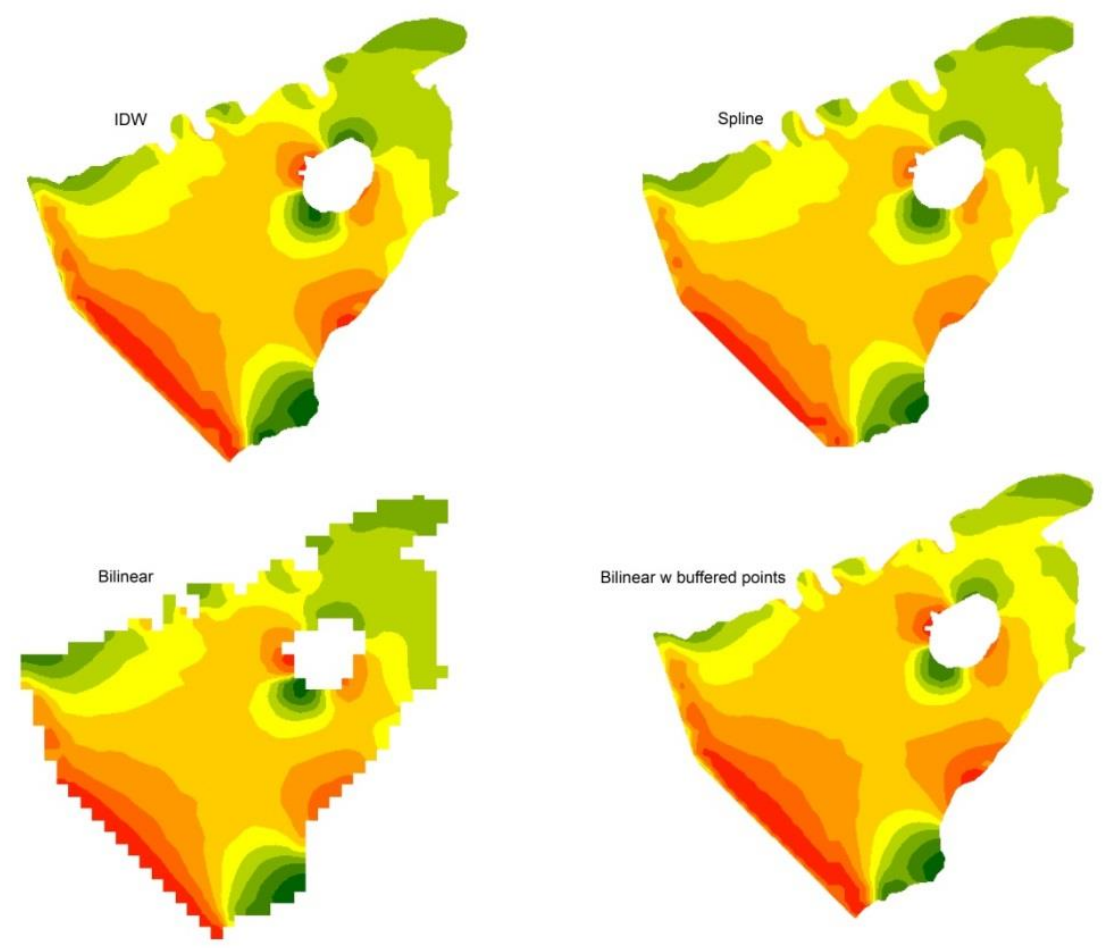

Figure 2-3: Comparison of considered interpolation methods.

Figure 2-3 illustrates the three interpolation outputs considered for use in this project. Note the default "blocky" look to the bilinear result without including points just off the water along the shoreline. Chapter 5 discusses the implementation of bilinear interpolation and the use of buffered points in detail. 


\section{Chapter 3 - Systems Analysis and Design}

\subsection{Problem Statement}

Due to the large spatial and temporal extent and subsequent computational intensity required to understand atmospheric deposition as a pollutant source to a water body, a geographic information system (GIS) was needed. A method was needed to calculate the rate at which contaminants precipitate from air, as they pass over open water. Specifically, the flux of particulate matter at the air - water interface of a lake surface needed to be quantified.

\subsection{Requirements Analysis}

The functional requirements of this project were to 1) evaluate the influence of terrain on wind speed and direction, 2) quantify the flux of contaminants across the surface of a lake, and 3) utilize Lake Perris as the lake of interest. The client provided the equation for overwater friction velocity ( $\mathrm{U}^{*}$ ) developed by S.A. Hsu and developed the flux equation which utilized the calculated $U^{*}$. Both equations had to be incorporated and calculated for each wind point generated across the lake. The end solution also had to accept user inputs for the water body, contaminant value, von Karman constant and wave form value in order to calculate the overwater friction velocity and in turn the flux of contaminants at the air/water interface.

The non-functional requirements of this project were varied since no single software package possessed all the necessary functionality. Pre-processing of large amounts of tabular data was essential to producing usable data. IshJava, an executable file for converting data used within the command line interface, was required to format NOAA's integrated surface hourly wind data into a space delimited format. Microsoft Excel 2010 was used to explore and format the input data for ArcGIS 10.0. ArcGIS 10.0 was used to further explore, summarize and finally produce the input data for both WindNinja and the models. A simple and easy to use software package was required for simulating the impact of terrain on wind speed and direction to understand the spatial distribution of wind. A USDA Forest Service software product, WindNinja, version 2.1.3 released on June $20^{\text {th }}$, 2012, was used to model wind behavior, and produce a shapefile of wind speed points for ArcGIS. Esri's ArcGIS was used to conduct the deposition rate estimation. Most of the tools used are part of the Spatial Analyst extension which provides the bulk of ArcGIS' raster analysis capabilities. 3D Analyst was also utilized, but primarily for data exploration and visualization. The minimal computing requirements for implementation of this solution can be seen in Appendix C. 
Table 1. Project Functional and Non-Functional Requirements

\begin{tabular}{|l|l|}
\hline Functional Requirements & Non-Functional Requirements \\
\hline $\begin{array}{l}\text { Must account for terrain influenced wind } \\
\text { speed }\end{array}$ & $\begin{array}{l}\text { User must provide wind speed, wind } \\
\text { direction and contaminant value }\end{array}$ \\
\hline Must use terrain of surrounding wind basin & Mathematical Formulae for U* and Flux \\
\hline $\begin{array}{l}\text { Must calculate overwater friction velocity } \\
\left(\mathrm{U}^{*}, \mathrm{~m} / \mathrm{s}\right) \text { by point, spatially across a lake }\end{array}$ & Microsoft Excel 2010 \\
\hline $\begin{array}{l}\text { Must calculate Flux of contaminants }(\mu \mathrm{g} / \mathrm{s}) \\
\text { spatially and collectively }\end{array}$ & WindNinja 2.1.3 \\
\hline $\begin{array}{l}\text { Must use inland water body as the modeled } \\
\text { surface }\end{array}$ & $\begin{array}{l}\text { ArcGIS } 10.0 \text { or greater with Spatial \& 3D } \\
\text { Analyst extensions }\end{array}$ \\
\hline
\end{tabular}

\subsection{System Design}

In order to provide a solution to a spatial problem, several processes must be completed. Five processes comprise the workflow of this desktop solution and are seen in Figure 3-1, in chronological order.

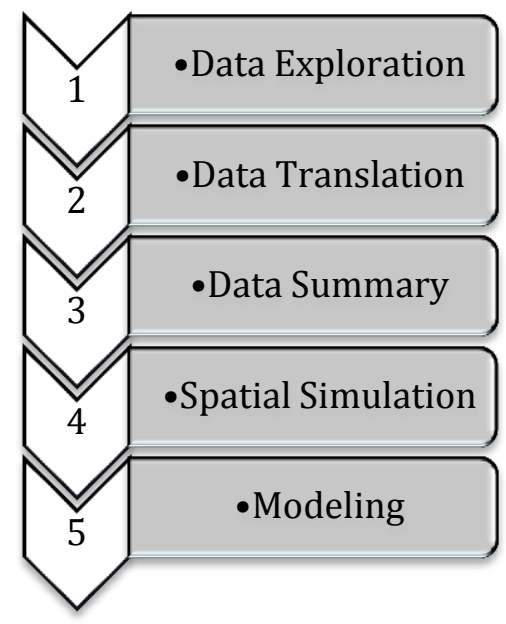

Figure 3-1: System Diagram

Data exploration during this project was comprised of downloading air quality and wind station locations, mapping the locations of each, and selecting the station numbers of interest. Once the station numbers of interest were obtained, the station data were downloaded and translated into a workable format. Data summation for this project then utilized the Summary Statistics and Data Management Tool sets within ArcMap (Section 4). Once the data were summarized, the wind speed and direction values were simulated within WindNinja and then visualized within ArcScene (Section 5.1.2) to evaluate WindNinja outputs and the effects of terrain on wind speed and direction. Finally, the summarized data and tools necessary to provide a solution using ModelBuilder within ArcMap were combined (Chapter 5). Figure 3-2 below shows the steps taken within the system workflow to provide an end solution. 
1. Data Exploration

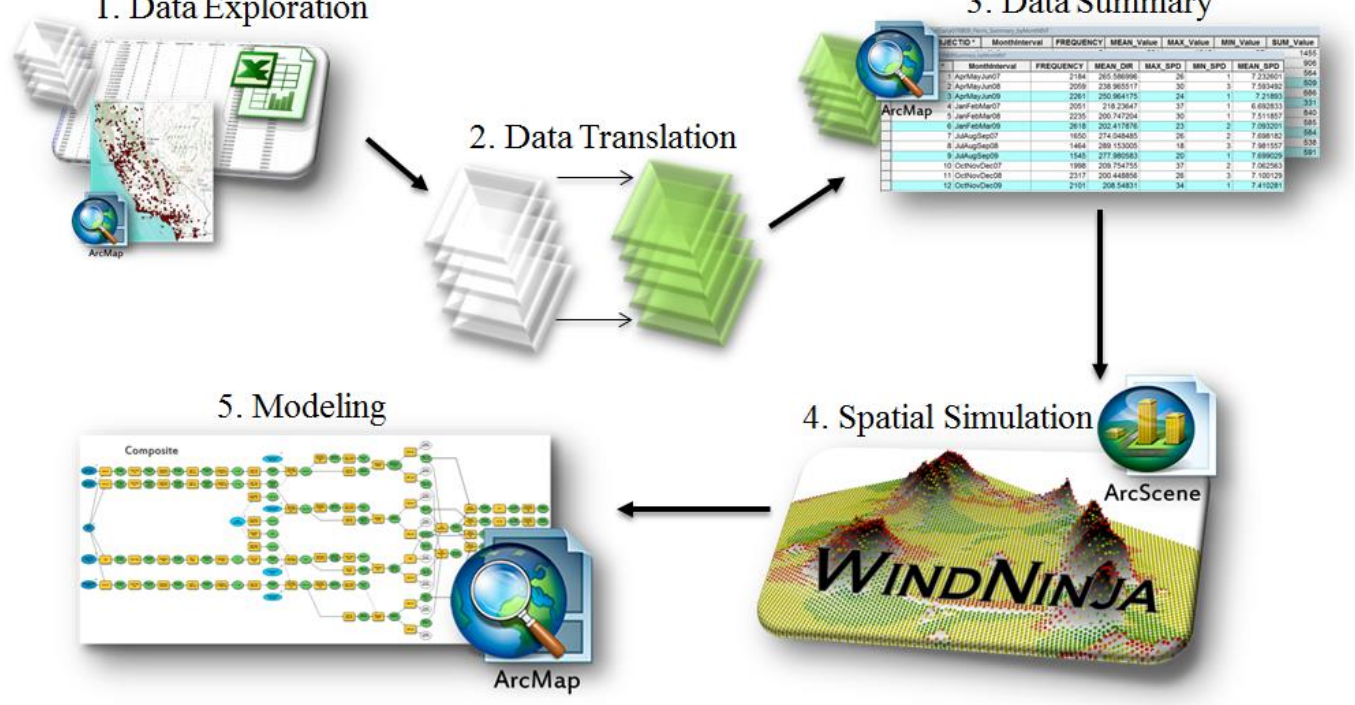

Figure 3-2: Project System Workflow

WindNinja, a program that computes spatially varying wind fields for wild land fire mapping, was created by the United States Forest Service in collaboration with the Missoula Fire Sciences Laboratory and Rocky Mountain Research Center. It was utilized within the project to determine the effects of terrain on wind speed and direction and is discussed in detail in section 5.1.

It requires elevation data for the modeling area (in the form of an ASCII Raster DEM file, FARSITE landscape file, GeoTiff, or ERDAS Imagine file), a domainmean initial wind speed and direction, and specification of the dominant vegetation in the area. A diurnal slope flow model can be optionally turned on or off. Outputs of the model are ASCII Raster grids of wind speed and direction (for use in spatial fire behavior models such as FARSITE and FlamMap), a GIS shapefile (for plotting wind vectors in GIS programs), and a .kmz file (for viewing in Google Earth). WindNinja is typically run on domain sizes up to 50 kilometers by 50 kilometers and at resolutions of around 100 meters (Missoula Fire Sciences Laboratory, 2010).

WindNinja was chosen for application within this project because of its ability to reflect the effect of topography on wind, its compatibility with PC platform running Windows 7, and its option to create shapefiles for compatibility with a GIS.

\subsection{Project Plan}

Over the course of this project, the project plan changed in terms of scope and time allotted for project tasks. At the beginning, the client was interested in calculating the flux of contaminants across three different lakes with no particular temporal window for comparison. Because of the time required for data retrieval and processing, the large datasets for the project and the limited availability of certain contaminant information, data handling narrowed the scope to one lake of interest, Lake Perris. The end solution also provided a temporal scale for analysis, which expanded the scope of the analysis portion of the project. This effect was simplified by performing analysis by season, rather 
than at the maximum temporal resolution of the data, in some cases by week or day, however the end solution may be used to compare other blocks of time. The main organizational effort consisted of creating a well-documented journal that contained notes on all meetings, research and project tasks. Figure 3-3 shows the changes in the initial project plan and the final revised version of the project plan timelines.
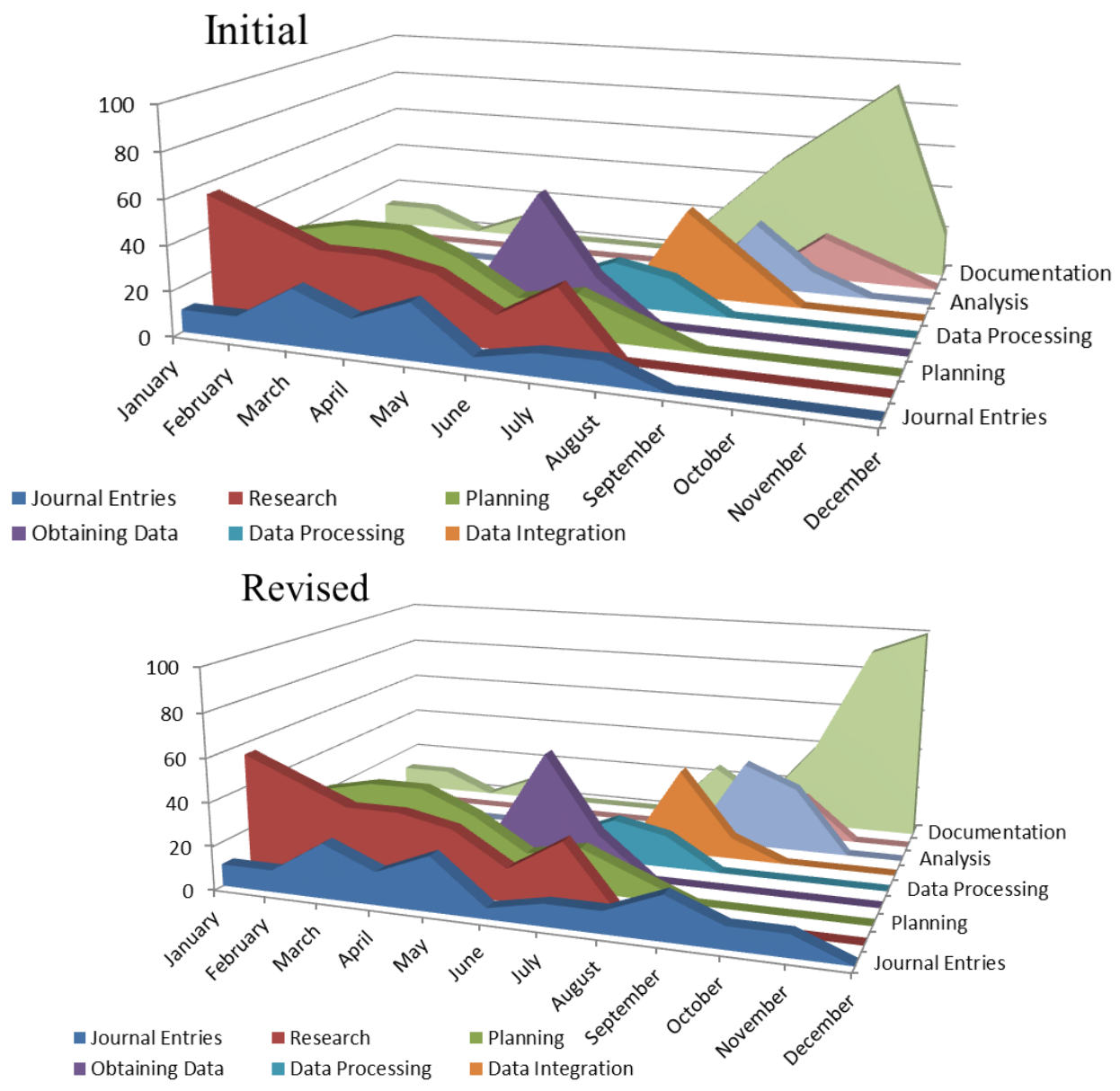

Figure 3-3: Initial and revised tasks as a percentage of time.

Obtaining and processing data consumed more than the allotted time for both tasks. The analysis stage took longer than expected due to troubleshooting with tools and critiquing for better results. Overall, the biggest change in the project task timeline occurred in documentation. Writing of the project document was meant to occur earlier in the project timeline, but due to changes in the analysis and the need to accommodate a multi-platform based workflow, writing was pushed back and the scale of documentation increased. As a result, the amount of journal entries increased.

\subsection{Summary}

The systems analysis and design for this project met the functional and non-functional requirements set for the project. A system workflow was created and a refined version of the project plan completed. The client's functional requirements were in a spatial context 
accounting for terrain influenced wind speed and direction. The calculation of required variables, friction velocity and flux, and the use of Lake Perris as the lake of interest were incorporated into the model. The functional requirements of the project were implemented through defined user inputs: 1) wind speed and direction point feature classes, 2) a polygon feature class of the lake, 3) contaminant values, and 4) cell size based on DEM resolution for the model. The system workflow for the solution was based on the five steps: 1) data exploration, 2) data translation, 3) data summary, 4) spatial simulation, and 5) modeling. This necessary workflow provides thorough detail in analysis and documentation allowing the process can be repeated in the future with different contaminant data, at alternative time frames, and at different geographic locations. The project plan time line was affected by having to obtain the datasets needed for the project, which in turn required heavy data exploration and processing. As a result, the time needed for documenting the project was more than allotted. 


\section{Chapter 4 - Database Design}

\subsection{Conceptual Data Model}

Air, as it moves over the surface of a water body, can deposit contaminants in the form of particulate matter. The flux of contaminants across the water surface was determined by the concentration of the contaminant in the air and the speed at which the air passed over the water surface. In general, water bodies have little, if any, resistance to wind flow. However, the terrain that surrounds the water can have a significant impact on wind speed and direction prior to passing over the lake. Wind speed and direction data were used to spatially model wind movement over a lake surface. The calculated surface wind speed and direction datasets were used along with contaminant datasets to calculate the flux of contaminants across different segments of the lake. Figure 4-1 illustrates the project's conceptual data model with the combination of a contaminant sample, and wind speed and direction value and the resulting calculated flux values by cell across the expanse of the lake.

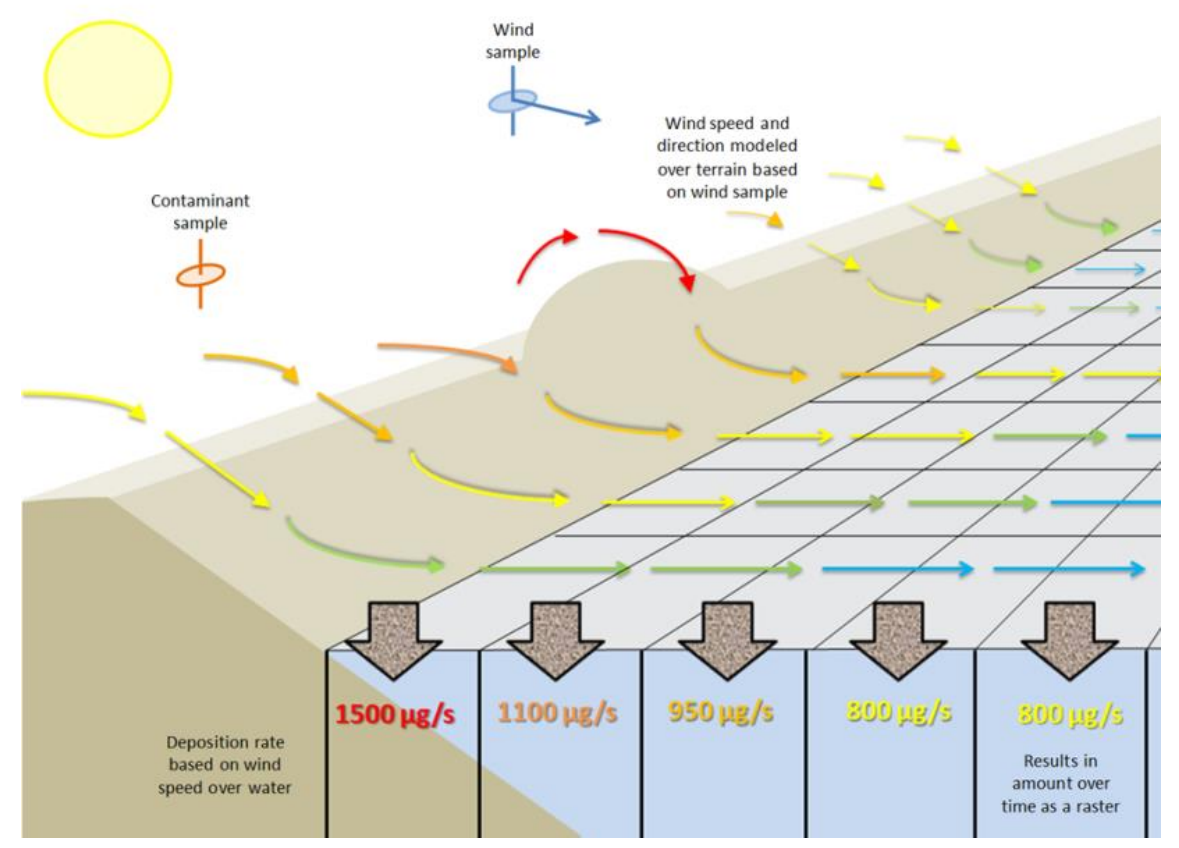

Figure 4-1: Conceptual Data Model.

\subsection{Logical Data Model}

Before implementation could begin, the original source data had to be synthesized into usable formats, with meaningful information. The synthesis workflow can be broken down into a series of decisions on how to select, subset, and summarize complex information to convert it into project data consumable by the implemented analysis workflow. Figure 4-2 represents the path from source data to project data, and each decision that was made. 


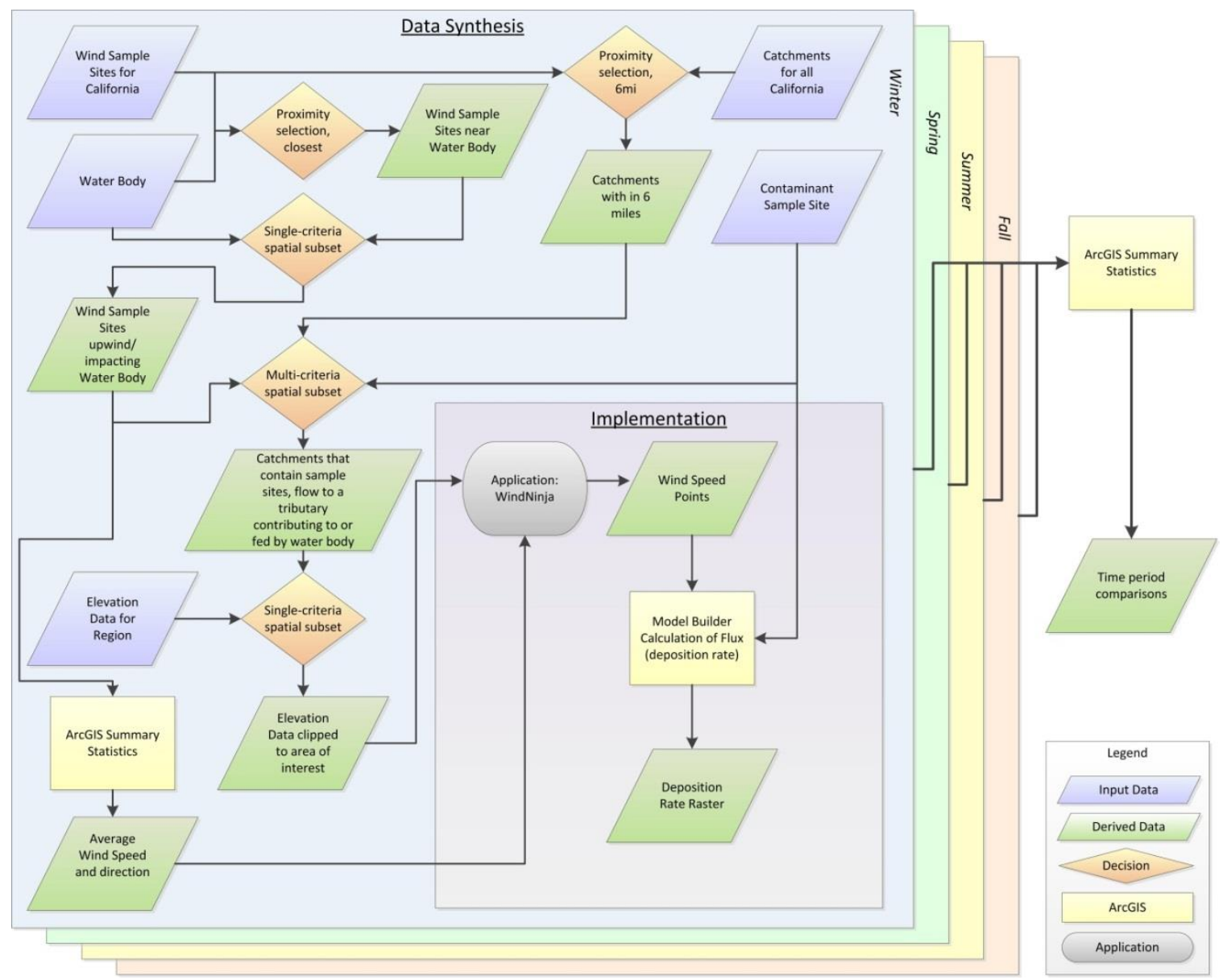

Figure 4-2: Data Synthesis decision workflow.

The data synthesis decision workflow considered, first, only the wind sample stations within closest proximity to the chosen water body. Once the proximal wind stations were chosen, a single criteria spatial subset decision was made to utilize only stations upwind of the water body. For this project, only one wind station satisfied the upwind requirement. Only one contaminant sample site existed within the domain of the study area and fortunately, also resided upwind from the lake. In order to determine the best coverage extent for the elevation dataset, a multi-criteria spatial subset decision was made using both of the determined sample sites and hydrologic basins of the study area. The hydrologic basins that contained the sample sites and flowed to a tributary contributing to the lake or the lake itself were used in the decision for determining the area of terrain influence or elevation dataset. The wind station data from the upwind station were then summarized by season within ArcGIS to provide a seasonal maximum wind speed and average wind direction. It should be noted that the maximum wind speed was used because the minimum and average wind speeds had little to no difference in seasonal value. Thus, the maximum wind speed and average direction for one season and the Digital Elevation Model were used in the implementation phase of the workflow. Each set of seasonal wind speed and direction and the study area DEM were processed through the implementation phase and then a comparison of seasonal flux values was calculated using ArcGIS Summary Statistics. 
Raw data and information files for wind, air quality and imagery were stored a in windows folder structure for processing and loading. Once processed into an ArcGIS compatible format, the datasets were imported into the data synthesis geodatabase, as shown in Figure 4-3.
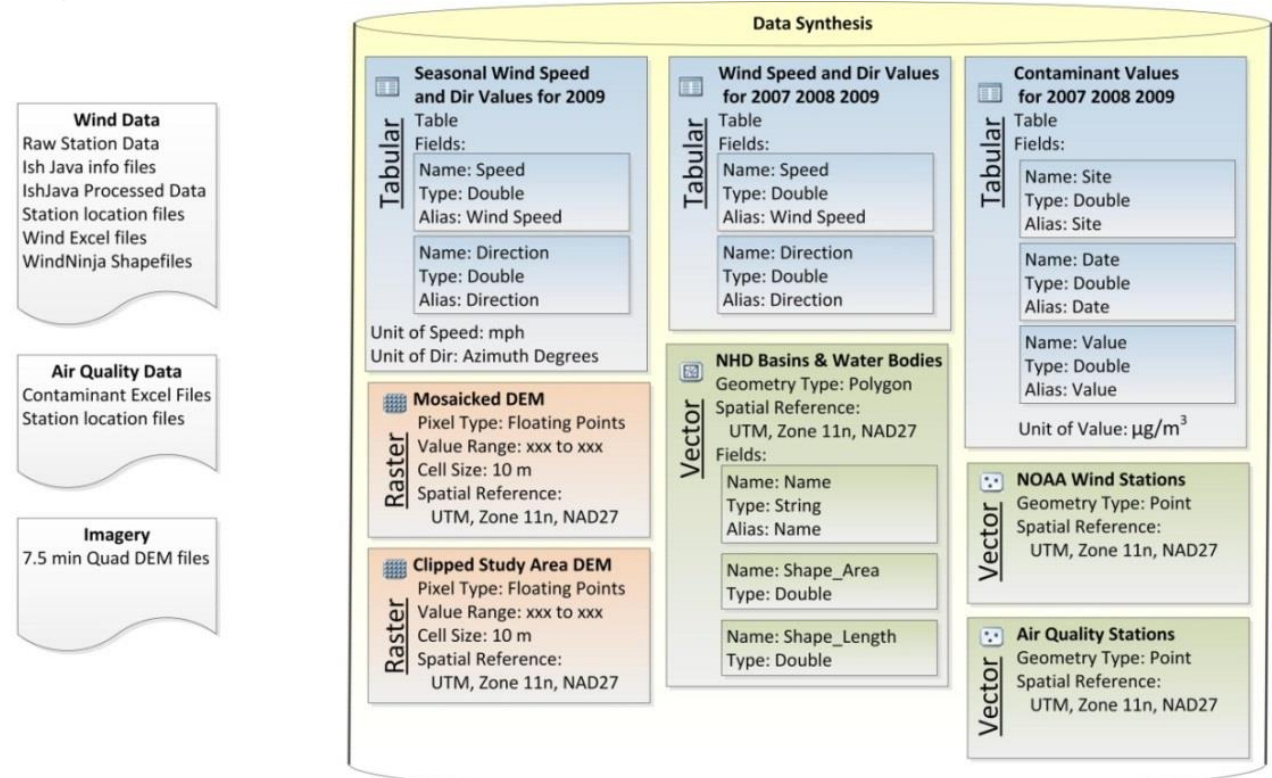

Figure 4-3: Windows File Folder and Data Synthesis geodatabase contents.

Wind speed, directional data and contaminant sample data were then summarized by season for the year 2009. Point feature classes of both the air quality and wind sample stations for the state of California were created and stored in the data synthesis geodatabase for geographic reference. The hydrologic basins and the water body of the study area were also brought into the data synthesis geodatabase for data exploration. Lastly, the .DDF files of imagery were imported into the geodatabase, mosaicked and then clipped to the determined extent of the influential terrain around the lake. The clipped DEM was then converted to a Tagged Image File (TIF) format and placed in the respective Windows File Folder for imagery for WindNinja consumption. Together the study area DEM and a wind speed and direction value were utilized as inputs for WindNinja, producing a shapefile of wind speed and direction points (Figure 4-4). 


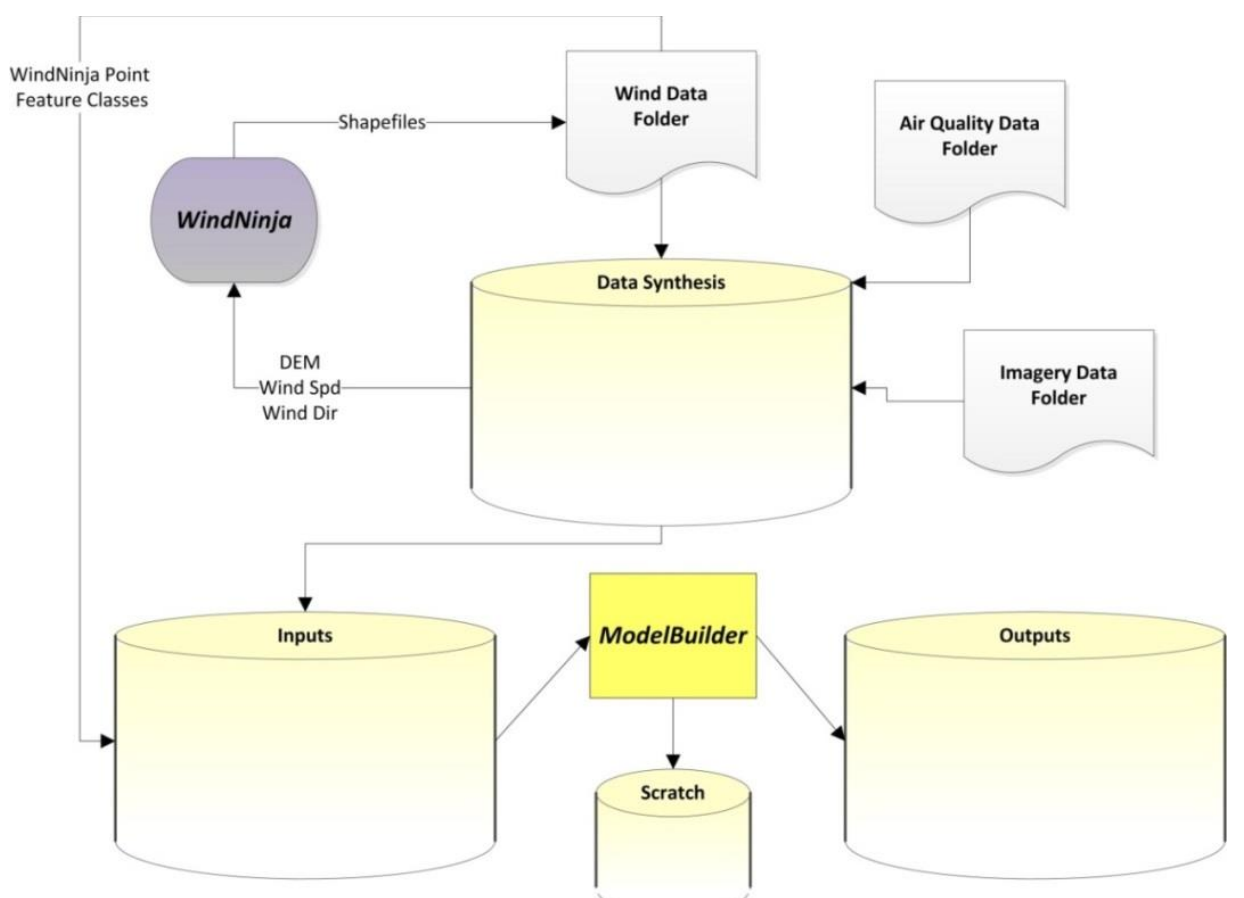

Figure 4-4: Data path structure, interaction and storage workflow.

The shapefile output of WindNinja was stored in the Windows file folder denoted for wind data and later imported into the input geodatabase for analysis. The polygon feature class of Lake Perris was projected and imported into the input geodatabase. A table of the summarized seasonal contaminant values for 2009 was also imported into the input geodatabase for reference when setting user parameters within ModelBuilder. Once all required datasets for analysis were stored in the input geodatabase, ModelBuilder was used to run the model. Temporary datasets created by ModelBuilder were stored in a scratch geodatabase. The required input datasets and the resulting output datasets were stored in the input and output geodatabases (Figure 4-5). 


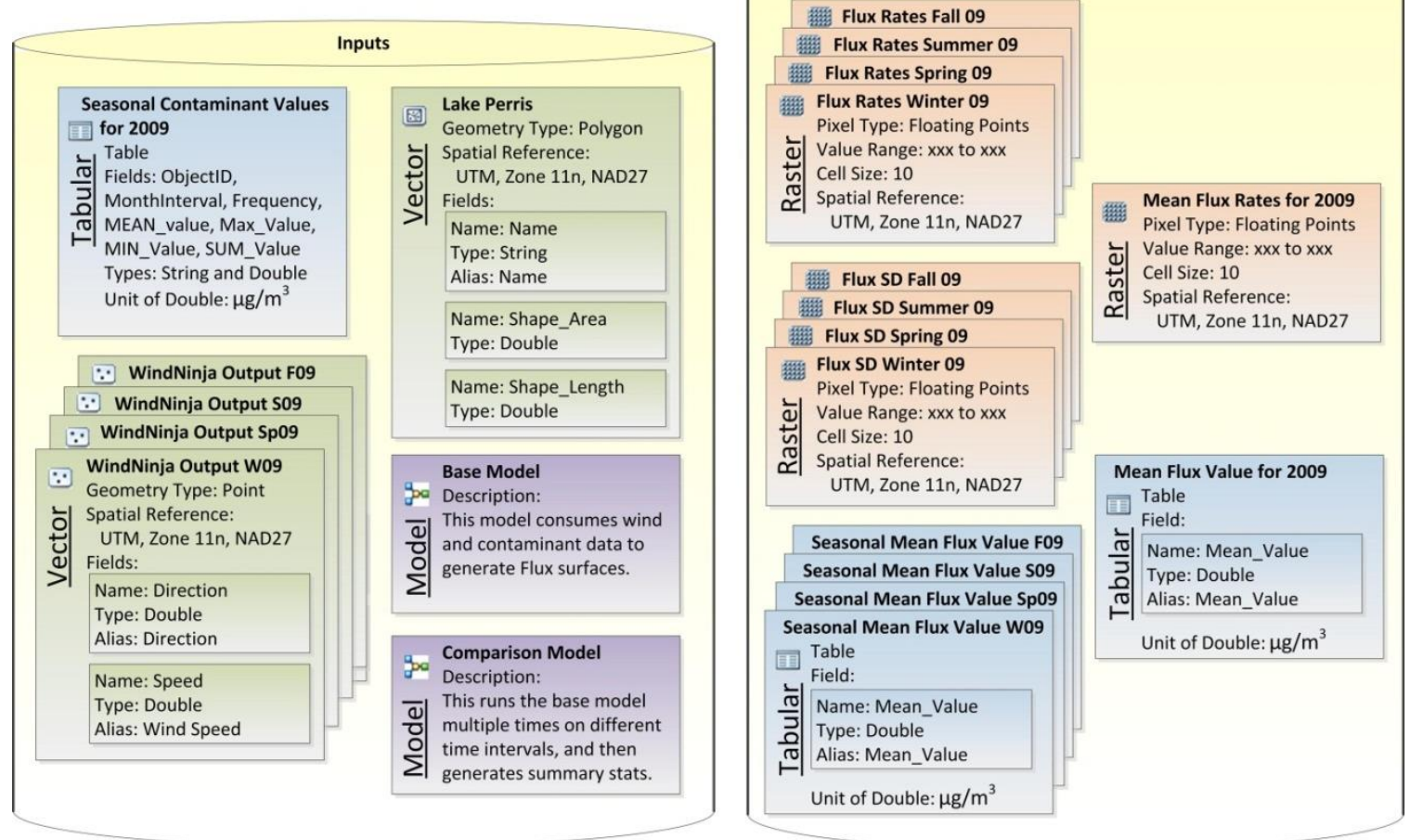

Figure 4-5: Input and Output geodatabase contents.

\subsection{Data Sources}

Data for the project was obtained by the author from four government entities, at no monetary cost, via the internet. Data sources include the National Climatic Data Center (NCDC) of the National Oceanic and Atmospheric Administration (NOAA) for wind speed and direction data and station locations, the California Air Resources Board (CARB) of the California Environmental Protection Agency for air quality sample data and station locations, the National Hydrography Dataset (NHD) webpage of the United States Geological Survey (USGS) for study area hydrography, and dual use of both the Map Finder webpage and GeoCommunity webpage for identifying and obtaining DEMs of the study area. Source locations are referenced in the table below for future use.

\section{Table 2. Master Data List}

\begin{tabular}{|l|l|l|l|l|l|}
\hline ID & \multicolumn{1}{|c|}{ Name } & $\begin{array}{c}\text { File } \\
\text { Type }\end{array}$ & \multicolumn{1}{|c|}{ Source } & $\begin{array}{l}\text { Formatting } \\
\text { Required }\end{array}$ & $\begin{array}{l}\text { Processing } \\
\text { Required }\end{array}$ \\
\hline 1 & $\begin{array}{l}\text { NOAA Wind } \\
\text { Speed and } \\
\begin{array}{l}\text { Direction } \\
\text { data }\end{array}\end{array}$ & $\begin{array}{l}\text { ishJava } \\
\text { file }\end{array}$ & $\begin{array}{l}\text { ftp3.ncdc.noaa.gov } \\
\text { or } \\
\text { http://www7.ncdc.noaa.gov/CDO/c } \\
\text { do } \\
\text { http://www.ncdc.noaa.gov/other- } \\
\text { data-access }\end{array}$ & Yes & Yes \\
\hline
\end{tabular}




\begin{tabular}{|c|c|c|c|c|c|}
\hline 2 & $\begin{array}{l}\text { NOAA } \\
\text { Station } \\
\text { Locations }\end{array}$ & $\mathrm{xml}$ & $\begin{array}{l}\text { ftp3.ncdc.noaa.gov } \\
\text { or } \\
\text { http://www7.ncdc.noaa.gov/CDO/c } \\
\text { do }\end{array}$ & No & Yes \\
\hline 3 & $\begin{array}{l}\text { CARB Air } \\
\text { Quality } \\
\text { Sample data }\end{array}$ & $\mathrm{xml}$ & $\begin{array}{l}\text { ftp.arb.ca.gov } \\
\text { or } \\
\text { http://www.arb.ca.gov/aqd/aqdcd/ } \\
\text { aqdcddld.htm }\end{array}$ & No & Yes \\
\hline 4 & $\begin{array}{l}\text { CARB Air } \\
\text { Quality } \\
\text { Station } \\
\text { Locations }\end{array}$ & $\mathrm{xml}$ & $\begin{array}{l}\text { ftp.arb.ca.gov } \\
\text { or } \\
\text { http://www.arb.ca.gov/aqd/aqdcd/ } \\
\text { aqdcddld.htm }\end{array}$ & No & Yes \\
\hline 5 & $\begin{array}{l}\text { USGS NHD } \\
\text { Sub region } \\
\text { Hydrography }\end{array}$ & shapefile & $\begin{array}{l}\text { http://viewer.nationalmap.gov/vie } \\
\text { wer/nhd.html?p=nhd }\end{array}$ & No & No \\
\hline 6 & $\begin{array}{l}\text { USGS } \\
\text { Digital } \\
\text { Elevation } \\
\text { Models }\end{array}$ &. $\mathrm{DDF}$ & $\begin{array}{l}\text { http://www.usgsquads.com/index. } \\
\text { php/map-indexes/mapfinder } \\
\text { and } \\
\text { http://data.geocomm.com/catalog/ } \\
\text { US/61069/sublist.html }\end{array}$ & Yes & Yes \\
\hline
\end{tabular}

\subsection{Data Collection Methods}

Prior to selecting datasets for download, station selection and visualization of station data in a geographic context was required. It was determined that in order to conduct sound analysis over the lake, wind stations had to reside upwind of the lake. Meaning, if a wind station had average wind direction for the time period of interest that did not blow across the lake, the station was not considered for project analysis. Only wind sample stations, within a certain distance of the water body, with average wind directions that propagated across the lake surface were deemed usable. (Figure 4-6).

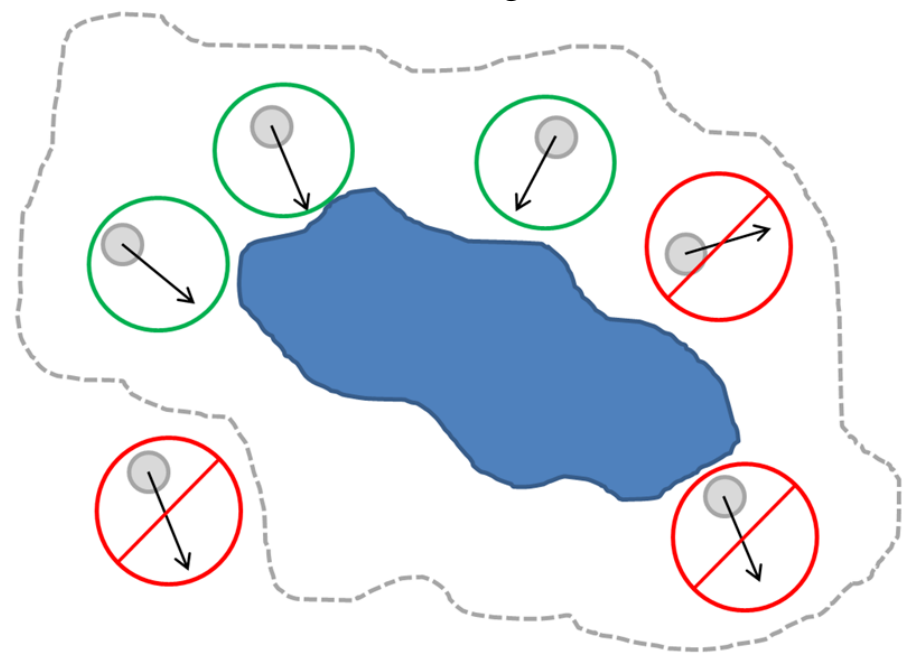

Figure 4-6: Conceptual diagram of wind station selection. 
It is advised that air quality stations be eliminated from use if they reside outside a set distance boundary of influence for analysis and if they reside downwind of the mean wind direction propagating across the lake. Stations that meet the criteria are shown in green and those that do not are shown in red (Figure 4-7).

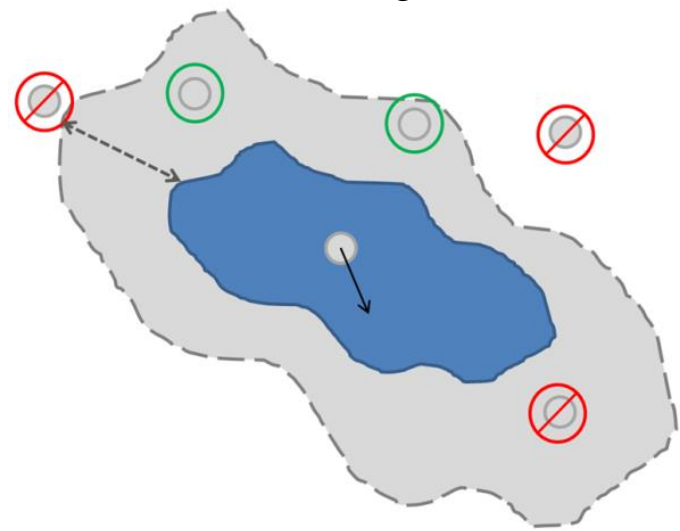

Figure 4-7: Proximal and upwind air quality stations.

Due to the location of the study area, only one wind speed and direction station and one air contaminant sampling station were available for use. It should be noted that fine tuning of analysis can be conducted in the future by planting wind and air quality stations proximal to the study area. This would lessen dependency on finding adequately placed stations.

\subsubsection{Elevation Dataset}

Two steps were taken to obtain an elevation dataset of the study area. The first step utilized Map Finder, an online viewing index of USGS topographic maps, to identify the names of the 1:24,000 topographic 7.5 minute quadrangles around the study area. The second step used the Geo-Community webpage for selecting the Digital Elevation Models (DEM) from a statewide dataset by county and then by quadrangle name. A user name and password were created in order to obtain the DEM for free from the webpage. Each DEM file was downloaded as a .DDF file, a Spatial Data Transfer Standard (SDTS) file type created by the USGS for transferring digital geospatial data. The DEMs of Riverside East, Sunnymeade, El Casco, Steele Peak, Perris and Lakeview all had a projection of NAD27 UTM z11N and 10 meter cell resolution and are shown in Figure 4-8 with the selected wind and air quality stations and lake polygon for scale reference. 


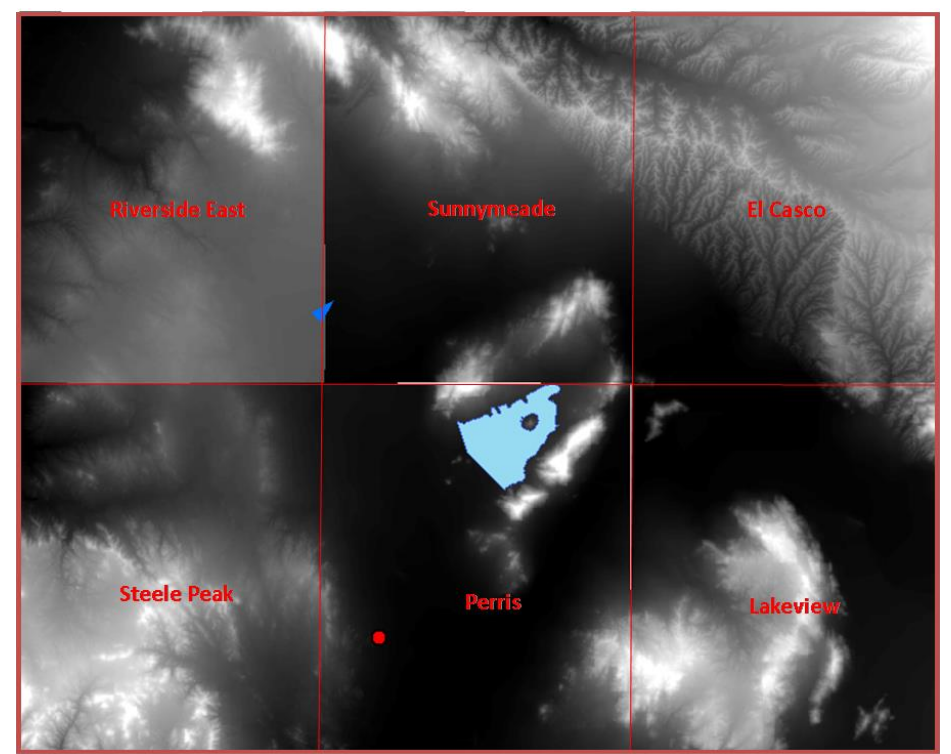

Figure 4-8: Mosaic of six DEMs over study area extent.

Once the selected DEMs for the study area were downloaded, each were individually extracted to a pre-named specified folder and renamed to include the quadrangle name. A text file (.txt) for image metadata was also created and stored in the same file location with each respective extracted DEM.

\subsubsection{Water Body and Drainage Basins}

The drainage basins and lake polygon for Lake Perris were obtained by downloading the San Jacinto Watershed from the USGS webpage for the National Hydrography Dataset (NHD). The webpage contained a map viewer and interactive tools for selecting datasets. The sub basins (watershed) of interest and water body datasets were selected. Once the dataset was chosen, the author submitted an email request for the data package. An FTP site address was then sent in return to the author when the data package was ready for download. The file was saved, extracted and the contents imported into a geodatabase for use within ArcGIS. The lake polygon was imported into the Input geodatabase as a polygon feature class for use within the model.

\subsubsection{Air Quality Data}

Air Quality datasets were downloaded directly from the California Air Resources Board (CARB) webpage in the form of Microsoft Excel files. Specifically, the "PMmass" file containing all "PMmass" sampling data from 1983 to 2009 for the State of California in one Excel workbook was downloaded.

\subsubsection{Wind Speed and Direction Data}

Due to the mass of the data provided by NOAA, an FTP client was used to obtain the wind speed and direction datasets. The FTP host sites were accessible with the given host site address and username "anonymous". No password was required when using the FTP 
client. Within the FTP client, a local default folder location was established for downloading the station data packs, and the FTP site folder structure was navigated to "pub/data/noaa/directory". Once at the "/directory" level, yearly integrated surface hourly (ish) data from 1901 to 2009 was then visible in the folder structure. The years of 2007, 2008 and 2009 were then selected in individual instances and searched for the selected station number of interest. The station and subsequent year data, containing hourly surface measurements, was then downloaded and unpacked as raw ishJava data (refer to section 4.5.4). Information on how to access the global hourly surface data was obtained from the FTP Bulk Access link provided by the "other-data-access" link found within the master data list.

\subsection{Data Synthesis}

The process of synthesizing data involved the use of non-ArcGIS tools and tools existing within ArcGIS to extract and summarize source data into workable formats. While the elevation dataset, water body and drainage basins and air quality data were primarily processed with ArcGIS tools, wind speed and direction data had to be preprocessed using a multistep workflow. The following sections cover the data synthesis process for each dataset used within the project.

\subsubsection{Elevation Dataset}

Elevation data file conversion was completed in ArcCatalog by right-clicking the .DDF file and using the "extract" option to save as a .TIF file (Tagged Image File Format). However, it was found that the process of "Building Pyramids" within ArcGIS corrupted the source data. Building pyramids should not be used when importing this data and automatic building of pyramids must be disabled. Within ArcMap, all six 1:24,000 scale quadrangle Digital Elevation Models (DEM), were mosaicked together to form one ArcGIS raster dataset of the study region. Using the rectangle tool within the Editor Toolbar, a $15 \mathrm{~km}$ by $14 \mathrm{~km}$ (approximately a 9 mile x 9 mile) polygon was drawn capturing the influencing drainage basins and stations of interest defined by the decision workflow discussed in section 4.2. Using the "Polygon to Raster" tool, the mosaicked DEM as the snap raster and importation of the same cell size, the boundary of study area was defined in raster form (Figure 4-9). 


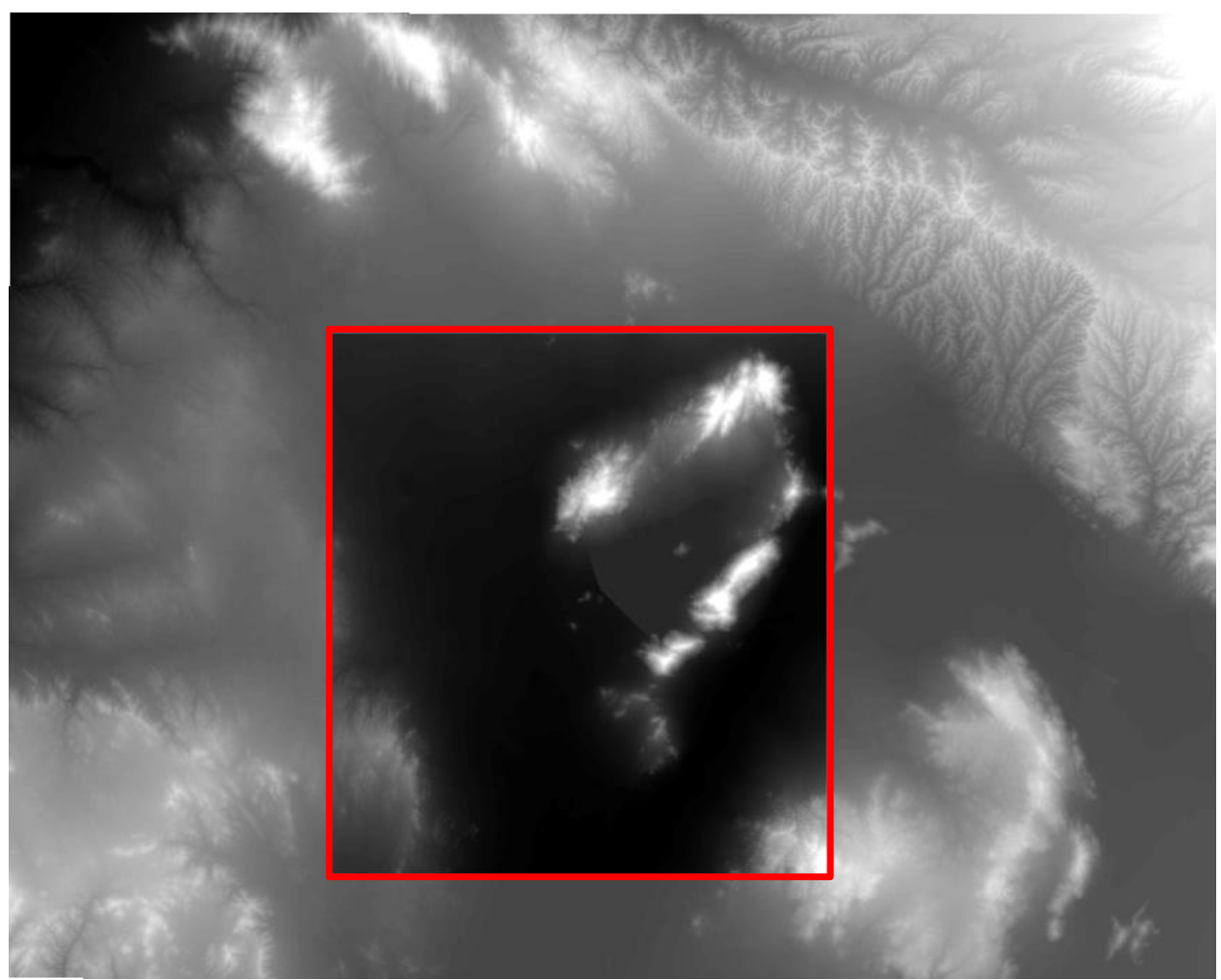

Figure 4-9: Final study area DEM (red bounding box).

"Extract by Mask", with the boundary raster set as the mask, was used to clip the mosaicked DEM and produce the area of terrain influence for processing in WindNinja. However, in order for the DEM to be consumable by WindNinja, all "No Data" values around the edges of the defined boundary had to be reclassified to real numbers, in this case a value of 1 was used. This was done using a combination of "IsNull" and "Conditional" tools. Instructions for addressing "No Data" values exist within the WindNinja PDF tutorials that install with version 2.2.0. It should also be noted, that the interface of the newest version of WindNinja, 2.2.0, has the ability to retrieve and extract DEM data given a user defined area. This new functionality was not available at the start of the project, but may serve to ease DEM processing time here forth.

The finalized DEM was placed in both the input geodatabase for user reference and exported as a TIF to the respective windows file folder for WindNinja consumption. Figure 4-10 illustrates the final extent of the DEM used for wind data processing noted with the wind and air quality stations, basins and the lake polygon for scale reference. 


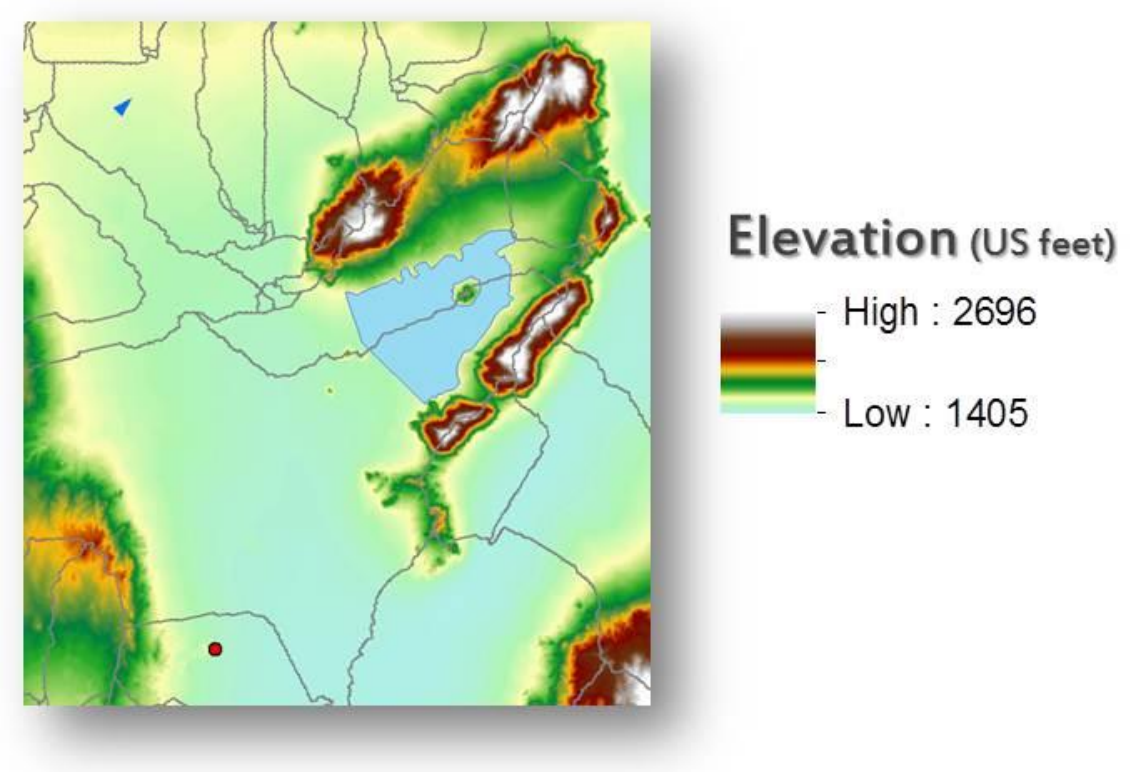

Figure 4-10: Final DEM extent used for wind simulation within WindNinja.

\subsubsection{Water Body and Drainage Basins}

The dataset obtained from the USGS National Hydrography Dataset webpage for the study area in and around Lake Perris was unzipped and the contents viewed in ArcMap. Lake Perris was selected from the dataset, exported as a polygon feature class, projected and saved into the input geodatabase for use within the model. The catchments were used to determine the extent of all terrain that might impact wind direction and speed.

\subsubsection{Air Quality Data}

Particulate matter sample data was obtained from the zipped "PMmass" file retrieved from the CARB dataset website. Included within the file were multiple Microsoft Excel workbooks broken down by location, temporal sampling period and particle size. This project utilized the workbook "PM10StdDaily20101103" that contained worksheets of sampling from 1983 to 2009. PM10StdDaily represented an averaged air sample over the course of 24 hours, once every six days (weekly sample automation). Using the "Table to Table" tool within ArcGIS, the worksheets containing sampling data for 2007, 2008, and 2009 were imported into the data exploration geodatabase taking special care in converting the sampling values to the format of float to enable summarizing the sample data. Once the sampling data for 2007, 2008 and 2009 were in the geodatabase, the "Append" tool was used to attach the data for the years 2008 and 2009 to the table of 2007 sample data. Appending the yearly tables allowed for a better understanding of sampling trends. To narrow down the dataset by location, all records for station 2525(Perris), were selected and exported as a new table. Next all null sample values were removed from the combined table. Two fields, month and season, were added to the table representing all air quality samples from 2007-2009 for station 2525. Each record in the table was then designated by month intervals (by season), as seen in Table 3 using the 
sampling date of each recorded value in order to conduct analysis on a standard temporal scale across all datasets used for the project.

Table 3. Breakdown of Seasons

\begin{tabular}{ll}
\hline Season & \\
\hline Winter & January, February, March \\
Spring & April, May, June \\
Summer & July, August, September \\
Fall & October, November, December \\
\hline
\end{tabular}

Using the "Summary Statistics" tool, the sample values within the seasonal table were then summarized by the sample value of each season record, creating a new table with the frequency of samples and the mean, maximum and minimum sample value in micrograms per cubic meter $\left(\mu \mathrm{g} / \mathrm{m}^{3}\right)$ per season (Figure 4-11).

\begin{tabular}{|c|c|c|c|c|c|c|c|}
\hline \multicolumn{8}{|c|}{ PM10StdDaily070809_Perris_Summary_byMonthINT } \\
\hline & OBJECTID * & MonthInterval & FREQUENCY & MEAN_Value & MAX_Value & MIN_Value & SUM_Value \\
\hline 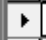 & 1 & $\langle$ Null $>$ & 5 & 291 & 1212 & 37 & 1455 \\
\hline & 2 & AprMayJun07 & 15 & 60.4 & 167 & 34 & 906 \\
\hline & 3 & AprMayJun08 & 15 & 37.6 & 59 & 10 & 564 \\
\hline & 4 & AprMayJun09 & 16 & 31.8125 & 54 & 12 & 509 \\
\hline & 5 & JanFebMar07 & 15 & 45.733333 & 120 & 16 & 686 \\
\hline & 6 & JanFebMar09 & 14 & 23.642857 & 42 & 4 & 331 \\
\hline & 7 & JulAugSep07 & 14 & 60 & 92 & 38 & 840 \\
\hline & 8 & JulAugSep08 & 15 & 39 & 62 & 21 & 585 \\
\hline & 9 & JulAugSep09 & 14 & 41.714286 & 53 & 26 & 584 \\
\hline & 10 & OctNovDec08 & 14 & 38.428571 & 85 & 10 & 538 \\
\hline 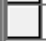 & 11 & OctNovDec09 & 14 & 42.214286 & 80 & 18 & 591 \\
\hline
\end{tabular}

Figure 4-11: ArcMap table of contaminant samples summarized by season.

During the fall of 2007 and winter of 2008 the Perris sampling station may have malfunctioned, as it did not provide the same frequency of sampling records nor accurate dates as compared to other seasons within the dataset. As a result the project model utilized only the mean seasonal sample values of 2009. The table shown in Figure 4-12 was saved into the input geodatabase for user reference when setting model input parameters.

\begin{tabular}{|c|c|c|c|c|c|c|c|}
\hline \multicolumn{8}{|c|}{ MarchAFB722860_23119_SeasonalSummary09 } \\
\hline & $\mathrm{OBJECTID*}^{*}$ & Monthlnterval & FREQUENCY & MEAN_DIR & MAX_SPD & MIN_SPD & MEAN_SPD \\
\hline & 2 & JanFebMar09 & 2618 & 202.417876 & 23 & 2 & 7.093201 \\
\hline & 1 & AprMayJun09 & 2261 & 250.964175 & 24 & 1 & 7.21893 \\
\hline & 3 & JulAugSep09 & 1545 & 277.980583 & 20 & 1 & 7.699029 \\
\hline & 4 & OctNovDec09 & 2101 & 208.54831 & 34 & 1 & 7.410281 \\
\hline
\end{tabular}

Figure 4-12: ArcMap table of seasonal wind speed and direction. 
Wind speed and direction data were only available for download in a format created by NOAA called IshJava. IshJava is a file format for storing integrated surface hourly (ish) data and utilizes Java code to package it. To convert the data files into a format usable within ArcGIS several steps were completed. First, using a command prompt window and change directory, the author navigated to the location of the unzipped station files and ishJava executable file. The data and ishJava converter file had to be in the same folder. To convert the ishJava formatted data to tab delimited for further processing in Microsoft Excel, the ishJava.exe file was called and ran by typing in the following line of command and hitting enter:

C:IFolderlocationwithfiles>java ishJava "station-numbers-year" "station-numbers-year-OUT"

\section{For Example: C:IMSGIS_FileDirectorylMIP_HarddrivelNOAA_NCDCFTP>java} ishJava "722860-23119-2009" "722860-23119-2009-OUT"

Upon hitting enter, the run successfully returned the "OUT" version of the file in the same folder location. This process was repeated for the years of 2007, 2008 and 2009 for wind the wind station of Lake Perris on March Air Base. The second step involved converting the tab delimited files into a format readable by ArcGIS using Microsoft Excel. Within Excel, several formatting measures had to be taken. For every null value represented in the data was a *(star). ArcGIS does not recognize "*” as notation for null values. In order to conduct a "find and replace" command the file had to be saved as a workbook first. Then using " $\sim$ *" as the find variable and replace all with a null value, Excel converted all null value notation to empty cells as required by ArcGIS. The date column was formatted to number with no decimal in order to recognize date notation. The workbook was then saved denoted with station name and number and the suffix "ffp" (final for processing).

The third and final step of scrubbing and loading wind speed and direction data was to summarize the data (Figure 4-13) using the same tools and similar workflow as processing the air quality sample data. Frequency count represents the total number of hourly samples per season recorded. The maximum wind speed and mean wind direction were used in seasonal WindNinja simulations. These parameters were chosen due to the fact that the minimum and mean wind speeds had little to no seasonal variance and as a prototype solution, zones of differentiation across the lake were needed to provide feedback on how results were produced. Maximum wind speed was also chosen based on the concept that high winds may make a bigger fetch, thereby increasing surface area and deposition flux, representing a "worst case scenario". In the future, more scientific testing should be conducted, given adequate and available sample data, to determine the direct correlations of wind speed, increased surface area and increased flux.

MarchAFB722860_23119_SeasonalSummary09
\begin{tabular}{|r|r|r|r|r|r|r|r|}
\hline & OBJECTID *'| & MonthInterval & FREQUENCY & MEAN_DIR & MAX_SPD & MIN_SPD & MEAN_SPD \\
\hline & 2 & JanFebMar09 & 2618 & 202.417876 & 23 & 2 & 7.093201 \\
\hline 1 & AprMayJun09 & 2261 & 250.964175 & 24 & 1 & 7.21893 \\
\hline & JulAugSep09 & 1545 & 277.980583 & 20 & 1 & 7.699029 \\
\hline & 4 & OctNovDec09 & 2101 & 208.54831 & 34 & 1 & 7.410281 \\
\hline
\end{tabular}

Figure 4-13: Summarized wind speed and direction values. 


\section{Chapter 5 - Implementation}

The implementation of the project solution was comprised of a multi-step workflow since no single piece of software could handle the job. Microsoft Excel was used to process the initial data, while ArcGIS was used to conduct statistical analysis on both contaminant and wind speed source data as discussed in Chapter 4. WindNinja was selected to model wind speed over terrain and the outputs of WindNinja were visualized in 3D within ArcScene to provide "visual insight" on the spatial distribution of wind speeds. At the core of the workflow were two ModelBuilder models that consumed the summarized contaminant information and the surface wind speed data, which generated a set of flux surfaces. The output surfaces were then classified and symbolized in 2D within ArcMap and are discussed in Chapter 6. The following sections discuss the implementation of WindNinja and its abilities, the mathematical equations used during analysis and the models built to run the analysis.

\subsection{WindNinja}

WindNinja was chosen for application within this project because of its ability to reflect the effect of topography on wind, its compatibility with a PC platform running Windows 7 and its ability to create shapefiles of wind speed and direction points for compatibility with a GIS. WindNinja, at the time was also available at no monetary cost. The WindNinja interface could be utilized for simulation at four different levels of complexity: basic, diurnal winds, point simulation, and weather model initialization.

\subsubsection{Application of WindNinja}

This project used the basic application of WindNinja, having only one wind speed and direction station within the area of influence to utilize. Each level of use required four inputs: a DEM of the simulation area, a domain-mean initial wind speed and direction, and the specification of the dominant vegetation found throughout the study area (Figure 5-1).
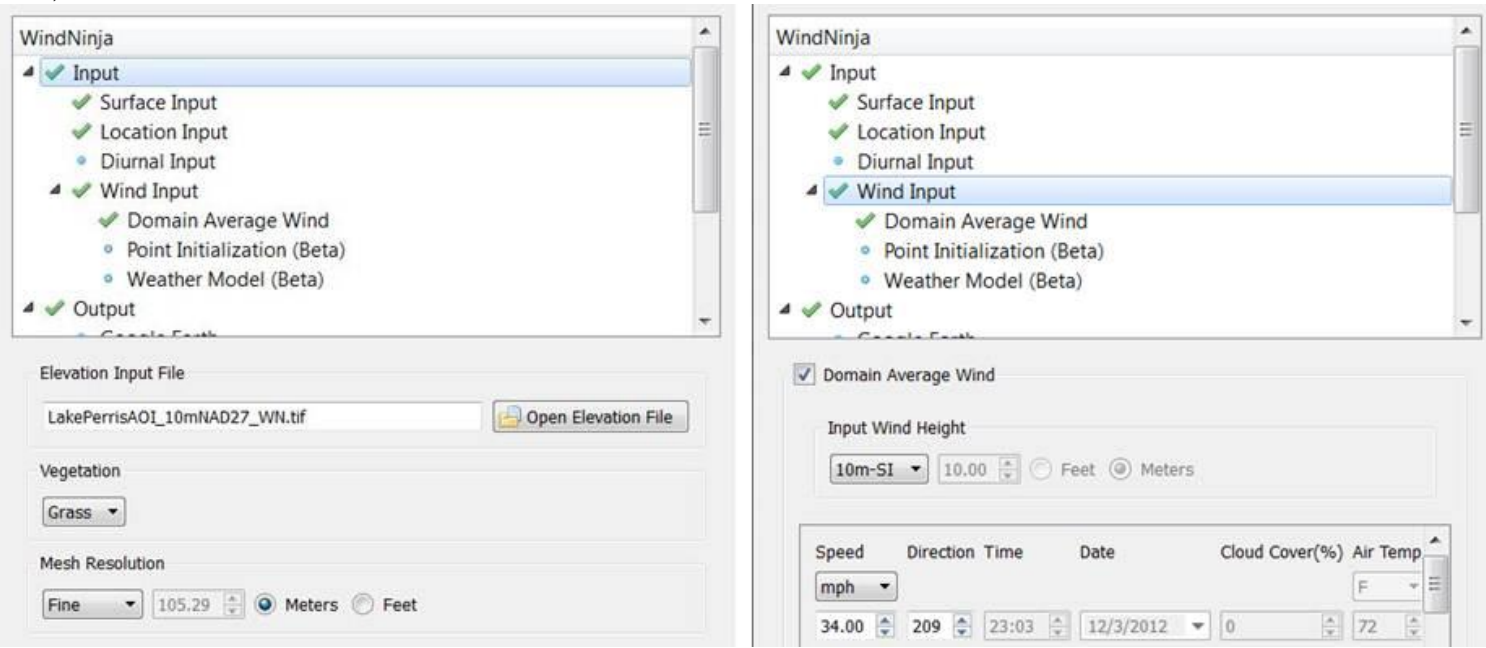

Figure 5-1: WindNinja interface for user inputs and parameter selection. 
Dominant vegetation coverage is specified by the user, allowing the drag affect vegetation has on wind flow to be simulated. The user can select grass, brush or trees as a dominant vegetation type. Because vegetation was sparse around the study area and the result of this project was based on the surface of a lake, the least friction causing vegetation type, grass, was chosen as the dominant vegetation type for all WindNinja runs. The height of the input wind flow was also parameterized with the options of simulating the wind at 10 meters or 20 feet above the designated vegetation type. Because the end product of this project, flux, used metric units, a wind height of 10 meters was chosen for unit consistency. An additional user setting, called the mesh resolution, the spacing of gridded points, controlled the resolution of the wind simulation and had four settings: course, medium, fine and custom. For this project, the mesh resolution (distance between each generated wind point) was set to fine, 100 meters, the highest resolution offered. When given a $15 \mathrm{~km}$ by $14 \mathrm{~km}$ DEM with a 10 meter cell size, one wind speed value in miles per hour, one wind direction in azimuth degrees with vegetation coverage of grass, fine mesh resolution, and three processors for computation, Wind Ninja took less than five seconds to "solve" and generate a shapefile output. The output of the simulation for the entire study area contained approximately 20,000 wind speed and direction points for each season run. These points were later clipped within the model to the water body polygon. Each wind point had the default attributes of objectID, shape, speed (mph), direction (degrees), and other attributes for other uses of WindNinja outputs (Figure 5-2).

\begin{tabular}{|c|c|c|c|c|c|c|c|}
\hline \multicolumn{8}{|c|}{ LakePerrisAOI_10mNAD27_WN_209_34_105mOND09_F09 } \\
\hline & OBJECTID * & Shape * & speed & dir & AV_dir & AM_dir & QGIS_dir \\
\hline \multirow[t]{12}{*}{ - } & 1 & Point & 33.99388 & 209 & 331 & 299 & 29 \\
\hline & 2 & Point & 33.803763 & 209 & 331 & 299 & 29 \\
\hline & 3 & Point & 33.241629 & 209 & 331 & 299 & 29 \\
\hline & 4 & Point & 32.273591 & 209 & 331 & 299 & 29 \\
\hline & 5 & Point & 31.225813 & 211 & 329 & 301 & 31 \\
\hline & 6 & Point & 30.639639 & 212 & 328 & 302 & 32 \\
\hline & 7 & Point & 30.476824 & 213 & 327 & 303 & 33 \\
\hline & 8 & Point & 30.154597 & 213 & 327 & 303 & 33 \\
\hline & 9 & Point & 29.600052 & 213 & 327 & 303 & 33 \\
\hline & 10 & Point & 29.446084 & 214 & 326 & 304 & 34 \\
\hline & 11 & Point & 29.875045 & 214 & 326 & 304 & 34 \\
\hline & 12 & Point & 301.92141 & 21.3 & 327 & 303 & 3.3 \\
\hline 14 & 1 . & " 圆国 & 0 out of 19 & $45 \mathrm{Se}$ & cted) & & \\
\hline
\end{tabular}

Figure 5-2: Sample of the WindNinja point attributes for the fall of 2009.

The outputs of the seasonal domain wind simulations were saved and stored in the designated Windows file folder for wind data and later imported into the input geodatabase as a point feature class for analysis. The 10 meter cell size of the DEM used was also noted for analysis.

\subsubsection{Spatial Simulation of WindNinja Outputs}

For best spatial comprehension each seasonal WindNinja output was visualized in 3D using ArcScene. This spatial simulation of the wind points over the terrain created by WindNinja allowed the user to visually check the distribution of the wind speeds generated. To start, the study area DEM was loaded and extruded within ArcScene (Figure 5-3). 


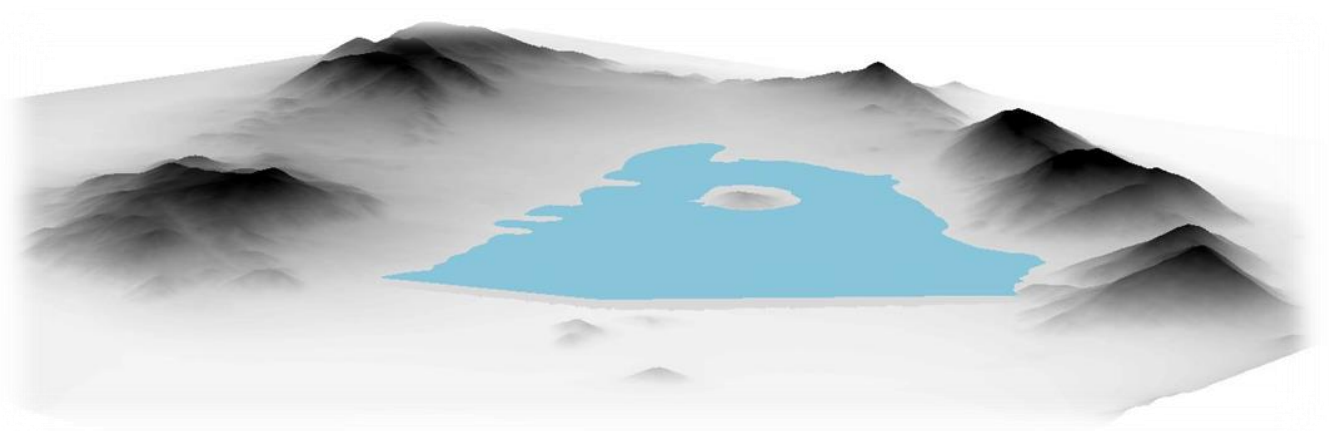

Figure 5-3: Digital Elevation Model of the Lake Perris State Recreation Area.

Second, the WindNinja output, the wind points, were draped over the DEM and classified by wind speed and symbolized with cones pointing in the direction of wind flow (Figure 5-4). Cones of red symbolize higher wind speeds, cones of yellow moderate wind speeds, and cones of green the slowest wind speeds for the season. Note the impact Alessandro Island, the Lake Perris Dam and surrounding terrain have on wind speed values.

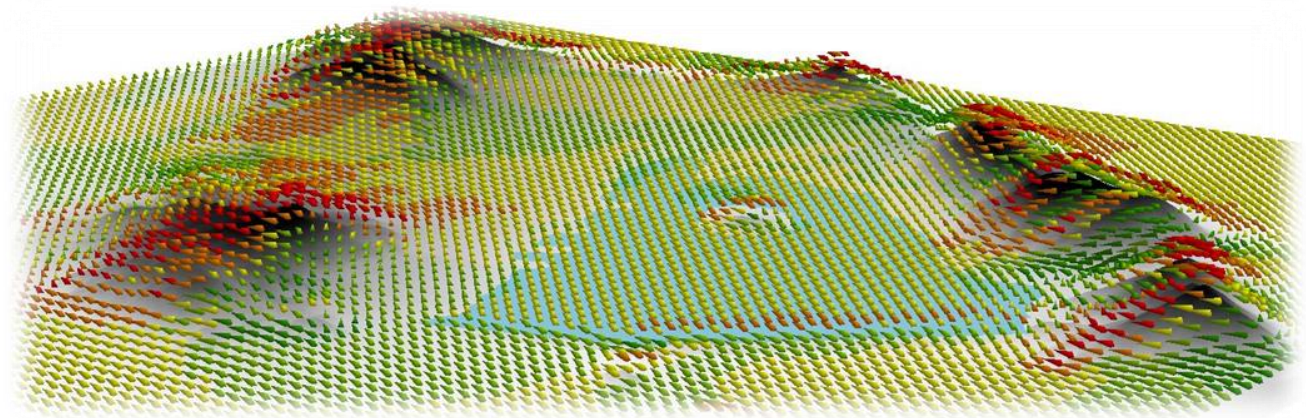

Figure 5-4: WindNinja 3D visualization check, for winter 2009.

\subsection{Physical Model Formulae for Flux}

Four mathematical equations were implemented within both the base and comparison models. Two equations were provided by the client and two were derived for analysis. The first equation provided by the client was used to calculate overwater friction velocity (U*) in meters per second. The overwater friction velocity equation created by Hsu, S.A., 2007 utilized a wind speed (U) at a height of 10 meters and set constants. A field was added to the attribute table of the wind points, named "Ustar", and overwater friction velocity was calculated for each wind point. $U^{*}$ was then inputted into the flux equation to calculate the flux of contaminants on the water surface (Eq 2.1).

$$
U^{*}=\frac{0.4\left(U_{10}\right)}{14.7-2 \ln \left(U_{10}\right)}
$$

The second equation provided by the client was used to calculate the flux of contaminants on the surface of the lake, in micrograms per second, for each wind point. The flux 
equation calculated the flux of contaminants by multiplying the contaminant value $\left(\mu \mathrm{g} / \mathrm{m}^{3}\right)$, the area $\left(\mathrm{m}^{2}\right)$ and the friction velocity $\left(\mathrm{U}^{*}, \mathrm{~m} / \mathrm{s}\right)$ together for each individual wind point $(\mathrm{Eq} 2.2)$. A field was added to the attribute of table of the wind points, named "Flux" and calculated utilizing the flux equation.

$$
\text { Flux }=(\text { Concentration })(\text { Area })\left(U^{*}\right)
$$

Equation 2-2

The first of the derived equations converted wind speed units of miles per hour into meters per second. A field was added to the attribute table of the wind points, named "speed_metersPsec", and calculated by multiplying the wind speed by the conversion factor of 0.44074 .

\subsection{Base Model}

The base model (Figure 5-5) requires two user inputs, the wind points, and the lake polygon and two user parameters upon startup: the contaminant value and the cell size (to match the resolution of the DEM used in WindNinja). A breakdown image of the model is available in the appendix for reference.

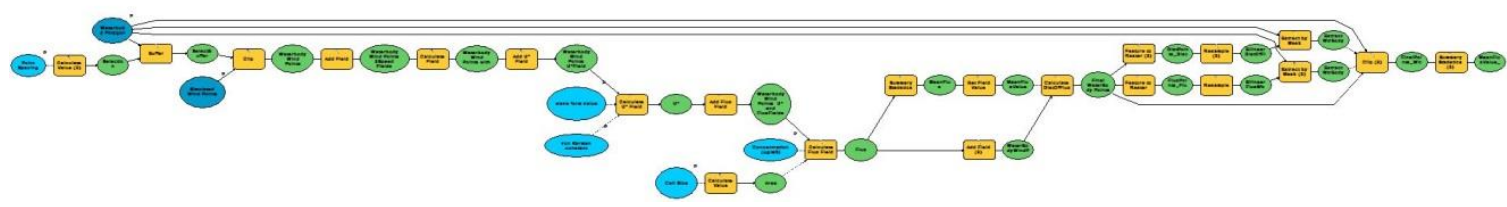

Figure 5-5: Base Model.

Once the inputs and parameters are set, the model starts by clipping the wind speed and direction points to the lake. It then adds and calculates fields for each individual wind point calculating the two primary variables, overwater friction velocity ( $\mathrm{U}^{*}$ ) and flux for each individual point and uses Resample (bilinear interpolation) tool within the Spatial Analyst extension to convert the WindNinja points to a surface (Figure 5-6).

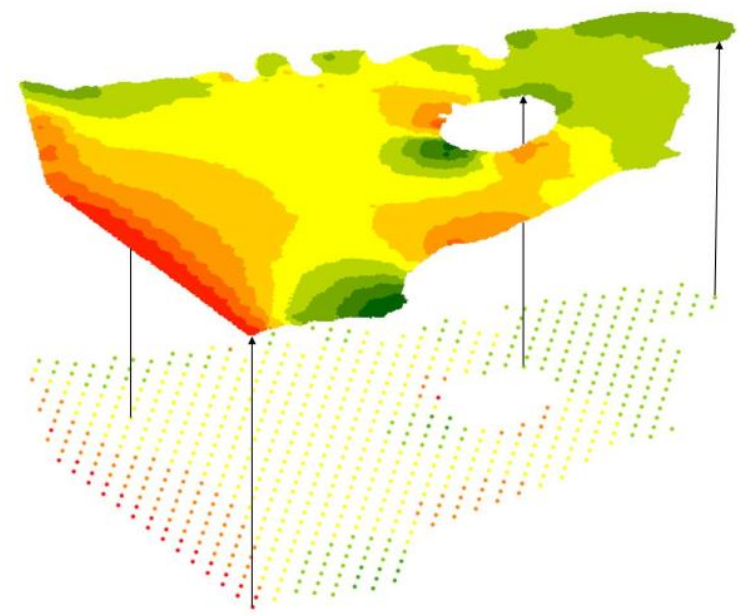

Figure 5-6: Point to surface interpolation.

A distance of 100 meters separated each of the 1075 wind speed points, specifically over the lake created by WindNinja. By using the Resample tool to 
interpolate a smooth surface from point values, the distance between values was reduced to 10 meters (higher cell resolution was obtained). Resample or bilinear interpolation was chosen due to its mathematical operation on 2D gridded data and calculating new cell values from the nearest existing four points. Due to the nature of bilinear interpolation, calculating cell values from the four nearest neighbors, water body wind points were buffered to an extent of 100 meters around the shore of the water body. This enabled interpolation to take into account points just outside the shoreline. This allowed for the shoreline to be represented as a smooth line and the lake, a continuous surface.
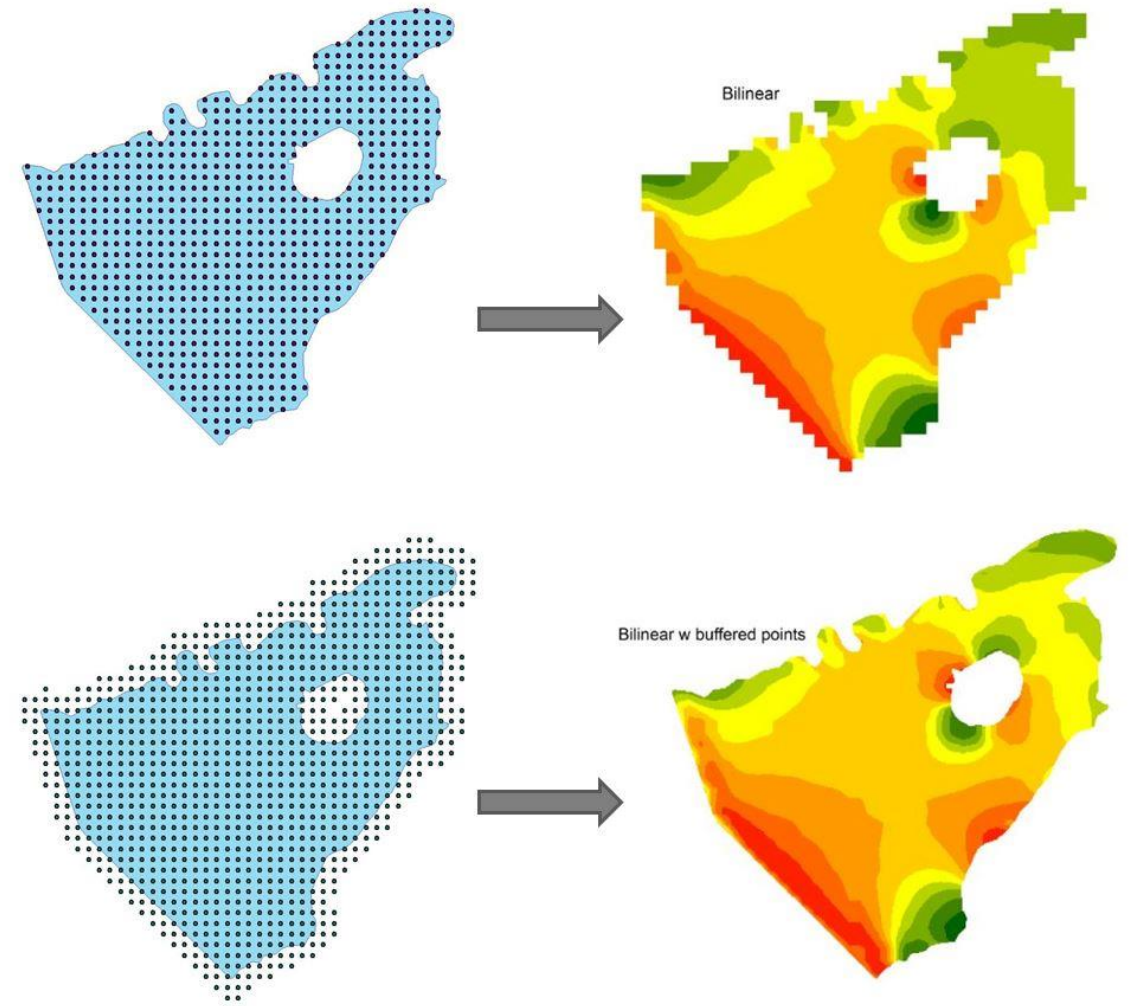

Figure 5-7: Bilinear interpolation of flux using buffered \& non-buffered points.

Point values external to the lake were compared to point values within the lake. Most differences in wind speed and direction values, external and internal of the lake, were found to be negligible. External points with speeds 1 to 2 meters per second faster or slower than neighboring values within the lake represented normal terrain influence.

In summary, the base model is composed of the following tools from the Analysis and Data Management Toolsets: Calculate Value, Buffer, Clip, Add Field, Calculate Field, Get Field Value, Summary Statistics, Feature to Raster, Resample and Extract by Mask from the Spatial Analyst extension. The base model was designed to be run using the Basic License level of ArcGIS 10.0 or greater accompanied by the extension of Spatial Analyst. It may be used for an individual water body and single block of time.

\subsection{Comparison Model}

The comparison model requires the same input and user parameters as the base model; however, the comparison model focuses on comparing different blocks of time at the 
same location. Thus, the comparison model is four iterations of the base model, plus tools for calculating statistics and comparing spatial distributions temporally. In this way, the comparison model offers more refined outputs giving not only the flux of contaminant cell by cell for an individual block of time, but four time frames. In addition to the tools used in the base model, the comparison model (Figure 5-8) utilizes Int (Integer) and Cell Statistics tools from the Spatial Analyst extension and the Get Value tool available only within ModelBuilder. A breakdown image of the comparison model is available for view in the appendix.

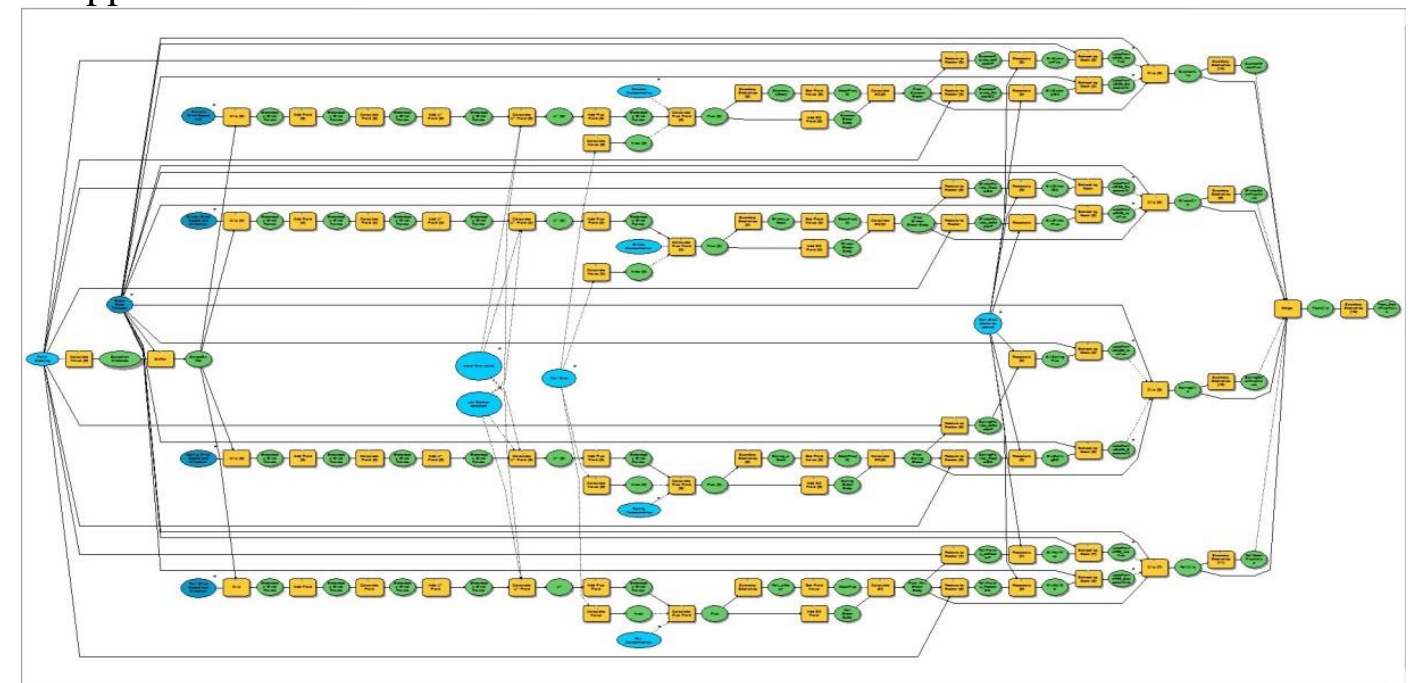

Figure 5-8: Comparison Model

\subsection{Zonal Standard Deviation and Mean Model}

The comparative lake zone statistics model was created for ease of labeling zones on maps. The zones were created using the natural breaks classification, a classification method that creates zones or polygons based on the natural ranges found within the data. The mean of each zone and the standard deviation of each zone were calculated from point values within the same respective zone, prior to interpolation. This enabled the mean and standard deviation values to represent the zones with respectively. This model creates the zonal values of standard deviation and mean for four different instances of time (time blocks) for comparison, given representative (matching) classified (zonal) surfaces and corresponding wind points for mapping purposes. 


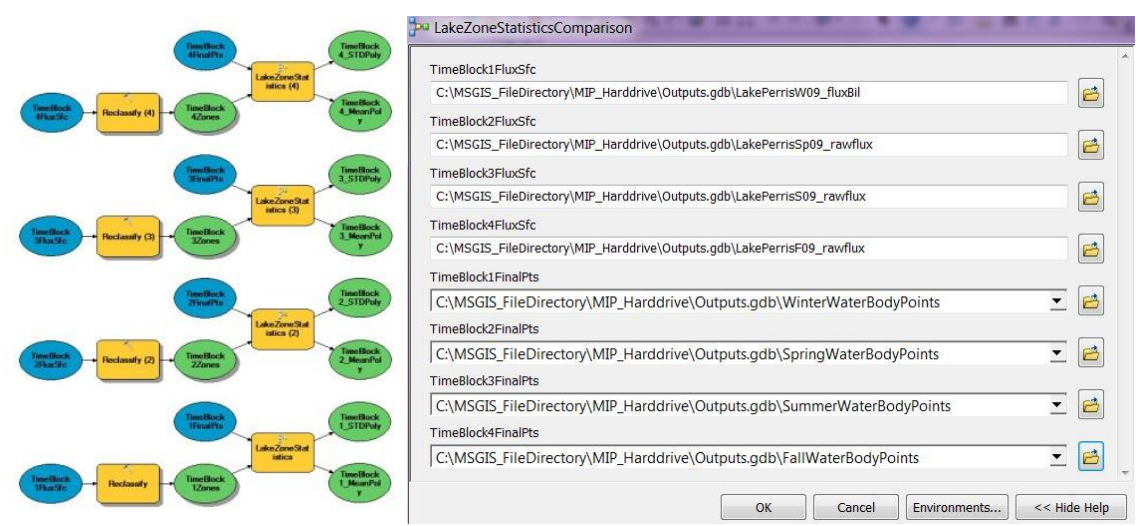

Figure 5-9: Comparative Lake Zone Statistics Model

\subsection{Summary}

In summary, implementation of this project required a multi-step workflow since a single piece of software could not handle the job. WindNinja was used to create a feature class of regularly gridded points containing wind speed and direction. In order to visually comprehend the impacts of terrain on wind speed, the points were symbolized in 3D within ArcScene. The points were then input into one of two main ModelBuilder models, depending on how many blocks of time were being simulated. Mathematical formulae used to define the physical model of flux were then applied to each wind point using map algebra tools. And finally surfaces were interpolated and a third model was implemented for mapping statistics of zones across a water body. 


\section{Chapter 6 - Results and Analysis}

\subsection{The Deliverables}

The main requirement of this project was to identify a method of mapping the flux of particulate matter across the surface of a water body. A secondary requirement was to develop and document the necessary workflow and models so that the process could be repeated in the future with different sample data, at alternative time frames, and at different geographic locations. A variety of technologies were required to provide a solution, hence a single GIS based model approach was inappropriate. In addition, the solution had to be able to handle one or many spatially distributed air samples at varying time intervals and ranges, so a fixed input model would not have been adaptable enough to meet these flexible input requirements. The decision was made to integrate a series of technologies into a single documented workflow that the client could easily repeat. Because the workflow utilizes separate technologies, in addition to the sample datasets, and the results, all interim data has been preserved to provide the user with a base line for comparison when conducting the workflow.

\subsubsection{Input Datasets}

The example datasets for wind and air quality were split into four subsets. Each group represented a season in 2009, as shown in Table 3. This allowed the primary datasets to be broken down into a standard temporal scale for analysis.

\section{Table 3: Breakdown of Seasons}

\begin{tabular}{ll}
\hline Season & \\
\hline Winter & January, February, March \\
Spring & April, May, June \\
Summer & July, August, September \\
Fall & October, November, December \\
\hline
\end{tabular}

Temporal coverage and inconsistency of data sampling found within the years of 2007 and 2008 for both wind and air quality datasets reduced the temporal range for analysis to the year of 2009. A mean wind direction and maximum wind speed value were calculated for each season of 2009 and a mean contaminant concentration was calculated for the same time periods (Table 4).

Table 4. Values used for wind simulation and modeling.

\begin{tabular}{llll}
\hline Season & $\begin{array}{l}\text { Mean Wind Direction } \\
\text { (azimuth) }\end{array}$ & $\begin{array}{l}\text { Maximum Wind } \\
\text { Speed }(\mathrm{mph})\end{array}$ & $\begin{array}{l}\text { Mean Concentration } \\
\left(\boldsymbol{\mu g} / \mathrm{m}^{\mathbf{3}}\right.\end{array}$ \\
\hline Winter & 202 & 23 & 23.6 \\
Spring & 251 & 24 & 31.8 \\
Summer & 278 & 20 & 41.7 \\
Fall & 209 & 34 & 42.2 \\
\hline
\end{tabular}


Due to the seasonal values of wind direction and the geography of the study area, only one station from each of the primary datasets was utilized for analysis. It is advised that for best fit spatial and temporal data coverage, portable stations be implemented around study area. Figure 6-1 illustrates the summarized seasonal wind directions, wind stations, air quality stations, and their combined influence on station selection, as stations were required to reside upwind of the lake of interest.

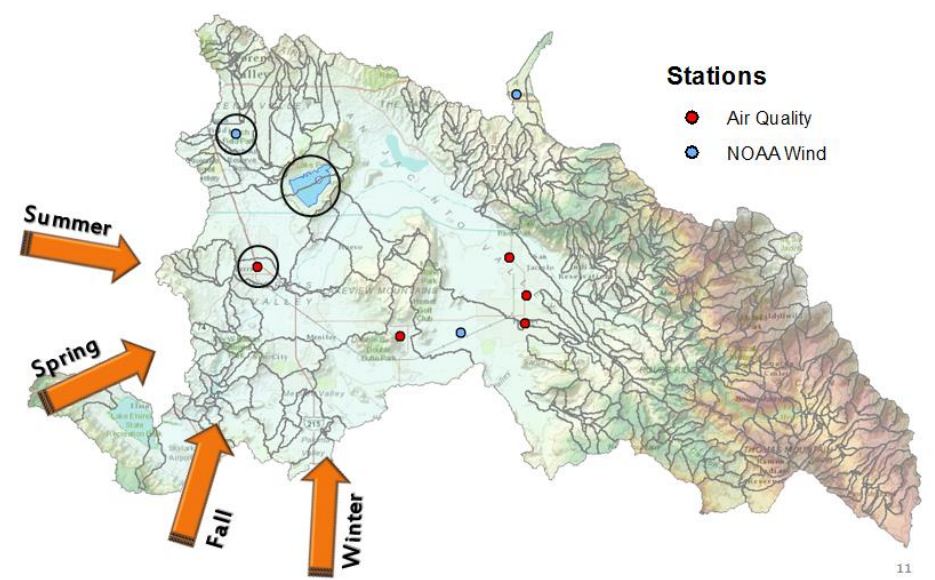

Figure 6-1: Seasonal wind directions and selected stations of interest.

The digital elevation model (DEM) used for the simulation of the impact of terrain on wind speed and direction within WindNinja has been included within the sample dataset. The Lake Perris polygon feature class, that contained the polygon used as the lake of interest, has also been included within the sample dataset. All geographic information was provided in a common projection, UTM Zone 11N, NAD27, meters.

\subsubsection{Base Model}

In order to simplify the analysis workflow, it was automated using ModelBuilder. Figure 6-2 shows the base model prompt for user defined input parameters for use within the model.

\section{Figure 6-2: Base Model Prompt.}

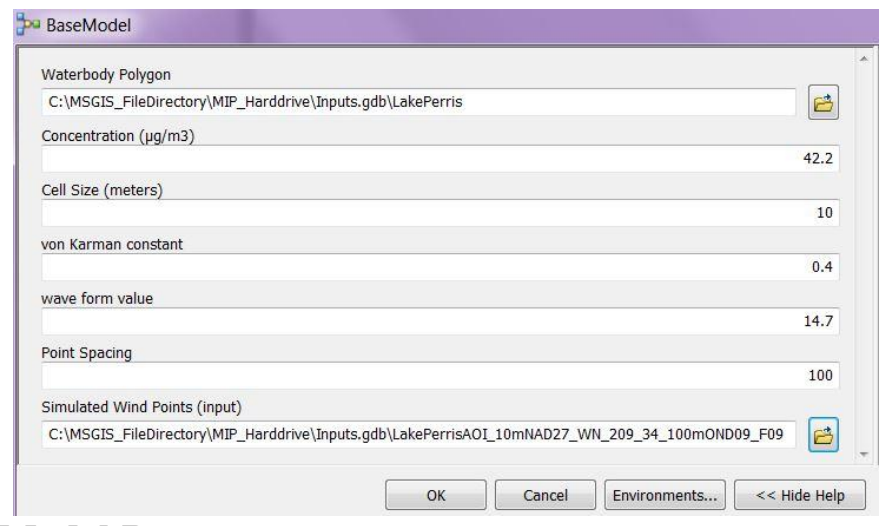

The base model consumes point features containing wind speed and direction. These point features can be in any ArcGIS readable format, such as a shapefile, feature 
class, or coverage. However, in order for the model to correctly calculate deposition velocity and flux at each point, these points should be a regularly spaced grid that covers the full extent of the water body of interest. The model, as seen in Figure 6-3, also intakes a user specified cell resolution, a user specified concentration value, and a user selected water body polygon as well as the changeable equation parameters wave form value and von Karman constant for adjustment of analysis. Input files are shown in dark blue and user specified values in light blue with the models.

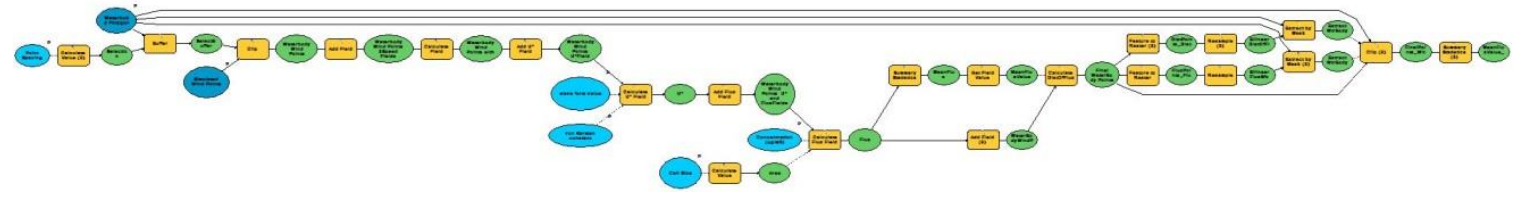

\section{Figure 6-3: Base Model.}

The below user defined parameters were intended to diversify the use of the solution.

- User selection of wind speed and direction points.

Finally, the user can easily adjust the temporal scale of analysis within the model, by running WindNinja on a representative wind speed and direction value of the time scale desired. For example, should the wind point inputs of the model need to represent a four weeks or four days, the user can compute the mean, maximum or minimum wind speed and wind direction within ArcMap, then within WindNinja input the representative values (wind speed in mph and wind direction in azimuthal degrees), run WindNinja and utilize WindNinja's output at the start of the model. If the user is only interested in running one instance of time, such as one day, one week or one month, the base solution should be utilized. The following items have been set as parameters within the model so that they may be set or changed using the "Open" command, found by right clicking on the model.

- User selection of water body.

A polygon feature class of a water body can be input through this parameter selection box. The user should check that the water body polygon and relative point set have the same and applicable projection for the area; otherwise results may not be an accurate representation of the surrounding terrain.

- User defined concentration value of contaminant.

The concentration value can be changed within the model prompt for the desired temporal window to be simulated. The concentration value may represent any contaminant so long as the units are in micrograms per cubic meter $\left(\mu \mathrm{g} / \mathrm{m}^{3}\right)$.

- User defined cell size.

This parameter is used to calculate the variable of area that is used when calculating the flux per wind point. This number must be an integer and should represent the cell size of the DEM utilized within WindNinja, if WindNinja was used, in order for interpolation to be sound.

- User adjusted von Karman constant 
This parameter represents a dimensionless constant describing the logarithmic velocity profile of turbulent fluid flow near a boundary with little to no-slip condition. The default value is set to 0.4 . This value may be changed based on a calculated adjustment.

- User adjusted wave form value

This parameter represents swell conditions or the effect of wave form on surface area. It is a calculated constant (default value of 14.7, representative of ocean conditions), based on the wave height and wave period of the water environment being modeled. The user should calculate and change this value accordingly, as a major adjustment is needed for use on inland lakes.

- User specified point spacing value

In order to obtain a continuous smooth shoreline around the water body using bilinear interpolation, wind speed and direction points just outside the polygon were incorporated. This parameter is defined by the user. The default value is set to 100 meters. The model multiplies this distance by two to include points within a 200 meter (500 feet) buffered zone outside the water body. Using a regular gridded point set, with each point 100 meters apart, this adds only 1 to 2 points from the outer shoreline region. These additional points are included in the clipped wind speed and direction points used for analysis. Wind speed and direction values from these external points were not drastically different from those across the lake, as the terrain just outside the water body was analogous to the immediate water body.

\subsubsection{Comparison Model}

The comparison model combines iterations of the base model to conduct analysis at five different time frames as seen in Figure 6-4 and in the appendix. It then conducts statistical analysis for the comparison of seasons.

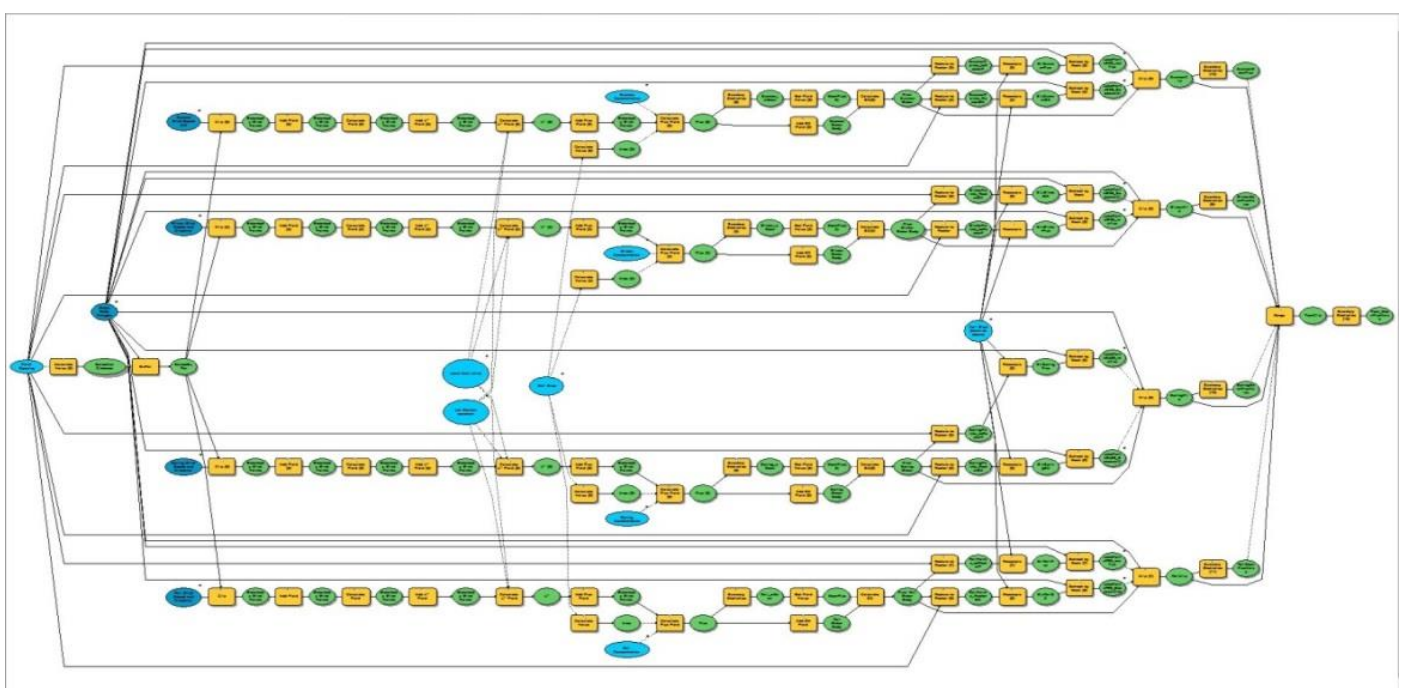

Figure 6-4: Comparison Model 
The comparison model allows the user to define of: where (which water body), when (points for a period of time), how much (concentration value for chosen contaminant), cell size, von Karman constant and wave form value just as within the base model. If the user is only interested in running one instance of time, such as one day, one week or one month, the base solution should be utilized. Figure 6-5 shows the comparison model prompt for user defined input parameters for use within the model.

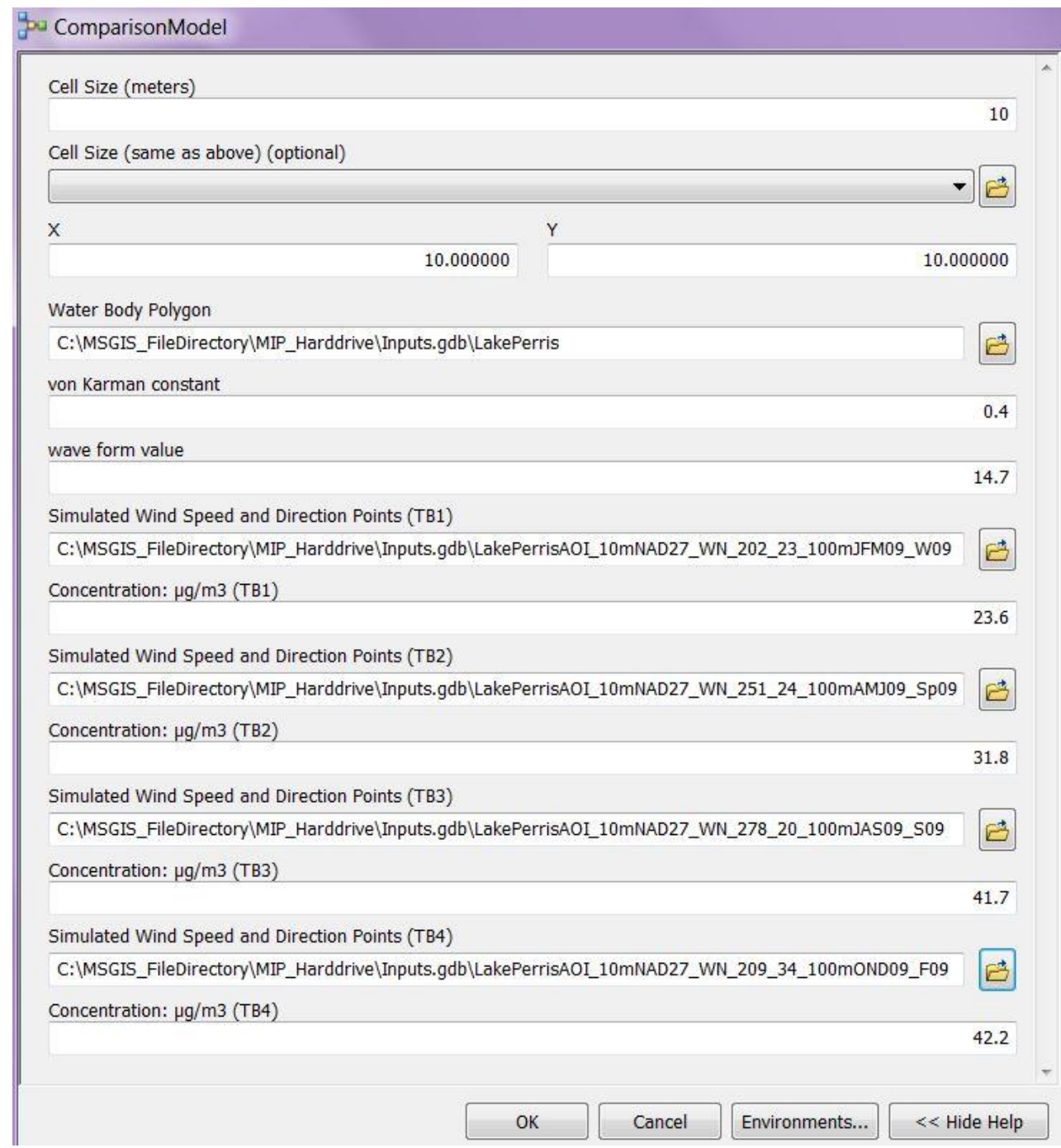

\section{Figure 6-5: Comparison Model Prompt.}

An additional version of this model, called the seasonal comparison model, functions exactly the same with one exception. The segments of the model have been named for a seasonal based analysis for ease of use instead of time blocks (TB1, TB2, etc...), should the user desire to use a seasonal approach.

\subsubsection{Zonal Standard Deviation and Mean Model}

This model labels the standard deviation and mean of statistical zones across a water body. It is main use is for map labeling. Statistical values were calculated from point 
values that fell within each zone, prior to interpolation. The natural breaks classification was applied to the data, prior to calculating values. Natural breaks, also called the Jenks natural breaks classification, is a data classification method designed to determine the best arrangement of values into different classes. This is done by seeking to minimize each class's (zone) average deviation from the class mean, while maximizing each class's deviation from the means of the other groups. In other words, the method seeks to reduce the variance within classes and maximize the variance between classes.

\subsection{Results of Analysis}

The results of analysis conducted were created by running the comparison model on data summarized by season for the year of 2009. Wind speed and direction greatly impacted the analytic results. To clarify, it is by convention that the degree value of wind direction represents the direction the wind is coming from. For example, in the fall of 2009 the wind blew from the southwest at 209 degrees (Figure 6-6).

Wind direction was predominantly responsible for the independent spatial distribution patterns of the flux values for each season (Figure 6-6 and Figure 6-7). Areas of red (Figure 6-6) propagate out across the lake along to the corresponding dominant wind direction for each season.

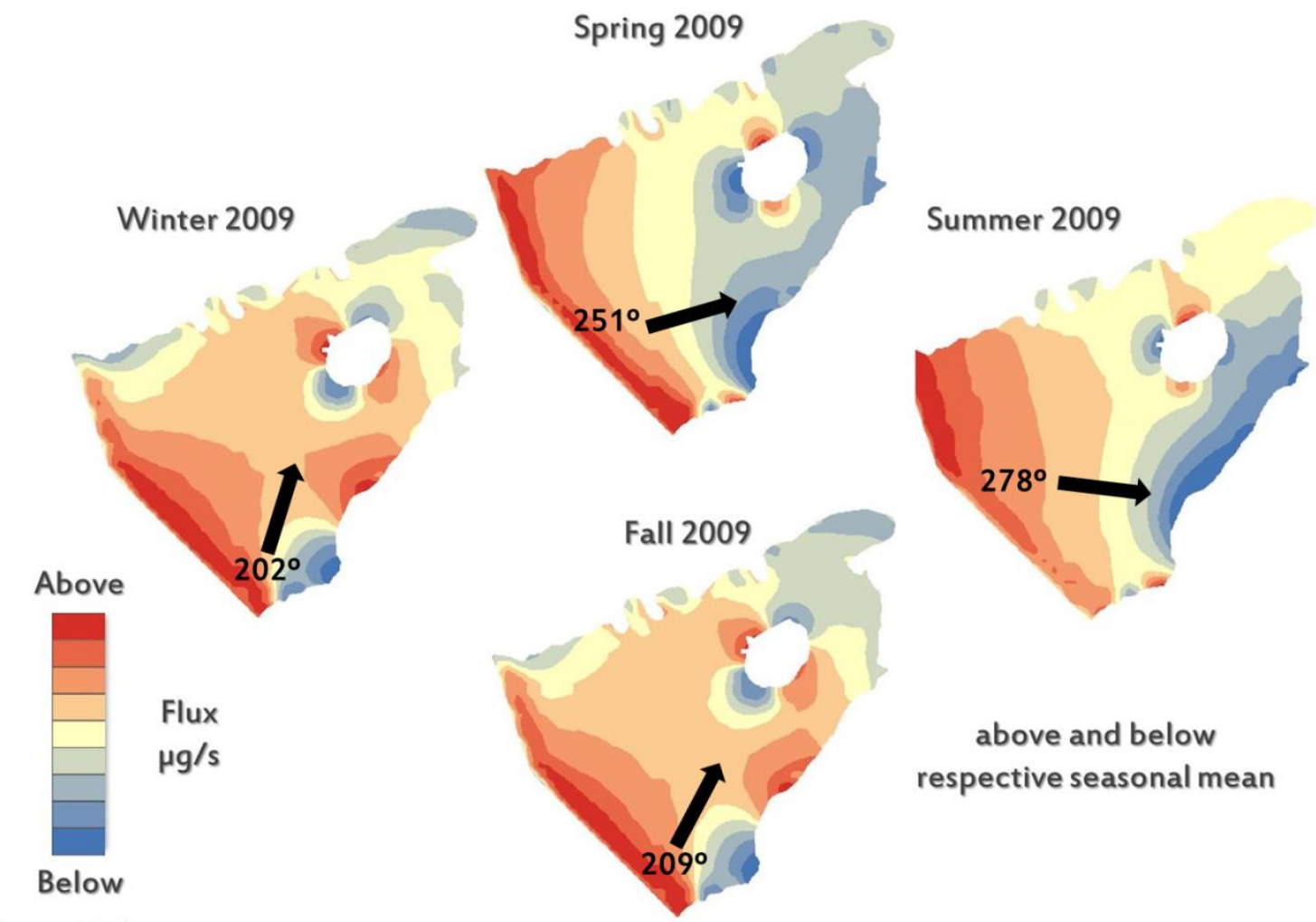

Figure 6-6: Spatial distribution of seasonal fluxes from seasonal mean.

Figure 6-6 shows the ranges of flux for each of the four seasons, areas of the lake that are above or below the seasonal mean flux. These results show changes in the distribution of flux values at different times of year. Note that in general, the southwest side of the lake contains above average flux values, areas shown in red, when compared 
to the seasonal mean flux in yellow and that it progressively extends out into the lake and back toward the southwest shore in fall. This figure also shows similarity between seasons, winter and fall, spring and summer. Note how areas of below seasonal average deposition rates, areas in blue, shift from the northwestern shore to the southeast shore from winter to summer. The island also impacts the pattern of flux values with areas of higher than the seasonal average flux and areas of lower than the seasonal average flux at its sides, orientated to the wind. The terrain around three of the four sides of the lake mainly consists of mountains. The season of spring has the sharpest distinction, the most diverse flux values.

When flux values of each individual season are put on an identical scale, it is simpler to see when the most and least flux of contaminant occurs over the course of a year. The seasons of winter, spring and summer have similar flux values, close to one another on the lower end of the flux values spectrum, as seen in the darker and lighter greens (Figure 6-7).

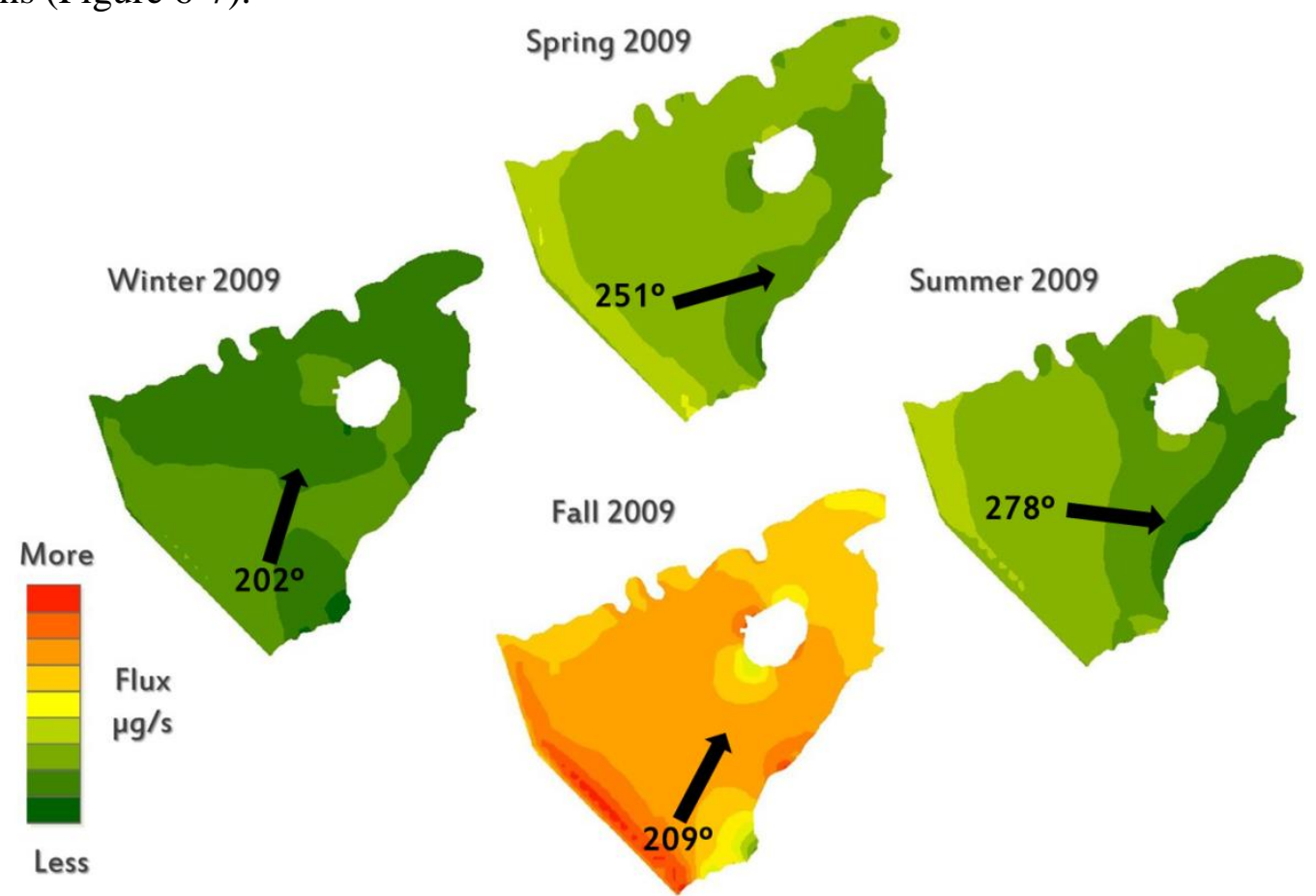

Figure 6-7: Seasonal Flux Comparison.

Fall had the highest flux values out of all four seasons during 2009. Fall is distinct in that it is mostly comprised of oranges and yellows, representing the higher end of the flux value range for the year. This may have been due to fall having the highest recorded seasonal maximum wind speed at $34 \mathrm{mph}$ and a predominantly unobstructed wind from 209 degrees, whereas lower wind speeds and more obstructive terrain most likely influenced the wind directions of winter, spring, and summer, causing more oblique winds over the lake and lower surface flux. 


\subsection{Summary}

In conclusion, these results are based on the user parameters set within the solution. The parameters may be changed and the solution will provide additional unique results.

Seasonal wind direction had a dominant effect on the spatial distribution of flux values. Higher wind speeds accompanied by an unobstructed wind seem to simulate higher flux values, as in the fall of 2009. However, further testing may indicate otherwise. See Appendix A for maps of all model outputs. 


\section{Chapter 7 - Conclusions and Future Work}

\subsection{Conclusions}

The main requirement of this project was to calculate the flux of particulate matter across a body of water. In doing so this project provided a method for quantifying atmospheric deposition as a pollutant source. It also went further, by enabling the user to spatially determine where on a water body, differing flux values of contaminant occur. The necessary workflow and models have been documented so that the process can be repeated in the future with different contaminant data, at alternative time frames, and at different geographic locations. The solution successfully combined ArcGIS and WindNinja as tools within the workflow, and effectively modeled air movement over terrain and identified where on the surface of a lake and at what rate per area particulate matter falls out of suspension in the air.

\subsection{Notes for Future Use}

As with any developed solution, it is essential to understand what the solution incorporates. The end solution provided by this project may be used at a different geographic location, for a different body of water and at a singular block of time or multiple time intervals. However, the lake polygon obtained for the new location of interest must have a coordinate system in common with the DEM obtained for wind simulation. Tools within ArcMap are available for projecting data.

While this project obtained and utilized data from government entities for wind speed, wind direction and air contaminant sample, the solution is meant to be used with summarized field data representative of the wind speed, direction and air sample values collected by field scientists. The von Karman constant (default value of 0.4) and wave form value (default value of 14.7) found within the overwater friction velocity ( $\mathrm{U}^{*}$ ) equation have been set as user parameters, enabling the values to be changed within the model prompt to represent the environment being modeled. Wind speed and direction values are first modeled within WindNinja to create terrain influenced wind points.

Take heed of the following assumptions. Due to the nature of the wind speed and direction data available, the maximum recorded seasonal wind speed was utilized within the model to create zones across the lake, thereby testing the model's ability to differentiate zones. It should be noted that this project did not test the impacts of using a maximum versus minimum or mean wind speed. Furthermore, it should be noted that this solution assumes that the entire concentration of contaminants sampled is modeled into flux. This model only accounts for the overwater friction velocity of particles; it does not include other variables regarding the specific interactions of particulate matter with respect to atmospheric physics, chemical engineering or complex fluid dynamics.

Available data sources change retrieval methodologies and data selection over time. For example, the primary source used for wind speed and direction data, NOAA's NCDC web page, has updated data formats available and methods of downloading the data since the data collection phase of this project. WindNinja version 2.2.0 was released after the analysis phase of this project and offers a new interface for selecting and importing a DEM at ease, not available in version 2.1.3. Should the user continue to use WindNinja 
version 2.1.3 and create DEMs using the tools described in section 4.5.1, the building pyramids option must be disabled as it will corrupt source data files.

\subsection{Future Work}

As with any solution there is always room for improvement and refinement. In this case, because the author and client were not experts in the domains of Atmospheric Physics and Chemical Engineering, the process could be improved by incorporating tools to model those processes. Future enhancements should include:

\subsubsection{Atmospheric Physics and its effects on the deposition of contaminants.}

The impact of both laminar and turbulent wind flow on the distribution and mixing of contaminants in the air was not considered in the existing model. To simulate and represent this kind of data requires much more complex technology capable of doing Computational Fluid Dynamics (CFD) modeling, as well as a more sophisticated knowledge of how particulates of different sizes behave under different wind and weather conditions. In the future utilizing Airflow Analyst, an Esri Japan $3^{\text {rd }}$ part ArcGIS Extension that does CFD assessment in high detail used to detect vortex and dead air in urban environments, might be adaptable for use in modeling airflow over a water body.

\subsubsection{Chemical Engineering and the air/water interface impact on contaminant deposition.}

Different sized particles and different contaminants behave differently at the air/water interface. In order to account for this, additional parameters would need to be added to the model to adjust resulting flux values. Extensive research into the behavior of the substance involved and the new models to simulate rate changes as they differ over the extent of the lake based on changing physical conditions would likely need to be developed.

\subsubsection{Fluid Dynamics, subsurface mixing of deposited contaminants and their accumulation within the water body.}

The flux of a contaminant can be impacted by its concentration at the water's surface. This means that subsurface mixing, rate of sediment deposition, and water turbidity all can have an impact on flux vallues. For example, in the Bay Area the Mercury concentration in the water are high enough that deposition is negligible, and the water becomes a source of the contaminant. Modeling subsurface concentration would require development of a 3D raster data model. Subsurface mixing would require complex CFD analysis with an unknown software package. This would probably be the most challenging of the model enhancements. Additional sources of accumulation would also have to be modeled in order to make subsurface modeling meaningful. That would mean conducting watershed non-point source contaminant analysis, along with the inclusion of some sort of monitoring program to track point source pollution such as motorized water craft. 


\subsection{Summary}

It was the author's intention to provide a solid sounding board for future workflow and analysis of atmospheric deposition of contaminants to be explored and conducted in the domains above, on and below the surface of a lake. 



\section{Bibliography}

Asian Institute of Technology. (2012, January 01). Manual for Wet and Dry Deposition. Retrieved November 28, 2012, from UNEP Regional Resource Centre for Asia and the Pacific: http://www.rrcap.ait.asia/male/manual/wetDry/04-chapter4.pdf

Environmental Protection Agency. (2012, June 15). Particulate Matter (PM) Basic Information. Retrieved November 15, 2012, from http://www.epa.gov/airscience/air-particulatematter.htm\#1

Environmental Protection Agency. (2012, May 18). Particulate Matter (PM10) Research. Retrieved November 16, 2012, from http://www.epa.gov/airscience/airparticulatematter.htm\#1

Environmental Protection Agency. (2012, December 04). What is Acid Rain? Retrieved November 16, 2012, from http://www.epa.gov/acidrain/what/index.html

Esri Press. (2006). A to Z GIS. Redlands, CA: Esri Press.

Hsu, S. A. (2007, January). A Parameterization of Overwater Friction Velocity During Hurricanes. Journal of Coastal Research, 23(1), 270-274. doi:10.2112/05-0511.1

Lyons, R. (2012, January 31). A Predictive Model for Atmospheric Deposition of Combustion By-Products., (p. 1). Redlands.

Missoula Fire Sciences Laboratory. (2010, November 22). Fire Behavior and Danger Software. Retrieved July 30, 2012, from http://www.firemodels.org/index.php/research-systems/windninja

Pima County Department of Environmental Quality. (2012, January 01). Air Info Now. Retrieved 11 10, 2012, from http://www.airinfonow.org/html/ed_particulate.html

Wikipedia. (2013, 2 26). Wikipedia. Retrieved 3 14, 2013, from Wikipedia.org: http://en.wikipedia.org/wiki/Bilinear_interpolation 


\section{Appendix A. Maps}

Map 1: Flux of PM10 Seasonal Comparison ...................................................69

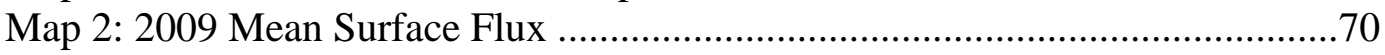

Map 3: Winter Zonal Means ........................................................................ 71

Map 4: Winter Zonal Standard Deviation........................................................ 72

Map 5: Spring Zonal Means .........................................................................73

Map 6: Spring Zonal Standard Deviation .......................................................74

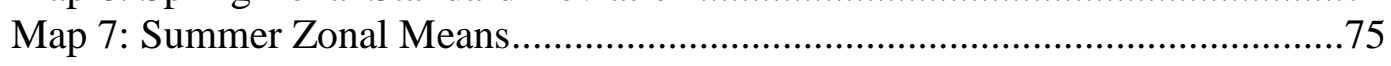

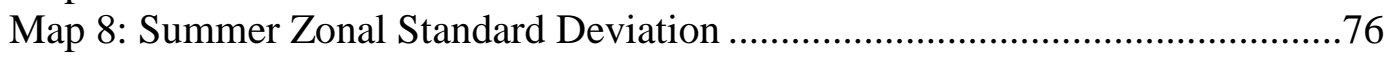

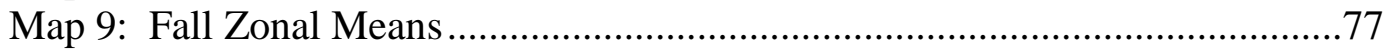

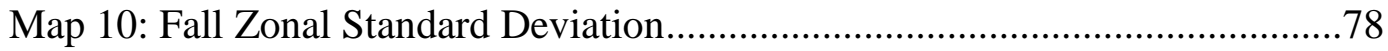

Map 11: Winter Spatial Distribution of Flux ....................................................79

Map 12: Spring Spatial Distribution of Flux .................................................. 80

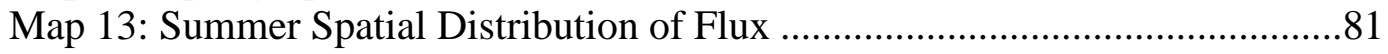

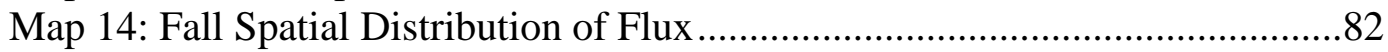

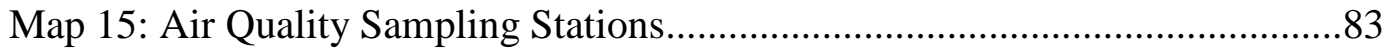

Map 16: NOAA Wind Speed and Direction Ground Sampling Stations...............84 


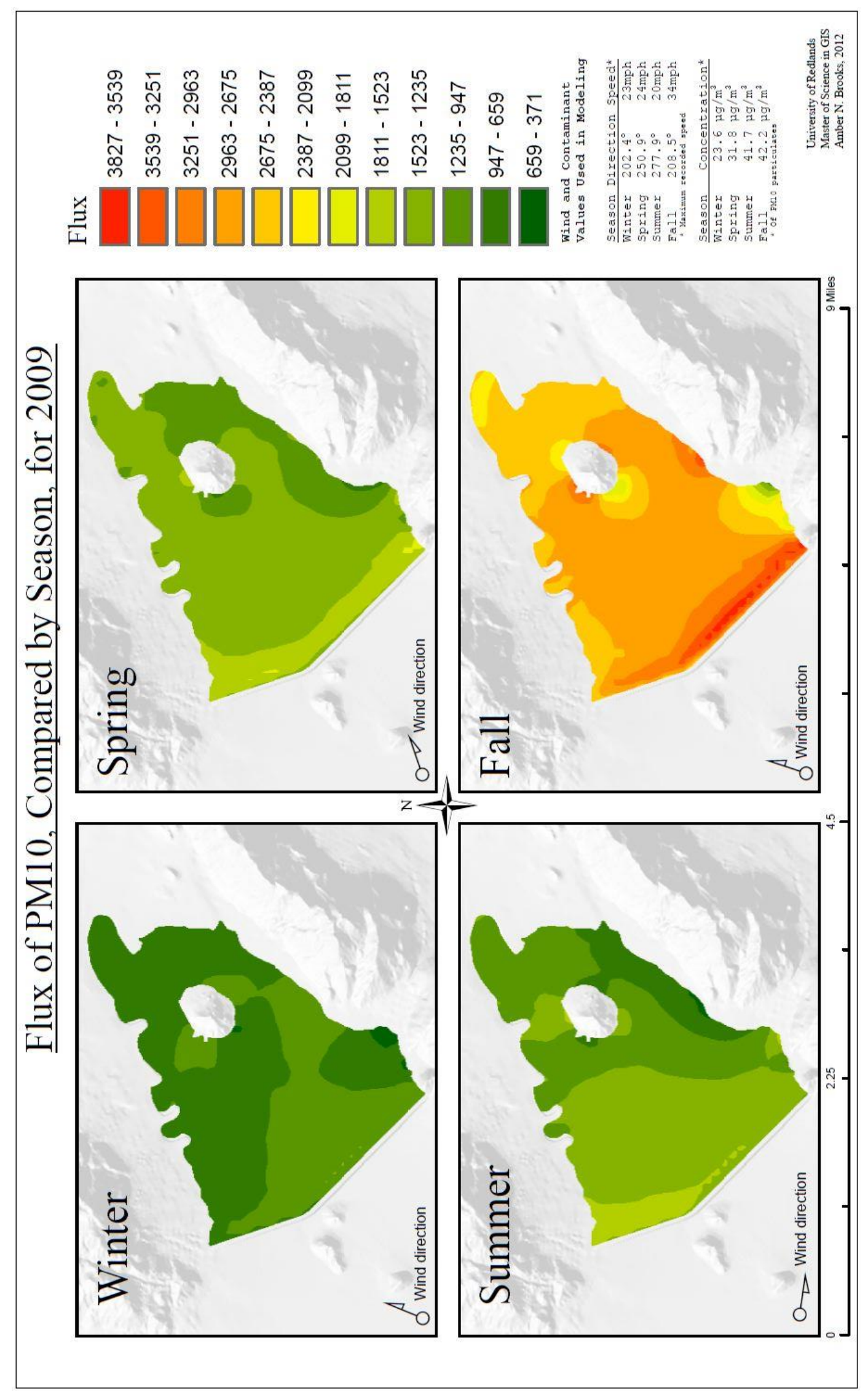




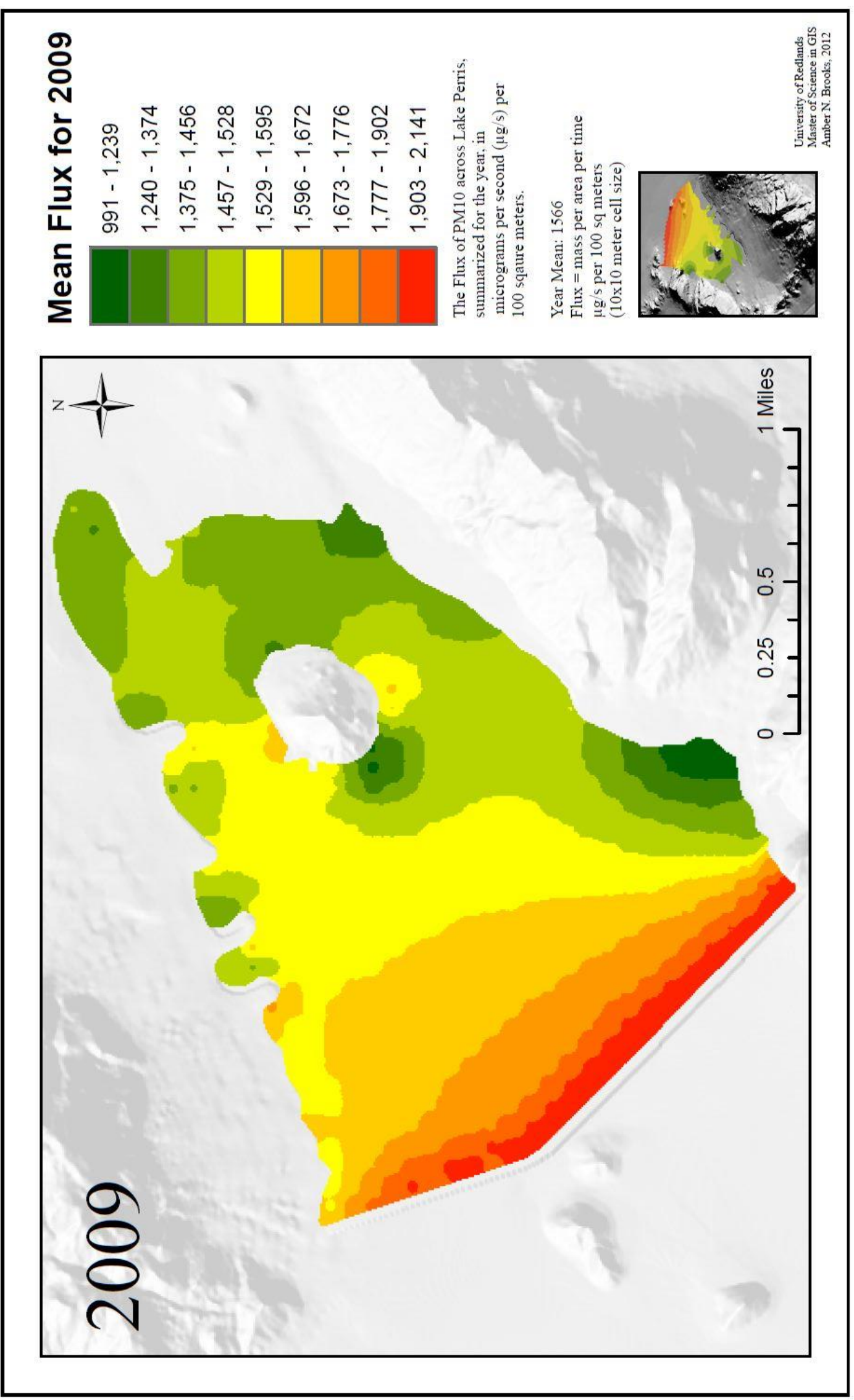




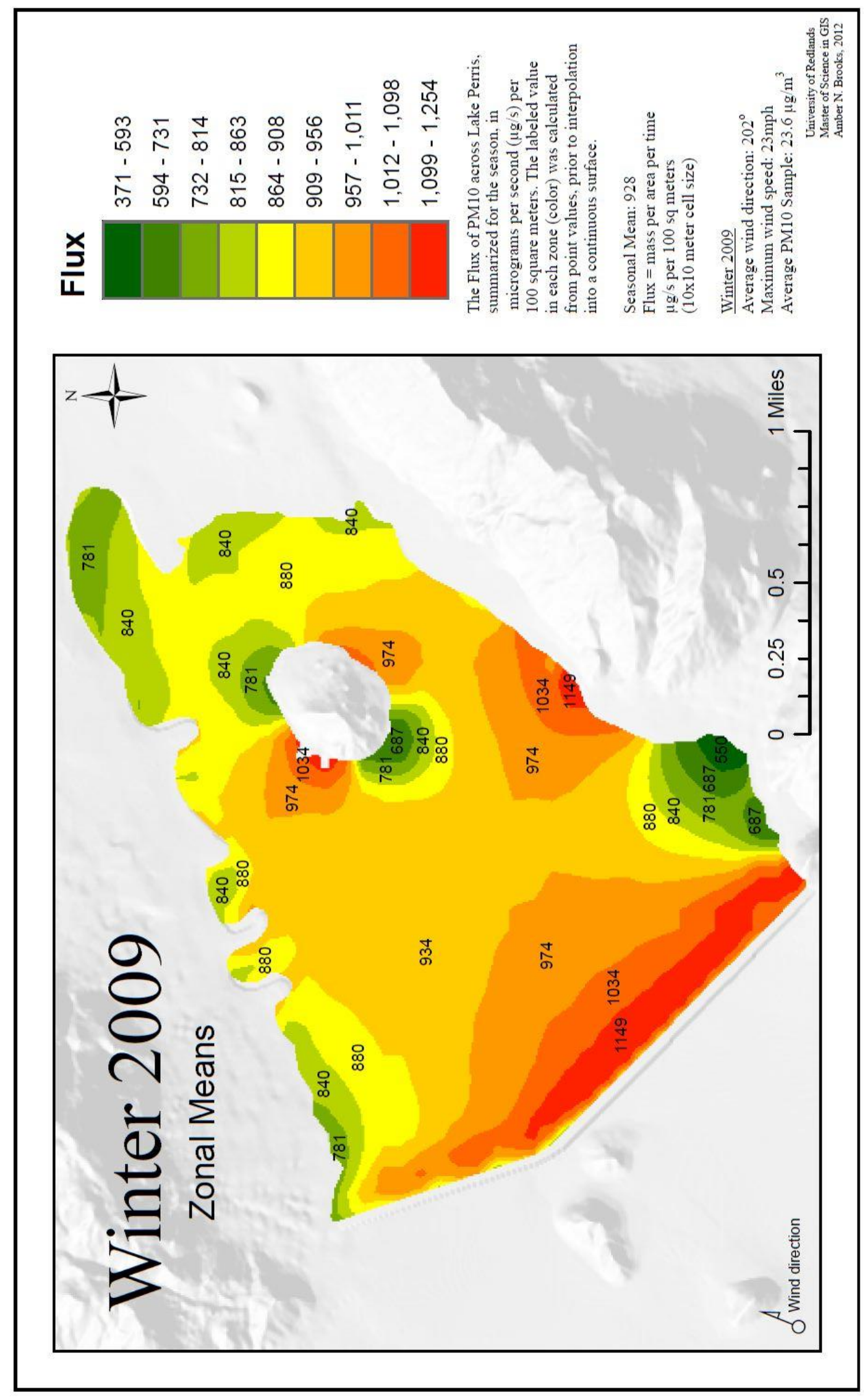




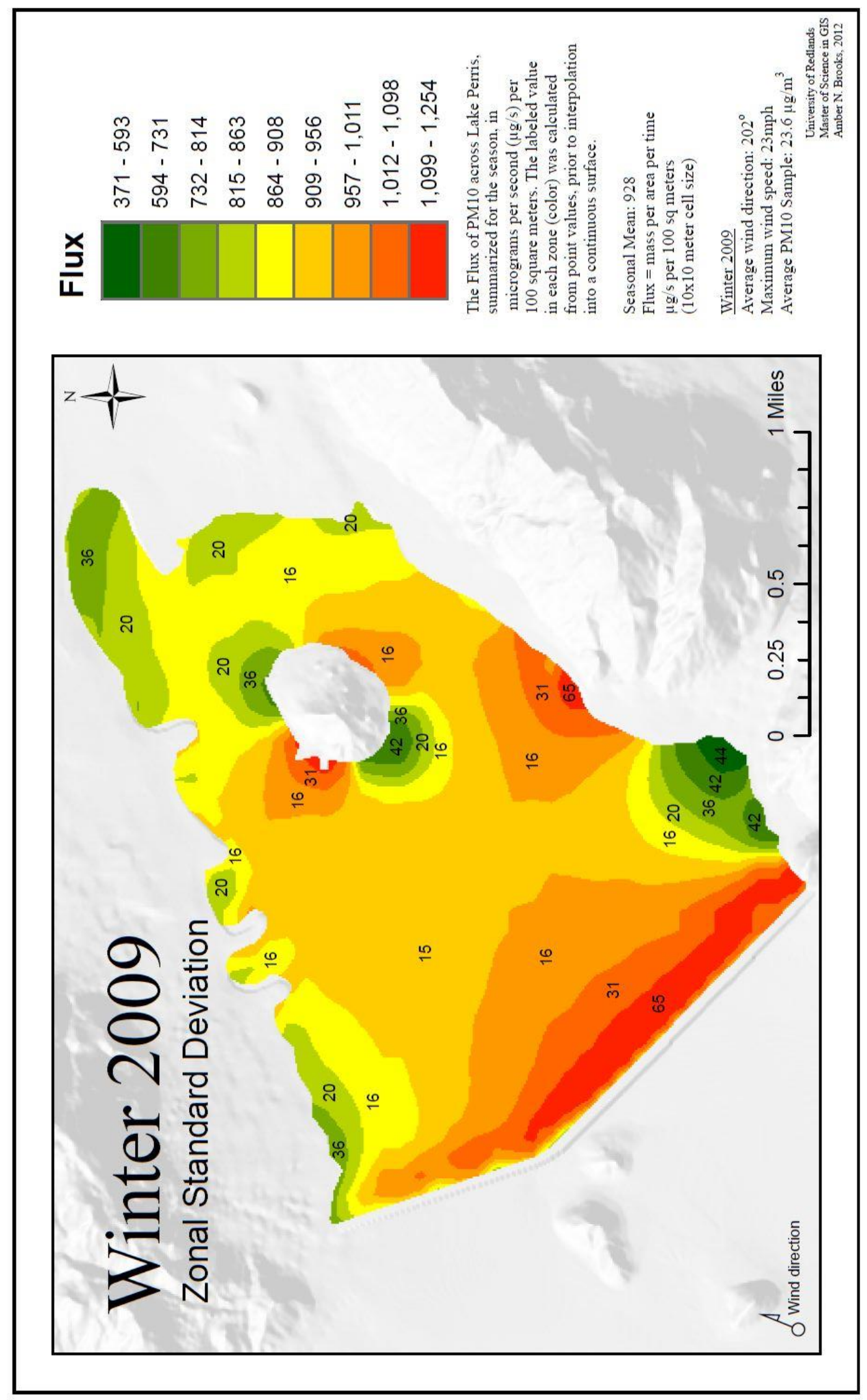




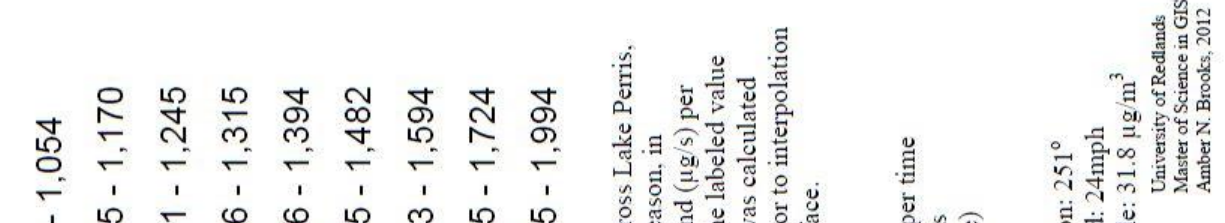

$$
\begin{aligned}
& \text { 官 } \\
& \text { 뜬 }
\end{aligned}
$$

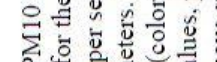

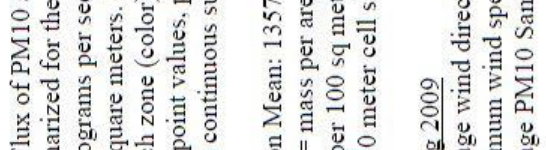

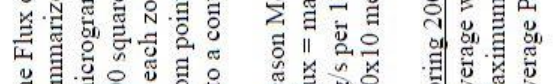

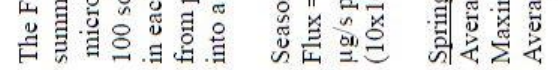

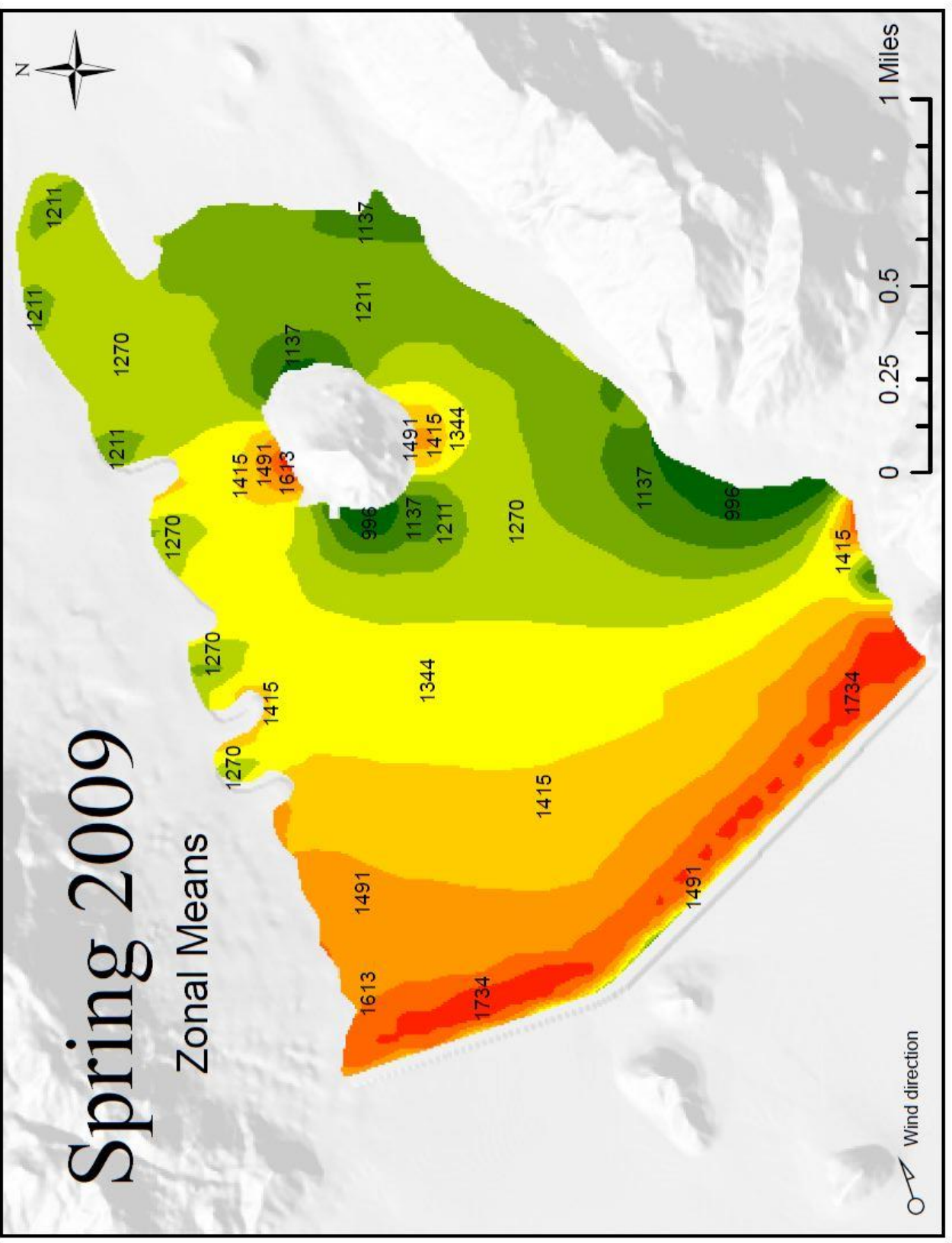



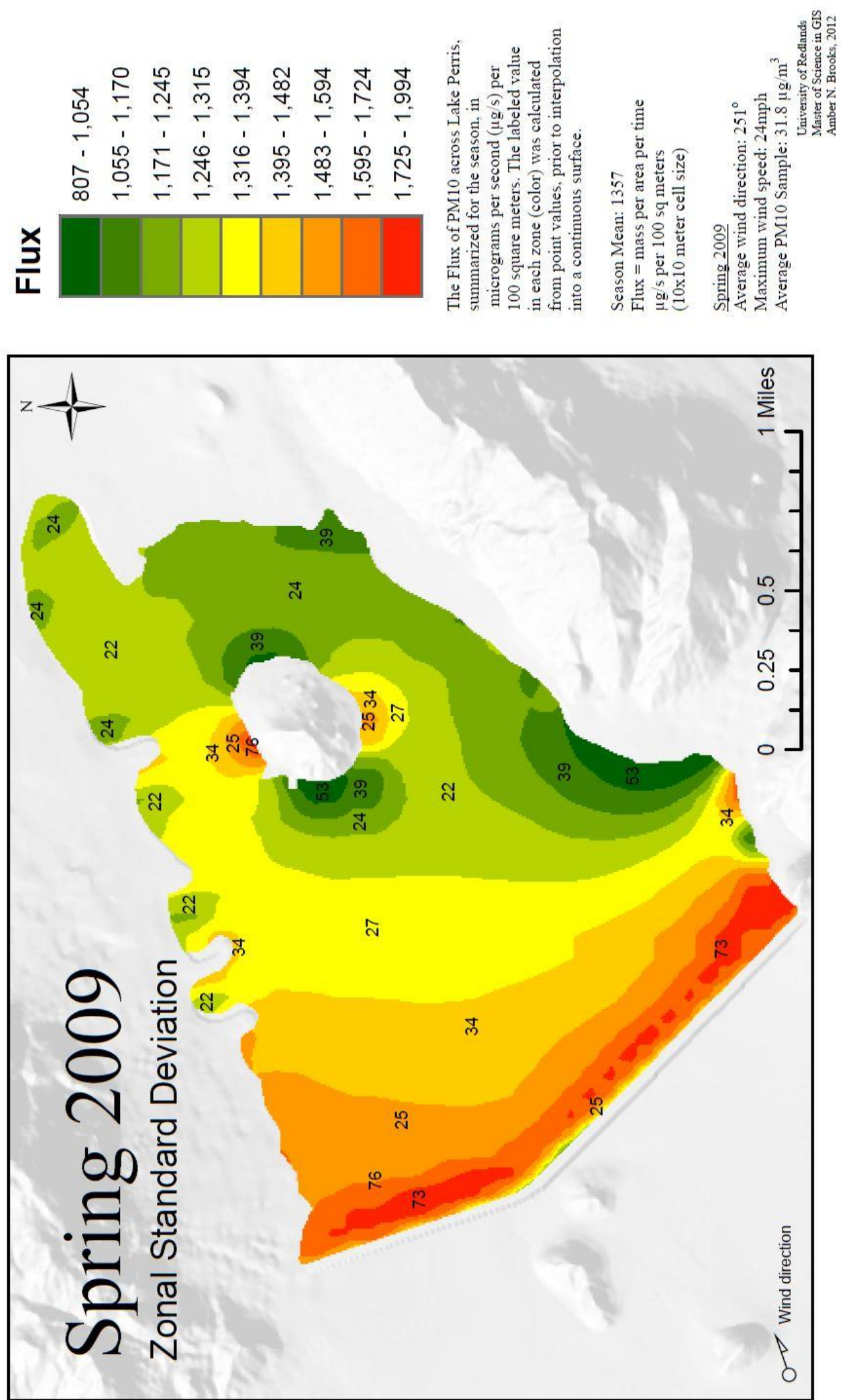


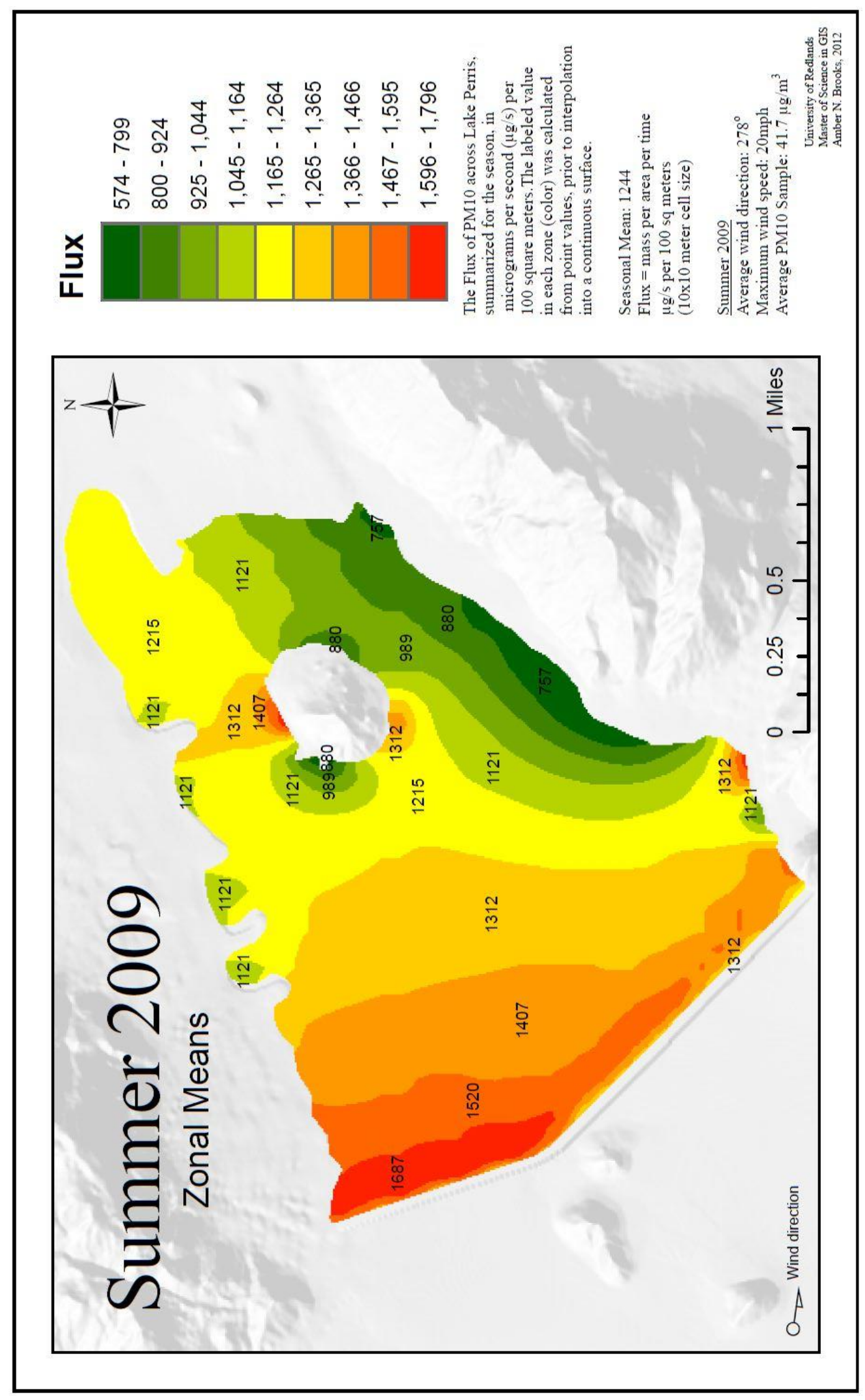



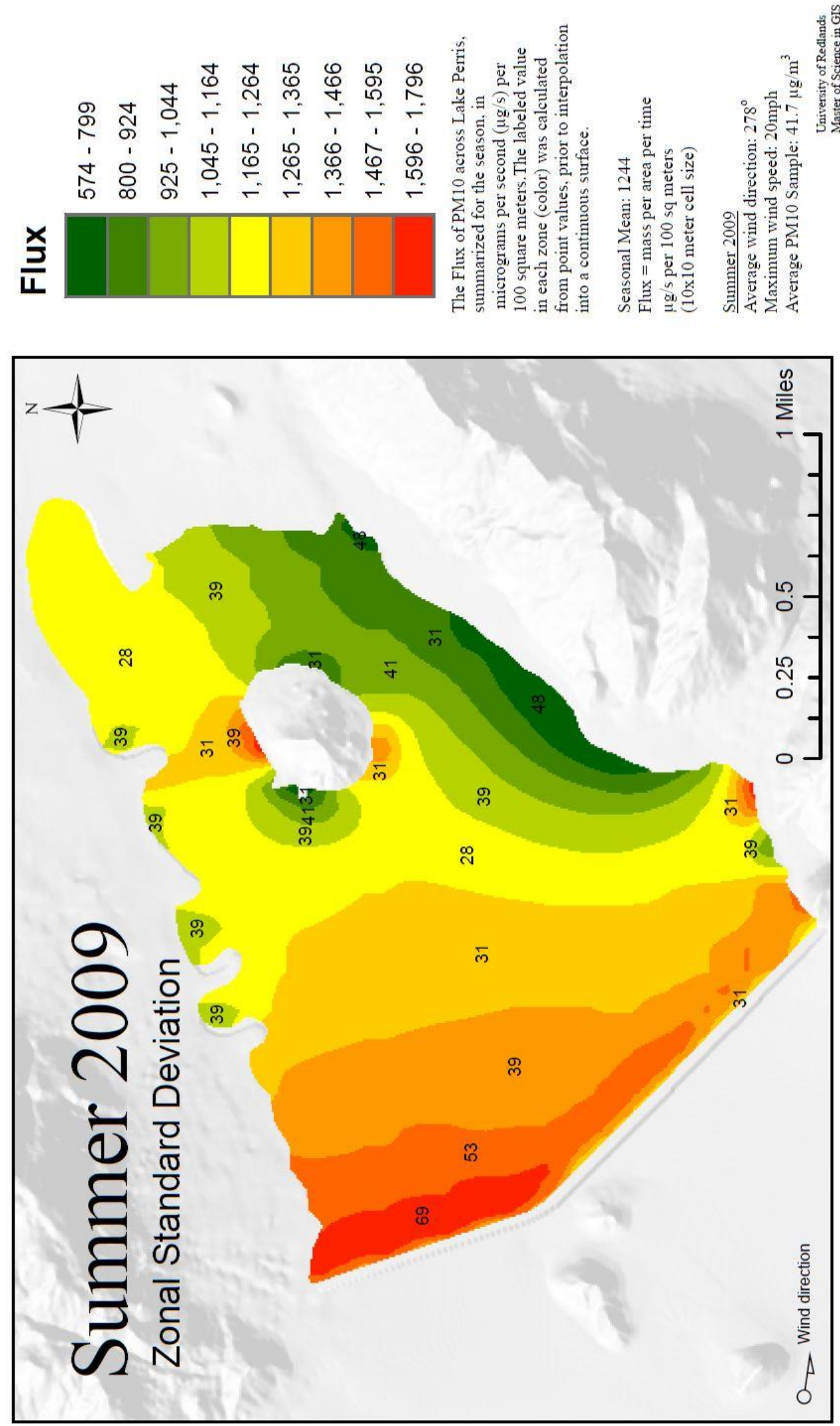


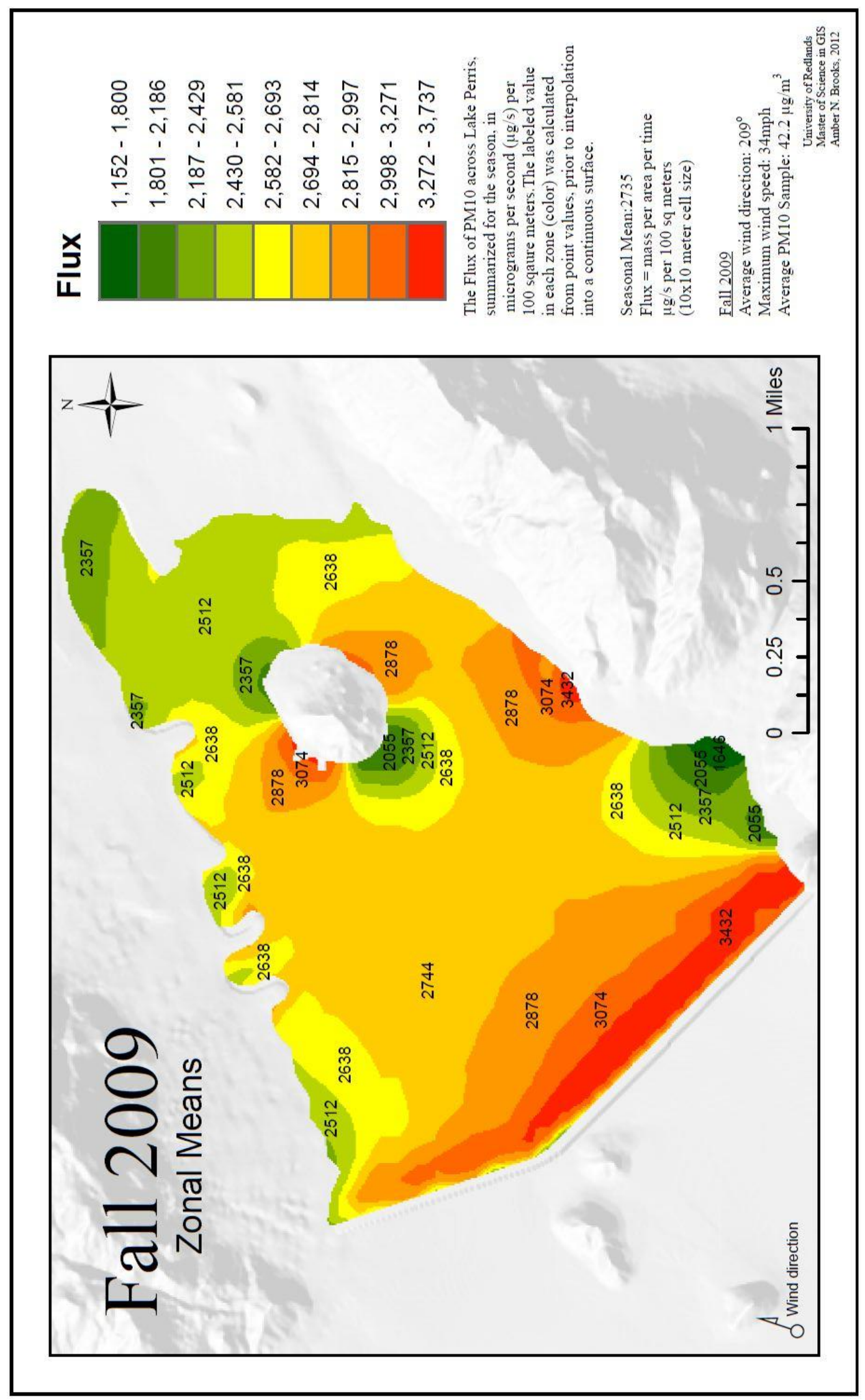




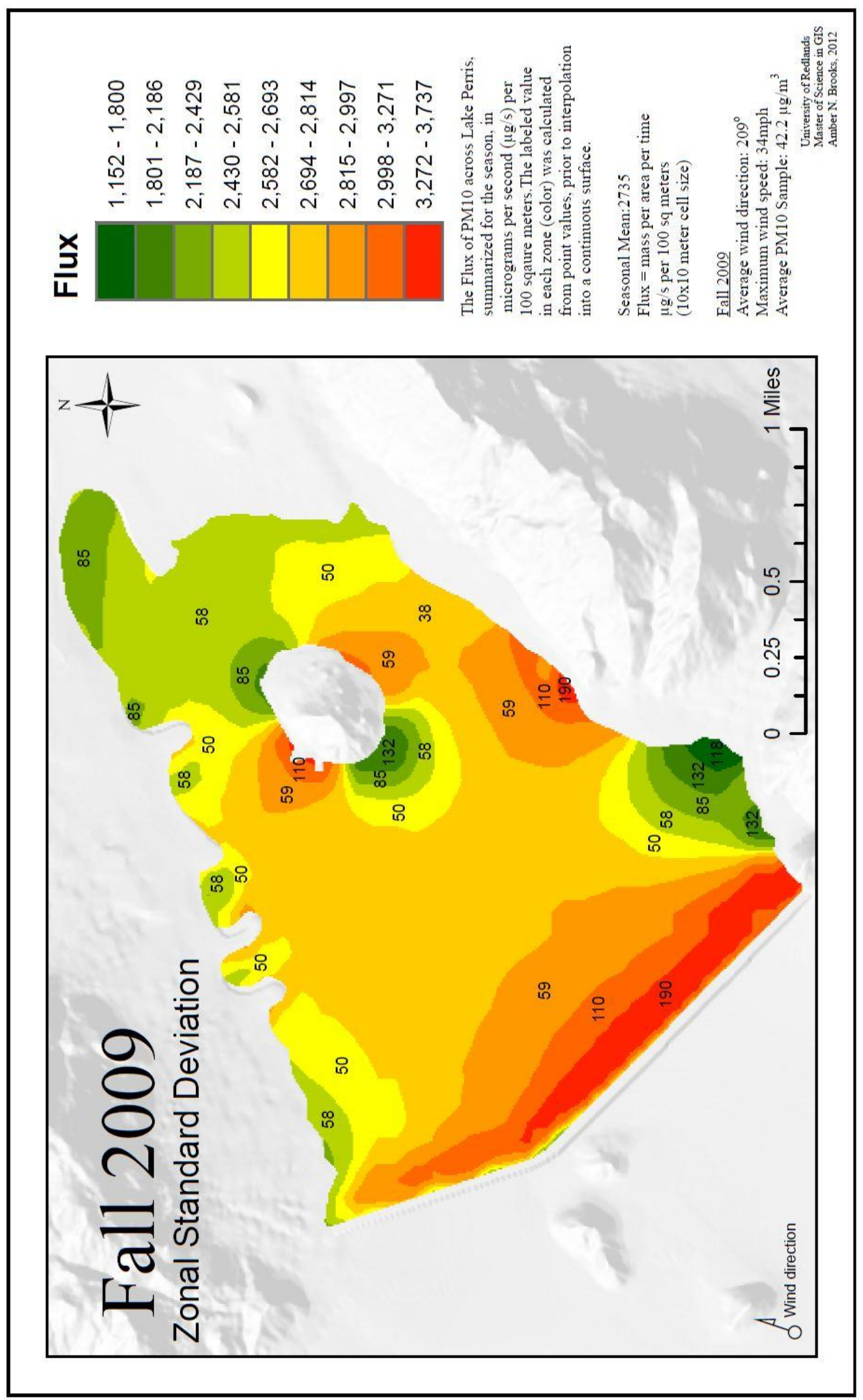



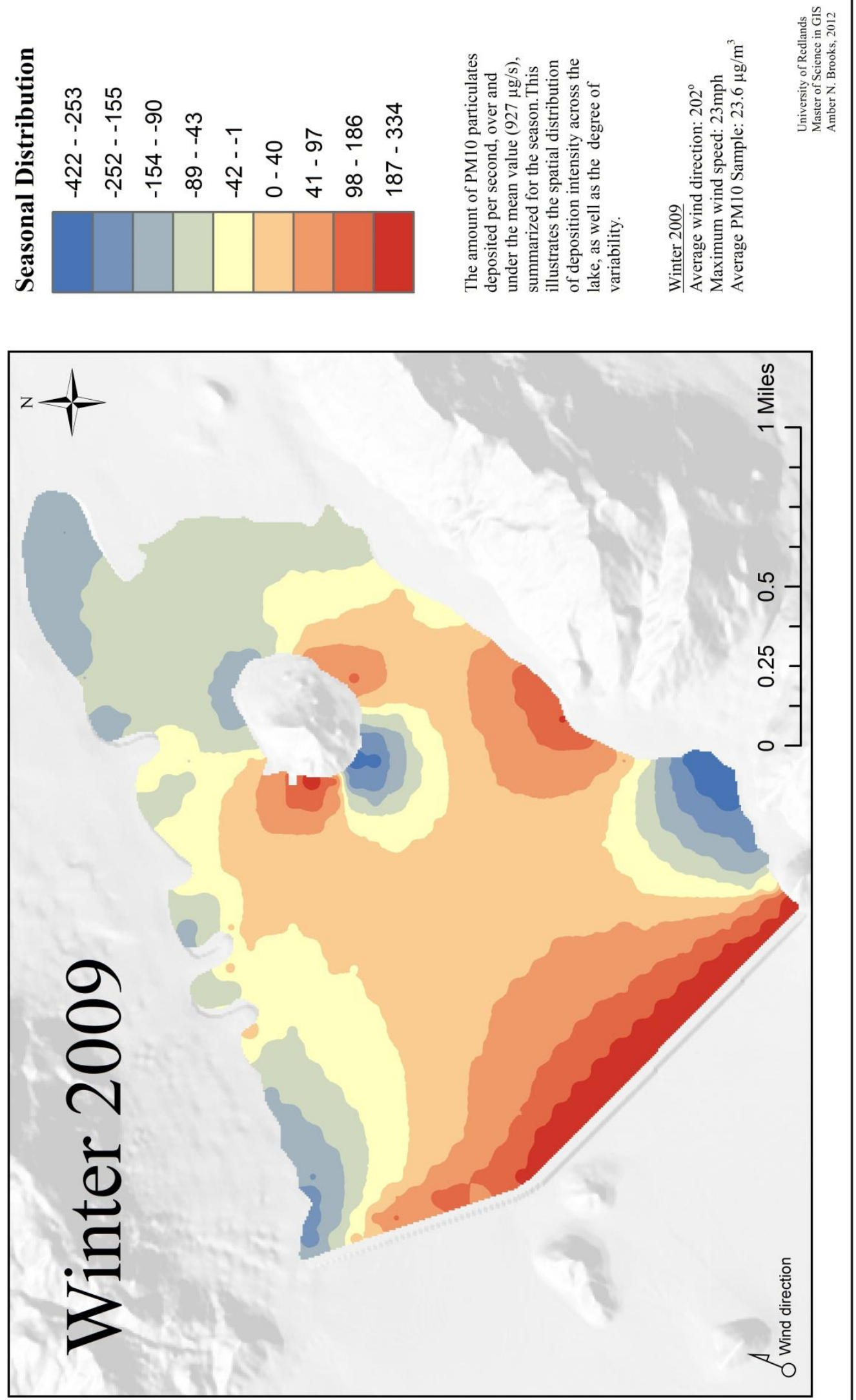

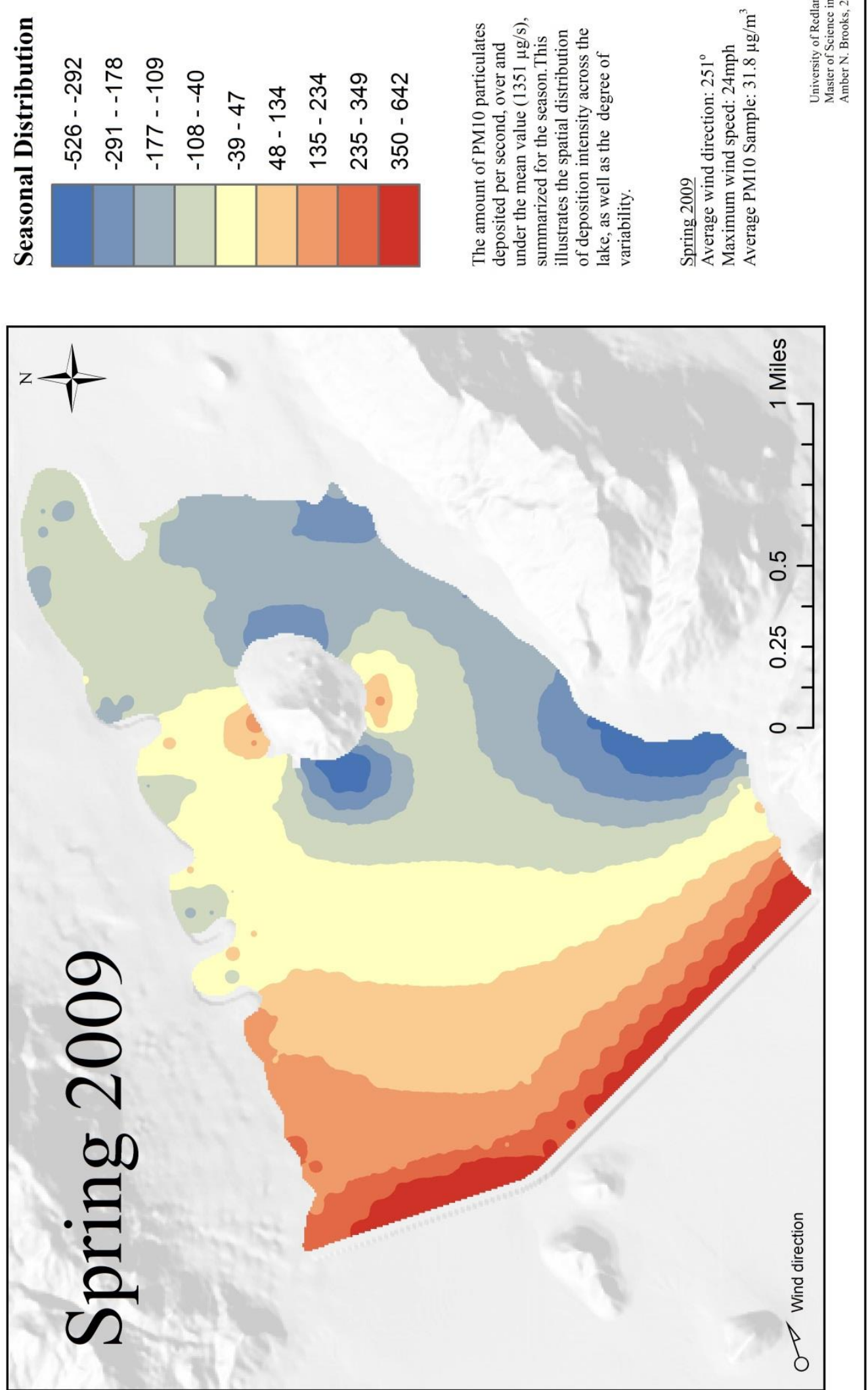

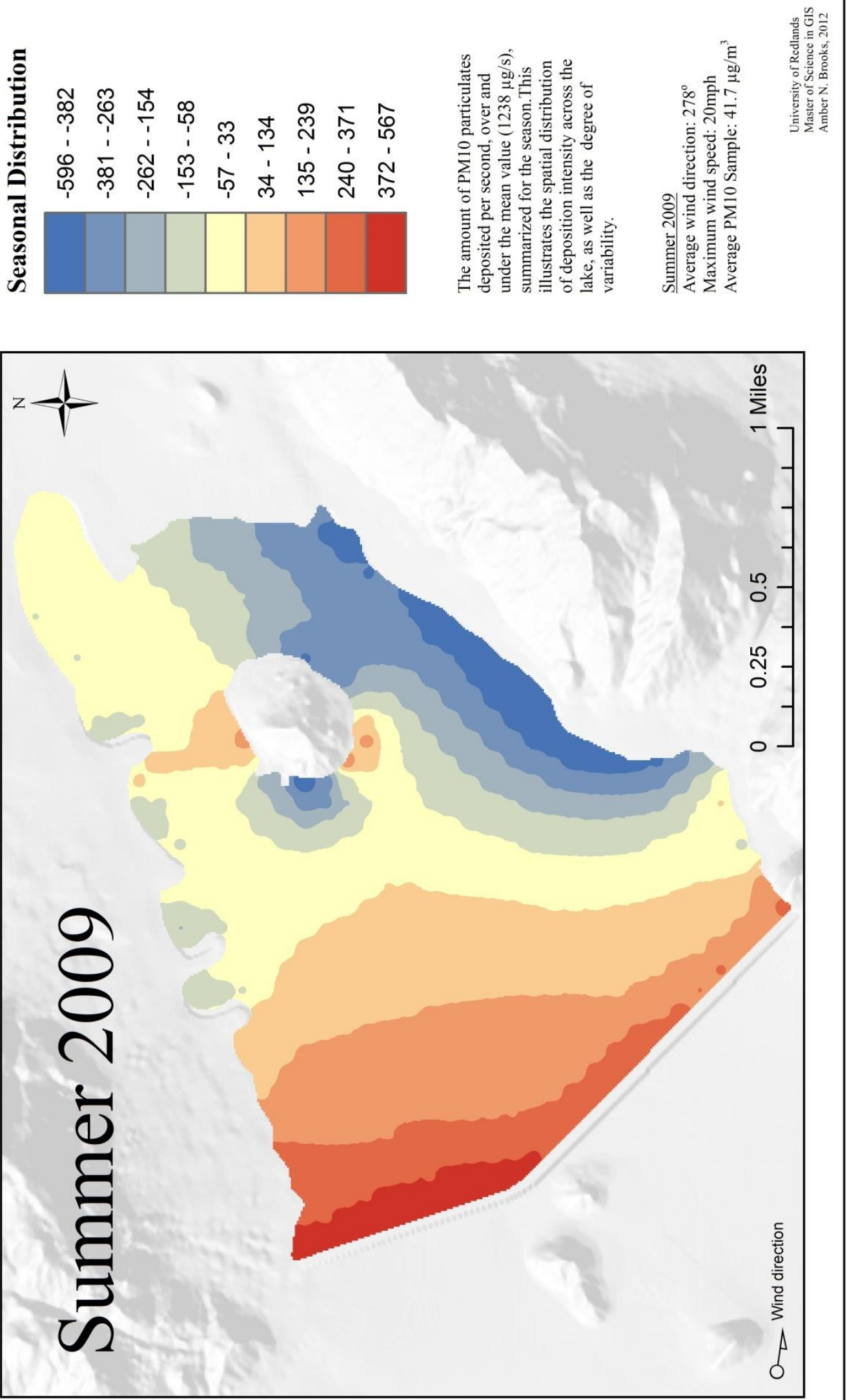

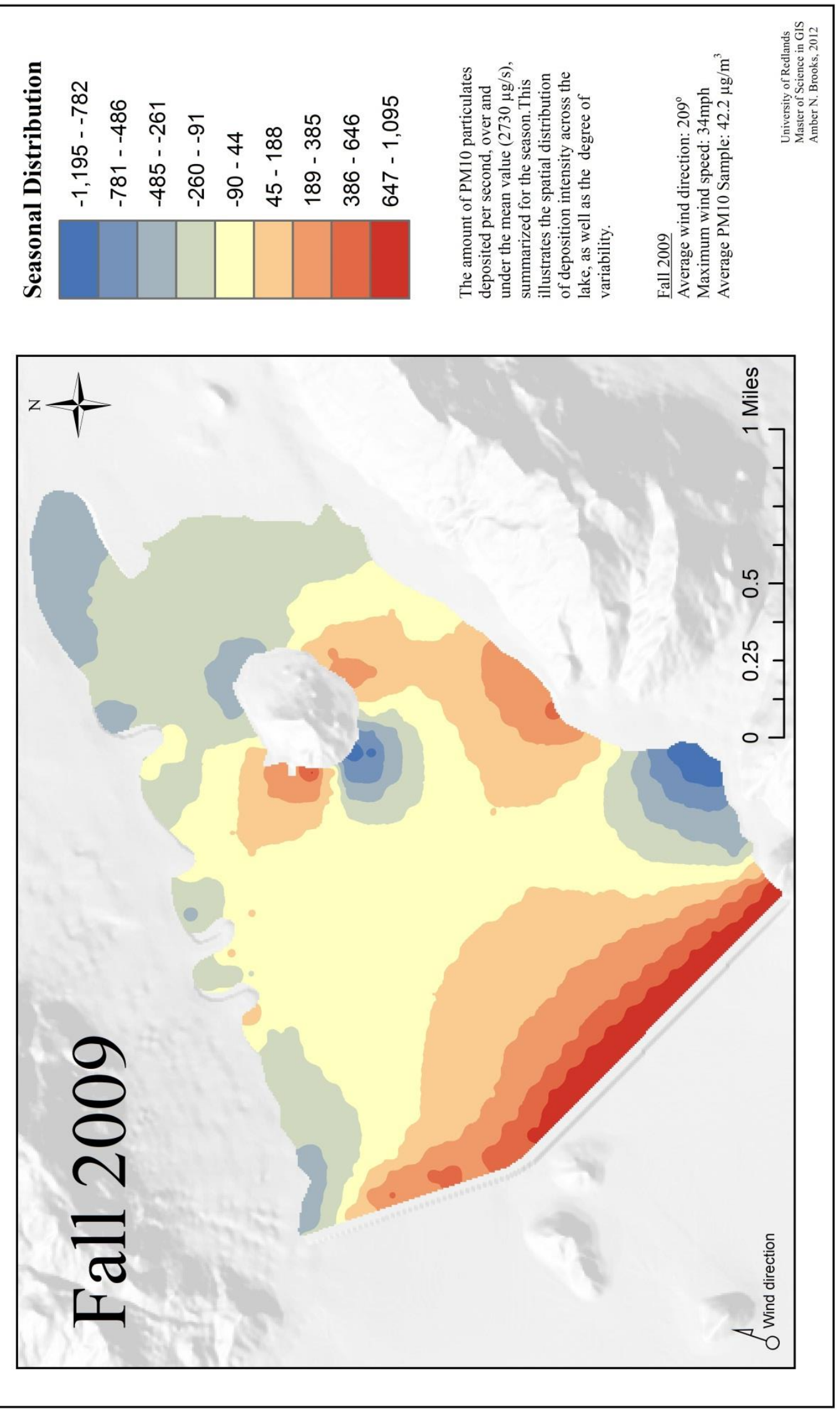


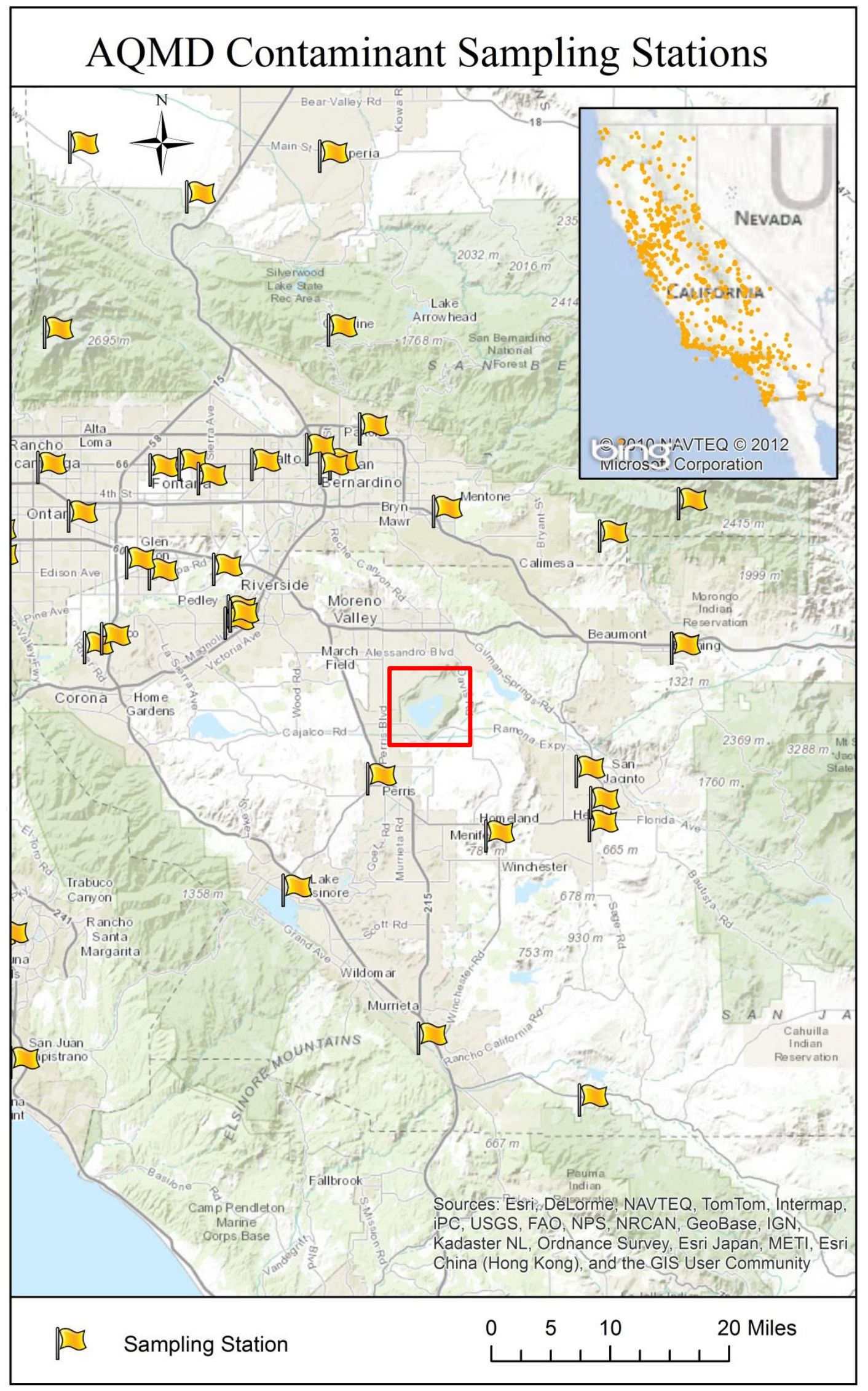




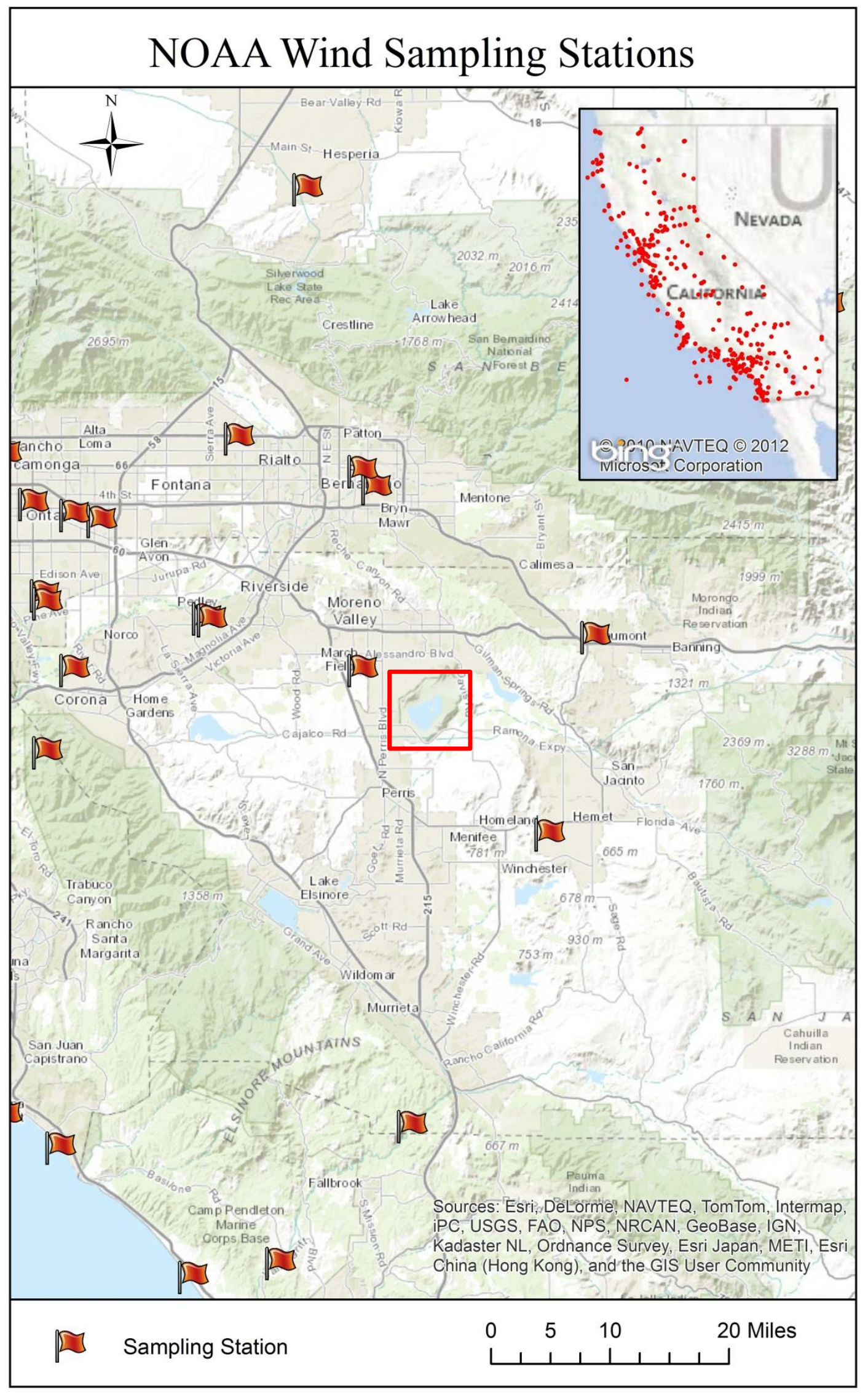




\section{Appendix B. Model Builder Models}

Breakdown of Base Model................................................69

Comparison and Base Model...........................................70 


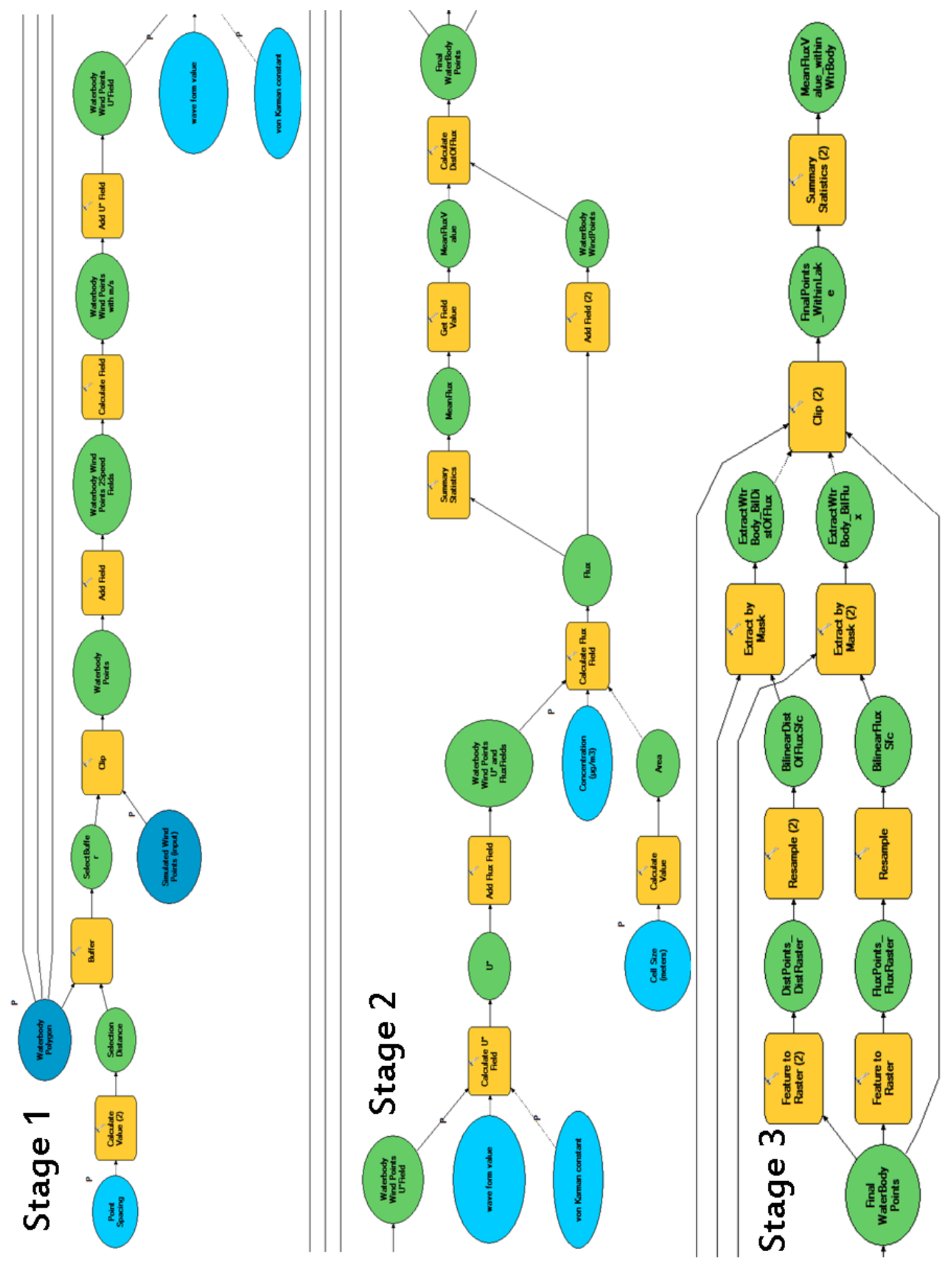




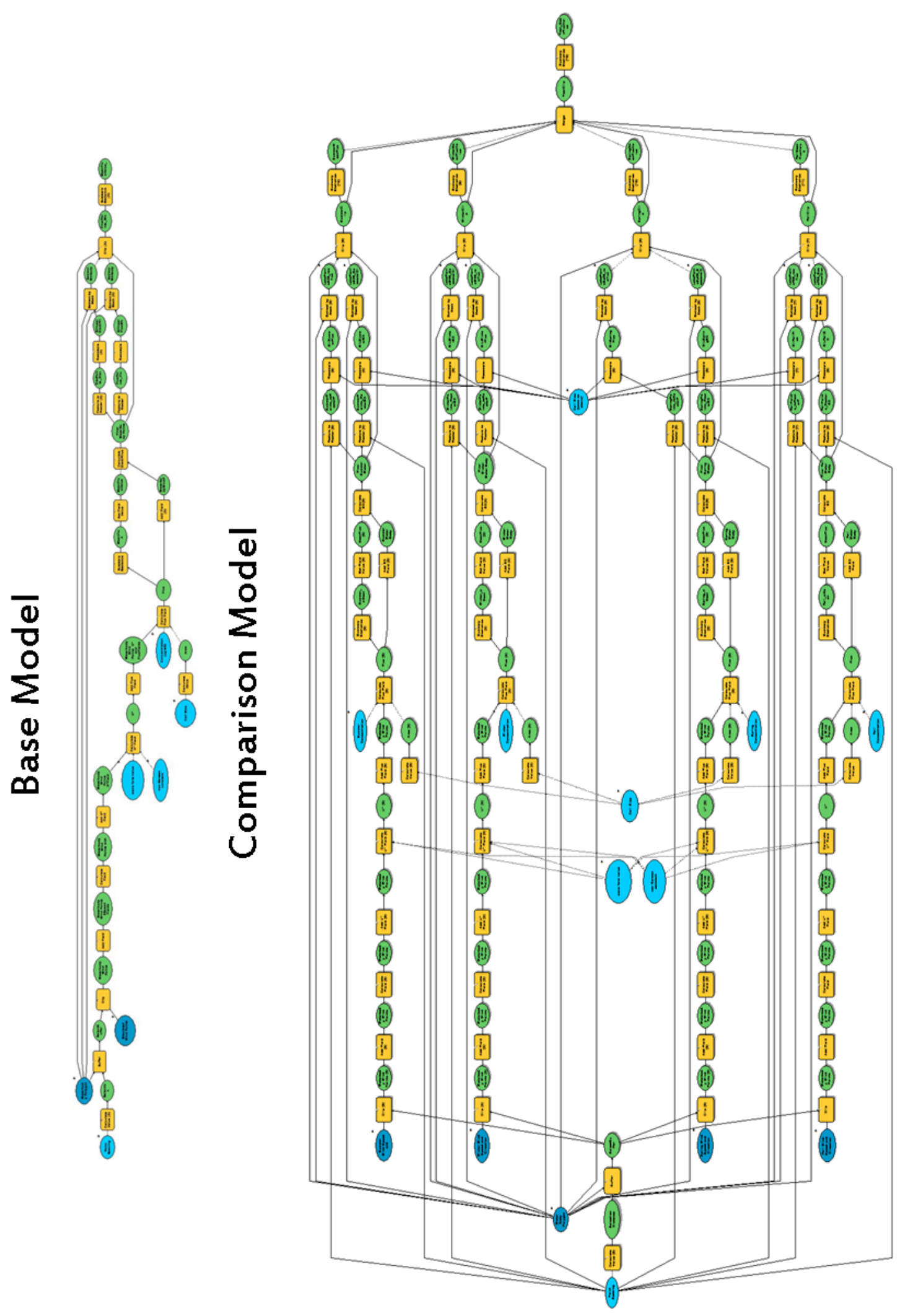




\section{Appendix C. Computer Requirements}

Combined personal computer requirements. Minimums are in bold typeface.

\begin{tabular}{|c|c|c|c|c|c|c|c|}
\hline Item & $\begin{array}{l}\text { Operating } \\
\text { System }\end{array}$ & Processor & RAM & $\begin{array}{l}\text { Hard } \\
\text { Drive } \\
\text { Space }\end{array}$ & $\begin{array}{l}\text { Graphics } \\
\text { Card }\end{array}$ & $\begin{array}{l}\text { OpenGL } \\
\text { version }\end{array}$ & Other \\
\hline ishJava & - & - & $\begin{array}{l}128 m \\
b\end{array}$ & - & - & - & Java \\
\hline $\begin{array}{l}\text { Microsoft } \\
\text { Excel } 2010\end{array}$ & $\begin{array}{l}\text { Windows XP } \\
\text { (must have } \\
\text { SP3) (32-bit) } \\
\text { or Newer }\end{array}$ & $\begin{array}{l}500 \mathrm{Mhz} \text { or } \\
\text { more }\end{array}$ & $\begin{array}{l}512 m \\
b\end{array}$ & 3 GB & $\begin{array}{l}\text { DirectX 9.0c } \\
\text { graphics card } \\
\text { with } \\
64 \mathrm{MB}+\text { video } \\
\text { memory }\end{array}$ & - & - \\
\hline $\begin{array}{l}\text { WindNinja } \\
2.1 .3\end{array}$ & $\begin{array}{l}\text { Windows XP } \\
\text { (32 or } 64 \text { bit) } \\
\text { or Newer }\end{array}$ & - & $\begin{array}{l}500 M \\
b\end{array}$ & - & - & - & - \\
\hline $\begin{array}{l}\text { ArcGIS } \\
10.0\end{array}$ & $\begin{array}{l}\text { Windows } \\
\text { 2003 Server } \\
\text { Standard, } \\
\text { Enterprise \& } \\
\text { Datacenter } \\
\text { (32-bit and } \\
\text { 64-bit } \\
\text { (EM64T)) or } \\
\text { Newer }\end{array}$ & $\begin{array}{l}\text { Intel } \\
\text { Pentium 4, } \\
\text { Intel Core } \\
\text { Duo, or Xeon } \\
\text { Processors; } \\
\text { SSE2 (or } \\
\text { greater) }\end{array}$ & $\begin{array}{l}2 \text { GB } \\
\text { or } \\
\text { higher }\end{array}$ & $\begin{array}{l}2.4 \text { GB } \\
\text { or more } \\
\text { See } \\
\text { Setup } \\
\text { Program }\end{array}$ & $\begin{array}{l}\text { NVIDIA, ATI } \\
\text { and INTEL } \\
\text { chipsets } \\
\text { supported } \\
64 \text { MB RAM } \\
\text { min., } 256 \text { MB } \\
\text { RAM or } \\
\text { higher } \\
\text { recommende } \\
\text { d }\end{array}$ & $\begin{array}{l}\text { OpenGL } \\
\text { version } 2.0 \\
\text { runtime or } \\
\text { higher \& } \\
\text { Shader } \\
\text { Model } 3.0 \text { or } \\
\text { higher } \\
\text { recommende } \\
\text { d }\end{array}$ & $\begin{array}{l}\text { Python } \\
2.6 . x \\
\text { and } \\
\text { Numer } \\
\text {-cal } \\
\text { Python } \\
1.3 .0\end{array}$ \\
\hline
\end{tabular}




\section{Appendix D. Master Data List}

\begin{tabular}{|c|c|c|c|c|c|}
\hline ID & Name & $\begin{array}{l}\text { File } \\
\text { Type }\end{array}$ & Source & $\begin{array}{c}\text { Formatting } \\
\text { Required }\end{array}$ & $\begin{array}{l}\text { Processing } \\
\text { Required }\end{array}$ \\
\hline 1 & $\begin{array}{l}\text { NOAA Wind } \\
\text { Speed and } \\
\text { Direction } \\
\text { data }\end{array}$ & $\begin{array}{l}\text { ishJava } \\
\text { file }\end{array}$ & $\begin{array}{l}\text { ftp3.ncdc.noaa.gov } \\
\text { or } \\
\text { http://www7.ncdc.noaa.gov/CDO/c } \\
\text { do } \\
\text { http://www.ncdc.noaa.gov/other- } \\
\text { data-access }\end{array}$ & Yes & Yes \\
\hline 2 & $\begin{array}{l}\text { NOAA } \\
\text { Station } \\
\text { Locations }\end{array}$ & $\mathrm{xml}$ & $\begin{array}{l}\text { ftp3.ncdc.noaa.gov } \\
\text { or } \\
\text { http://www7.ncdc.noaa.gov/CDO/c } \\
\text { do }\end{array}$ & No & Yes \\
\hline 3 & $\begin{array}{l}\text { CARB Air } \\
\text { Quality } \\
\text { Sample data }\end{array}$ & $\mathrm{xml}$ & $\begin{array}{l}\text { ftp.arb.ca.gov } \\
\text { or } \\
\text { http://www.arb.ca.gov/aqd/aqdcd/ } \\
\text { aqdcddld.htm }\end{array}$ & No & Yes \\
\hline 4 & $\begin{array}{l}\text { CARB Air } \\
\text { Quality } \\
\text { Station } \\
\text { Locations }\end{array}$ & $\mathrm{xml}$ & $\begin{array}{l}\text { ftp.arb.ca.gov } \\
\text { or } \\
\text { http://www.arb.ca.gov/aqd/aqdcd/ } \\
\text { aqdcddld.htm }\end{array}$ & No & Yes \\
\hline 5 & $\begin{array}{l}\text { USGS NHD } \\
\text { Sub region } \\
\text { Hydrography }\end{array}$ & shapefile & $\begin{array}{l}\text { http://viewer.nationalmap.gov/vie } \\
\text { wer/nhd.html?p=nhd }\end{array}$ & No & No \\
\hline 6 & $\begin{array}{l}\text { USGS } \\
\text { Digital } \\
\text { Elevation } \\
\text { Models }\end{array}$ & .DDF & $\begin{array}{l}\text { http://www.usgsquads.com/index. } \\
\text { php/map-indexes/mapfinder } \\
\text { and } \\
\text { http://data.geocomm.com/catalog/ } \\
\text { US/61069/sublist.html }\end{array}$ & Yes & Yes \\
\hline
\end{tabular}

